Cochrane Database of Systematic Reviews

\title{
Systematic versus opportunistic risk assessment for the primary prevention of cardiovascular disease (Review)
}

Dyakova M, Shantikumar S, Colquitt JL, Drew CM, Sime M, Maclver J, Wright N, Clarke A, Rees K

Dyakova M, Shantikumar S, Colquitt JL, Drew CM, Sime M, Maclver J, Wright N, Clarke A, Rees K.

Systematic versus opportunistic risk assessment for the primary prevention of cardiovascular disease.

Cochrane Database of Systematic Reviews 2016, Issue 1. Art. No.: CD010411.

DOI: 10.1002/14651858.CD010411.pub2.

www.cochranelibrary.com 
TABLE OF CONTENTS

HEADER 1

ABSTRACT

PLAIN LANGUAGE SUMMARY

SUMMARY OF FINDINGS

BACKGROUND

OBJECTIVES

METHODS

RESULTS

Figure 1.

Figure 2.

Figure 3.

DISCUSSION

AUTHORS' CONCLUSIONS

ACKNOWLEDGEMENTS

REFERENCES

CHARACTERISTICS OF STUDIES

DATA AND ANALYSES

Analysis 1.1. Comparison 1 Systematic screening vs no/opportunistic screening, Outcome 1 All-cause mortality.

Analysis 1.2. Comparison 1 Systematic screening vs no/opportunistic screening, Outcome 2 Outcomes in residents admitted to hospital per 1000 (post-intervention rate).

Analysis 1.3. Comparison 1 Systematic screening vs no/opportunistic screening, Outcome 3 Cardiovascular mortality. ..........

Analysis 1.4. Comparison 1 Systematic screening vs no/opportunistic screening, Outcome 4 Mortality due to stroke. ..............

Analysis 1.5. Comparison 1 Systematic screening vs no/opportunistic screening, Outcome 5 Stroke (total).

Analysis 1.6. Comparison 1 Systematic screening vs no/opportunistic screening, Outcome 6 Coronary heart disease (total). ....

Analysis 1.7. Comparison 1 Systematic screening vs no/opportunistic screening, Outcome 7 Non-fatal coronary heart disease.

Analysis 1.8. Comparison 1 Systematic screening vs no/opportunistic screening, Outcome 8 Non-fatal stroke.

Analysis 1.9. Comparison 1 Systematic screening vs no/opportunistic screening, Outcome 9 Total cholesterol, mmol/l. ...........

Analysis 1.10. Comparison 1 Systematic screening vs no/opportunistic screening, Outcome $10 \mathrm{HDL}$ cholesterol, $\mathrm{mmol} / \mathrm{l}$. ........

Analysis 1.11. Comparison 1 Systematic screening vs no/opportunistic screening, Outcome 11 LDL cholesterol, mmol/l. ........

Analysis 1.12. Comparison 1 Systematic screening vs no/opportunistic screening, Outcome 12 Triglycerides, mmol/l. ............

Analysis 1.13. Comparison 1 Systematic screening vs no/opportunistic screening, Outcome 13 Systolic blood pressure, $\mathrm{mmHg}$.

Analysis 1.14. Comparison 1 Systematic screening vs no/opportunistic screening, Outcome 14 Diastolic blood pressure, $\mathrm{mmHg}$.

Analysis 1.15. Comparison 1 Systematic screening vs no/opportunistic screening, Outcome 15 Number with elevated cholesterol.

Analysis 1.16. Comparison 1 Systematic screening vs no/opportunistic screening, Outcome 16 Number with elevated SBP. ....

Analysis 1.17. Comparison 1 Systematic screening vs no/opportunistic screening, Outcome 17 Number with elevated DBP. .....

Analysis 1.18. Comparison 1 Systematic screening vs no/opportunistic screening, Outcome 18 Number with diabetes. ...........

Analysis 1.19. Comparison 1 Systematic screening vs no/opportunistic screening, Outcome 19 Number with elevated cardiovascular risk score.

Analysis 1.20. Comparison 1 Systematic screening vs no/opportunistic screening, Outcome 20 Attendance rates. APPENDICES

WHAT'S NEW

HISTORY

CONTRIBUTIONS OF AUTHORS

DECLARATIONS OF INTEREST

SOURCES OF SUPPORT

DIFFERENCES BETWEEN PROTOCOL AND REVIEW

INDEX TERMS 
[Intervention Review]

\section{Systematic versus opportunistic risk assessment for the primary prevention of cardiovascular disease}

Mariana Dyakova ${ }^{1}$, Saran Shantikumar ${ }^{1}$, Jill L Colquitt ${ }^{2}$, Christian M Drew ${ }^{1}$, Morag Sime ${ }^{1}$, Joanna Maclver ${ }^{1}$, Nicola Wright ${ }^{3}$, Aileen Clarke $^{1}$, Karen Rees ${ }^{1}$

1Division of Health Sciences, Warwick Medical School, University of Warwick, Coventry, UK. ${ }^{2}$ Effective Evidence LLP, Waterlooville, UK. 3 Public Health Department, NHS Warwickshire, Warwick, UK

Contact address: Karen Rees, Division of Health Sciences, Warwick Medical School, University of Warwick, Gibbet Hill Campus, Coventry, Warwickshire, CV4 7AL, UK. Karen.Rees@warwick.ac.uk, rees_karen@yahoo.co.uk.

Editorial group: Cochrane Heart Group.

Publication status and date: Edited (no change to conclusions), published in Issue 3, 2018.

Citation: Dyakova M, Shantikumar S, Colquitt JL, Drew CM, Sime M, Maclver J, Wright N, Clarke A, Rees K. Systematic versus opportunistic risk assessment for the primary prevention of cardiovascular disease. Cochrane Database of Systematic Reviews 2016 , Issue 1. Art. No.: CD010411. DOI: 10.1002/14651858.CD010411.pub2.

Copyright ( 2018 The Cochrane Collaboration. Published by John Wiley \& Sons, Ltd.

\section{A B S T R A C T}

\section{Background}

Screening programmes can potentially identify people at high cardiovascular risk and reduce cardiovascular disease (CVD) morbidity and mortality. However, there is currently not enough evidence showing clear clinical or economic benefits of systematic screening-like programmes over the widely practised opportunistic risk assessment of CVD in primary care settings.

\section{Objectives}

The primary objective of this review was to assess the effectiveness, costs and adverse effects of systematic risk assessment compared to opportunistic risk assessment for the primary prevention of CVD.

\section{Search methods}

We searched the Cochrane Central Register of Controlled Trials (CENTRAL) on the Cochrane Library, MEDLINE, EMBASE on 30 January 2015, and Web of Science Core Collection and additional databases on the Cochrane Library on 4 December 2014. We also searched two clinical trial registers and checked reference lists of relevant articles. We applied no language restrictions.

\section{Selection criteria}

We selected randomised controlled trials (RCTs) that assessed the effects of systematic risk assessment, defined as a screening-like programme involving a predetermined selection process of people, compared with opportunistic risk assessment which ranged from no risk assessment at all to incentivised case finding of CVD and related risk factors. Participants included healthy adults from the general population, including those who are at risk of CVD.

\section{Data collection and analysis}

Two review authors independently selected studies. One review author extracted data and assessed them for risk of bias and a second checked them. We assessed evidence quality using the GRADE approach and present this in a 'Summary of findings' table.

\section{Main results}

Nine completed RCTs met the inclusion criteria, of which four were cluster-randomised. We also identified five ongoing trials. The included studies had a high or unclear risk of bias, and the GRADE ratings of overall quality were low or very low. The length of follow-up varied from one year in four studies, three years in one study, five or six years in two studies, and ten years in two studies. Eight studies recruited 
participants from the general population, although there were differences in the age ranges targeted. One study recruited family members of cardiac patients (high risk assessment). There were considerable differences between the studies in the interventions received by the intervention and control groups. There was insufficient evidence to stratify by the types of risk assessment approaches.

Limited data were available on all-cause mortality (risk ratio (RR) $0.98,95 \%$ confidence interval (CI) 0.93 to 1.03 ; 3 studies,103,571 participants, $\mathrm{I}^{2}=0 \%$; low-quality evidence) and cardiovascular mortality (RR $1.00,95 \% \mathrm{Cl} 0.90$ to $1.11 ; 2$ studies, 43,955 participants, $\mathrm{I}^{2}$ $=0 \%$ ), and suggest that screening has no effect on these outcomes. Data were also limited for combined non-fatal endpoints; overall, evidence indicates no difference in total coronary heart disease (RR 1.01,95\% Cl 0.95 to 1.07; 4 studies, 5 comparisons, 110,168 participants, $\mathrm{I}^{2}=0 \%$; low-quality evidence), non-fatal coronary heart disease (RR $0.98,95 \% \mathrm{Cl} 0.89$ to $1.09 ; 2$ studies, 43,955 participants, $\mathrm{I}^{2}=39 \%$ ), total stroke (RR $0.99,95 \% \mathrm{Cl} 0.90$ to $1.10 ; 2$ studies, 79,631 participants, $\mathrm{I}^{2}=0 \%$, low-quality evidence), and non-fatal stroke (RR $1.17,95 \% \mathrm{Cl}$ 0.94 to $1.47 ; 1$ study, 20,015 participants).

Overall, systematic risk assessment appears to result in lower total cholesterol levels (mean difference (MD) $-0.11 \mathrm{mmol} / \mathrm{l}, 95 \% \mathrm{Cl}-0.17$ to $-0.04,6$ studies, 7 comparisons, 12,591 participants, $\mathrm{I}^{2}=57 \%$; very low-quality evidence), lower systolic blood pressure (MD $-3.05 \mathrm{mmHg}$, $95 \% \mathrm{Cl}-4.84$ to $-1.25,6$ studies, 7 comparisons, 12,591 participants, $\mathrm{I}^{2}=82 \%$; very low-quality evidence) and lower diastolic blood pressure (MD - $1.34 \mathrm{mmHg}, 95 \% \mathrm{Cl}-1.76$ to $-0.93,6$ studies, 7 comparisons, 12,591 participants, $\mathrm{I}^{2}=0 \%$; low-quality evidence). One study assessed adverse effects and found no difference in psychological distress at five years (1126 participants).

\section{Authors' conclusions}

The results are limited by the heterogeneity between trials in terms of participants recruited, interventions and duration of follow-up. Limited data suggest that systematic risk assessment for CVD has no statistically significant effects on clinical endpoints. There is limited evidence to suggest that CVD systematic risk assessment may have some favourable effects on cardiovascular risk factors. The completion of the five ongoing trials will add to the evidence base.

\section{PLAIN LANGUAGESUMMARY}

\section{Systematic risk assessment (screening) for preventing cardiovascular disease}

\section{Review question}

Are systematic risk assessment (screening) programmes helpful in the prevention of cardiovascular disease?

\section{Background}

Cardiovascular disease (CVD) is a group of conditions affecting the heart and blood vessels. CVD is a global burden and is still the number one cause of early death and disability worldwide. Identification of those at increased risk of cardiovascular disease through screeninglike programmes may help with CVD prevention and management.This review assessed the effectiveness of systematic risk assessment or a screening-like programme in reducing cardiovascular death, death from any cause, non-fatal events (such as heart attacks, strokes and angina) and CVD risk factors in healthy adults and adults at high risk of CVD.

\section{Study characteristics}

We searched scientific databases for randomised controlled trials (clinical trials where people are allocated at random to one of two or more treatments), looking at the effects of systematic risk assessment in healthy adults or those at high risk of developing CVD. We did not include people who already had CVD (e.g. heart attacks and strokes), as these are already known to health services and are being treated. The evidence is current to January 2015.

\section{Key results}

Nine trials met our inclusion criteria. Limited data suggest that screening has no effect on deaths (from any cause) or the number of people having a stroke or developing coronary heart disease. Data were also limited for cardiovascular risk factors (blood lipids and blood pressure) where there were some favourable effects with systematic risk assessment, but there were differences between studies and so results are not certain.

\section{Quality of the evidence}

The evidence was generally of low or very low quality. Included studies were at some risk of bias, with four studies judged at high risk of bias. Bearing this in mind, the results of this review need to be interpreted cautiously.

There is currently limited evidence on the effects of systematic risk assessment for the prevention of CVD. We identified five ongoing trials and when the results are available we will incorporate these. 


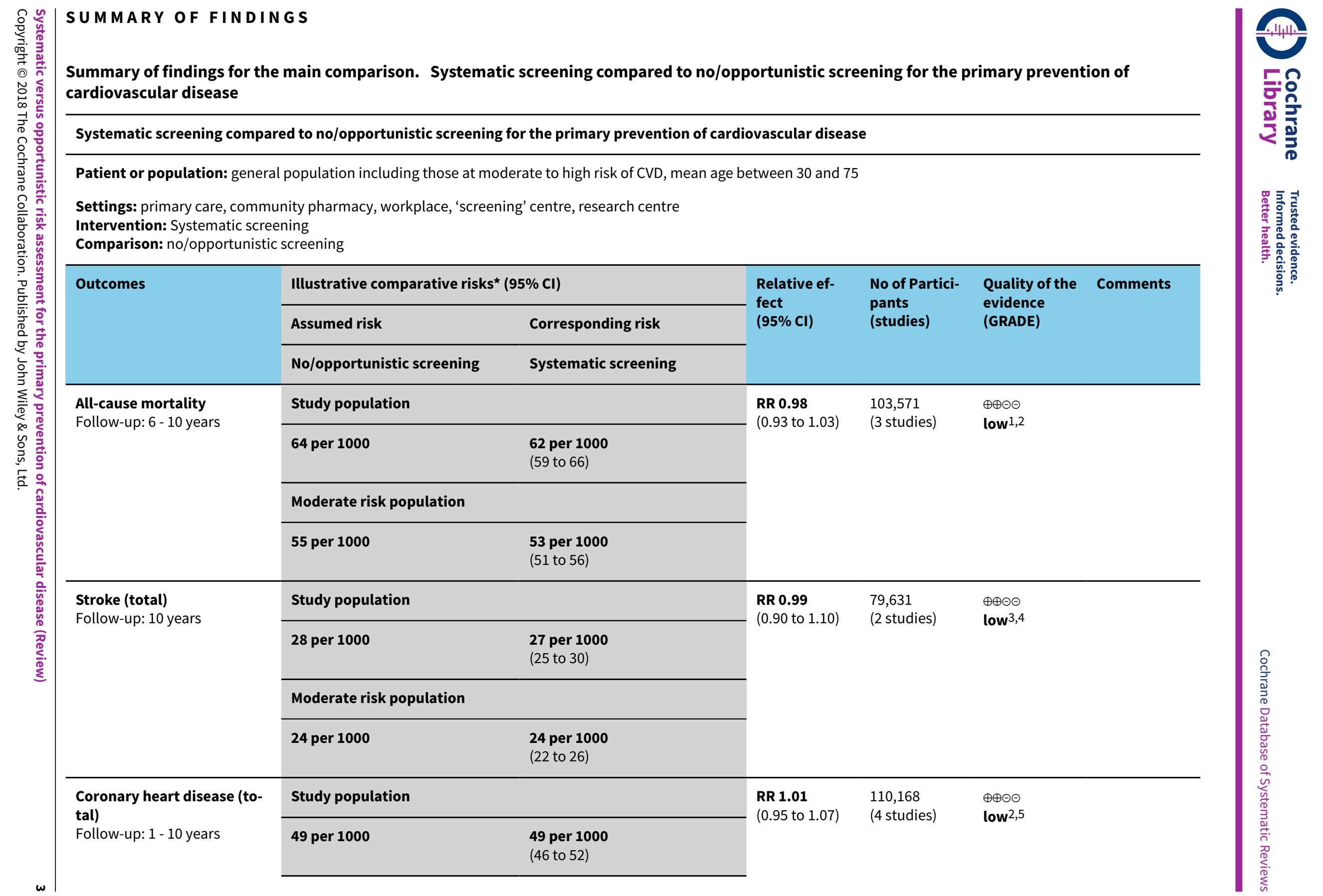


Moderate risk population

\begin{tabular}{|c|c|c|c|c|}
\hline & 46 per 1000 & $\begin{array}{l}46 \text { per } 1000 \\
(44 \text { to } 49)\end{array}$ & & \\
\hline $\begin{array}{l}\text { Total cholesterol, } \mathbf{m m o l} / \mathbf{l} \\
\text { Follow-up: } 1 \text { - } 5 \text { years }\end{array}$ & $\begin{array}{l}\text { range of means in the control } \\
\text { group } 5.25 \text { to } 6.18\end{array}$ & $\begin{array}{l}\text { The mean total cholesterol, } \\
\mathrm{mmol} / \mathrm{l} \text { in the intervention } \\
\text { groups was } \\
\mathbf{0 . 1 1} \text { lower } \\
\text { ( } 0.17 \text { to } 0.04 \text { lower) }\end{array}$ & $\begin{array}{l}12,591 \\
\text { (6 studies) }\end{array}$ & $\begin{array}{l}\oplus \ominus \ominus \ominus \\
\text { very low } 4,6,7\end{array}$ \\
\hline $\begin{array}{l}\text { Diastolic blood pressure, } \\
\mathbf{m m H g} \\
\text { Follow-up: } 1 \text { - } 5 \text { years }\end{array}$ & $\begin{array}{l}\text { range of means in the control } \\
\text { group } 74.4 \text { to } 86\end{array}$ & $\begin{array}{l}\text { The mean diastolic blood pres- } \\
\text { sure, } \mathrm{mmHg} \text { in the intervention } \\
\text { groups was } \\
\mathbf{1 . 3 4} \text { lower } \\
\text { (1.76 to } 0.93 \text { lower) }\end{array}$ & $\begin{array}{l}12,591 \\
\text { ( } 6 \text { studies) }\end{array}$ & $\begin{array}{l}\oplus \oplus \ominus \ominus \\
\text { low } 4,6\end{array}$ \\
\hline
\end{tabular}

*The basis for the assumed risk (e.g. the median control group risk across studies) is provided in footnotes. The corresponding risk (and its $95 \%$ confidence interval) is based on the assumed risk in the comparison group and the relative effect of the intervention (and its $95 \% \mathrm{Cl}$ ).

Cl: Confidence interval; RR: Risk ratio

GRADE Working Group grades of evidence

High quality: Further research is very unlikely to change our confidence in the estimate of effect.

Moderate quality: Further research is likely to have an important impact on our confidence in the estimate of effect and may change the estimate.

Low quality: Further research is very likely to have an important impact on our confidence in the estimate of effect and is likely to change the estimate.

Very low quality: We are very uncertain about the estimate.

${ }^{1}$ For all three studies there was a high risk of reporting bias (Inter99 2014; WHO 1986; Wilhelmsen 1986)

${ }^{2}$ Two studies (WHO 1986; Wilhelmsen 1986) recruited only male participants so results are not generalisable to all those at risk of CVD.

${ }^{3}$ For both studies (Inter99 2014; Wilhelmsen 1986) there was a high risk of reporting bias.

4One study (Wilhelmsen 1986) recruited only male participants so results are not generalisable to all those at risk of CVD.

${ }^{5}$ For all studies (BFHS 1994; Inter99 2014; WHO 1986; Wilhelmsen 1986) there was a high risk of reporting bias, and for BFHS 1994 there was a high risk of attrition bias.

6There was a high risk of reporting bias for Wilhelmsen 1986 and a high risk of both reporting and attrition bias in BFHS 1994.

${ }^{7}$ There was substantial heterogeneity between studies $\left(I^{2}=57 \%\right)$, so we used a random-effects model to pool studies.

8 There was considerable heterogeneity between studies $\left(I^{2}=82 \%\right)$, so we used a random-effects model to pool studies. 


\section{B A C K G R O U N D}

\section{Description of the condition}

Cardiovascular disease (CVD) includes coronary heart disease (CHD), stroke and peripheral arterial disease. It is related to conditions such as heart failure, chronic kidney disease, diabetes, and together with these forms the group of vascular disease (DH 2008a). The underlying pathology is atherosclerosis, which develops over many years and is usually advanced by the time symptoms occur (BHF 2012a). Acute coronary and cerebrovascular events happen suddenly, usually in middle age, and are often fatal before medical care can be given.

CVD is still the number one cause of premature death and disability worldwide, contributing largely to the escalating costs of health care (WHO 2011a). Cardiovascular disease accounts for most noncommunicable disease deaths, in 17.5 million people annually (WHO 2014a). A substantial proportion of these deaths (46\%) are in people under 70 years of age, in their most productive period of life (WHO 2007). Two of the top three causes of years of life lost (YLL) due to premature mortality in 2012 were ischaemic heart disease (IHD) and stroke (WHO 2014b). It is estimated that by 2030 CVD will account for almost 23.6 million deaths (WHO 2011a). In the European region, diseases of the circulatory system account for nearly $50 \%$ of all deaths with wide variation in total and premature mortality between and within countries and by age, sex and the distribution of important determinants (WHO 2013). In the UK, heart and circulatory disease causes more than one in three of all deaths, and a fifth of all hospital admissions, and accounts for more than 191,000 deaths each year at an estimated cost of GBP 30 billion. There are nearly 2.7 million people living with heart disease in the UK (BHF 2012b). In the United States 35\% of the total deaths in 2010 were accounted for by CVD compared to $45 \%$ in Germany, $31 \%$ in Denmark, $48 \%$ in Greece, $32 \%$ in Japan, $26 \%$ in Mexico and $38 \%$ in China (WHO 2011b).

Huge improvements have been made in the prevention and treatment of CVD over the last decade. Although premature mortality from IHD is generally decreasing, in some countries the rate is decreasing more slowly, remains unchanged or is even increasing (DH 2013; WHO 2013). The ageing and growth of populations have led to an increase in the total number of cardiovascular deaths (GBD 2013). Increased levels of obesity, leading to a higher prevalence of type 2 diabetes, increase the risk for CVD and can reduce the gains made (DH 2013). CVD death rates are no longer falling among young and middle-aged people in the UK, the USA and Australia. This reflects a combination of adverse risk factors including smoking, a poor diet and social disadvantage (O'Flaherty 2009).

Many risk factors contribute to the development of CVD, most of which are related to lifestyle, such as physical inactivity, smoking, excess alcohol use and an unhealthy diet (WHO 2011a). In more than $90 \%$ of cases, the risk of a first heart attack is related to nine potentially modifiable risk factors (Yusuf 2004): smoking/tobacco use; poor diet; high blood cholesterol; high blood pressure (BP); insufficient physical activity; overweight/obesity; diabetes; psychosocial stress; and excess alcohol consumption. The combined effect of different co-existing cardiovascular risk factors determines the total or global or absolute risk of developing CVD. An individual with several mildly-raised risk factors may be at a higher total risk of CVD than someone with just one elevated risk factor. Many people are unaware of their risk status and total risk assessment is potentially useful for finding high-risk individuals and guiding clinical decisions (Tunstall-Pedoe 2003). Such a risk stratification approach is particularly suited to settings with limited resources (WHO 2002). Much research has been undertaken to validate different CVD risk-scoring methods, so that individual CVD risk is correctly identified (Beswick 2008). Regardless of which scoring mechanism is used, assessing someone's level does not actually change their CVD risk. Short 2009 emphasises that there is no advantage in assessment without the ability to intervene and to make changes to lower that risk.

A significant proportion of CVD morbidity and mortality can be prevented through population strategies for primary prevention. Efficient and effective means of identifying high-risk individuals and then providing the support to enable them to modify their lifestyles requires a delivery system which gives priority to preventive services rather than focusing on treatment (Bernard 2009). Evidence supporting the 'Rose hypothesis' (Rose 2008) has been growing. A recent study (Cooney 2009) pooling data from six European general population cohort studies with 109,954 participants has compared different CVD strategies. The analysis has shown that a $10 \%$ population-wide reduction in blood cholesterol, blood pressure and smoking prevalence (with population-wide policies/strategies) is saving approximately 9120 lives per million people over 10 years, while treating $40 \%$ of highrisk individuals with a 'polypill' (statin + three half-dose antihypertensives + aspirin) would save about 3720 lives per million (Cooney 2009).

Despite various public health and clinical efforts for primary prevention of CVD, a large number of the population considered at increased risk of vascular disease remains unidentified, untreated and not reached by lifestyle advice or intervention. This has prompted the initiation of screening/systematic risk assessment programmes for vascular disease in healthy populations. These exist in contrast and in addition to the more ad hoc opportunistic risk assessment initiatives undertaken worldwide.

\section{Description of the intervention}

A health risk assessment is one of the most widely used screening tools in the field of health promotion. The main objectives of a risk assessment are to assess health status, to estimate health risk, and to inform and provide feedback to participants in order to reduce health risks (NPSA 2007).

This review focuses on comparing systematic (intervention) with opportunistic risk assessment (control) for primary prevention of CVD. Considering the variability of risk assessment methods and practices, we provide definitions of systematic and opportunistic risk assessment below.

Systematic risk assessment for primary prevention of CVD we defined here as a screening-like programme, involving a predetermined process for selection of people, who are systematically invited to attend a CVD health check in a primary care or similar setting.

Systematic here means that selection, invitation and followup processes are determined in advance, for example, specific inclusion/exclusion criteria are set; a unified method of invitation is used, such as letter/birthday card/phone call; and there is a system 
for providing feedback or referral. Such a programme is repeated at predefined intervals, for example every five or 10 years.

The assessment process includes finding out and measuring CVD risk factors (for example, blood pressure, serum cholesterol or physical activity) as well as estimating the total (global/absolute) CVD risk, using a specific risk-scoring tool (chart/programme).

Primary prevention here means that the target population for such systematic risk assessment includes healthy individuals - in this case, those who have not been previously diagnosed with CVD. This population group consists of individuals at different levels of risk, ranging from very low (minimal) through moderate up to high risk for developing CVD in the future. Many of these people may already have been diagnosed with one or more CVD risk factors, including hypertension, dyslipidaemia, diabetes, among others.

Similarly to other screening programmes, systematic risk assessment can be realised in two ways: population (universal/ mass) systematic risk assessment - targeted to the general population in a certain age group with no regard for any underlying risk factors; high-risk systematic risk assessment - targeted to a specific group of individuals, considered potentially to be at increased risk of CVD due to some pre-existing risk factors, for example, the population of a deprived area or from a minority ethnic group.

An example of such an approach is the NHS Health (Vascular) Check Programme (NHS 2012). Designed as a population-based screening initiative, it is aimed at all those aged 40 to 74 , ensuring that everyone in this age range is invited to determine his/her vascular risk. The Health Check is undertaken in primary care (general practices in the UK) and consists of a review of: height, weight and body mass index (BMI); demographics; smoking and lifestyle status; blood pressure; lipid profile; and, where appropriate, diabetes review and serum creatinine levels. Risk analysis and risk stratification are performed, followed by an advice and management plan for high-risk individuals. This is repeated every five years. A potential strength of the NHS Health Checks is the opportunity it provides for primary care to re-engage with their population who are relatively hard to reach, allowing support not only for vascular risk assessment but also for other concerns (Short 2009). Such a population approach may inadvertently widen health inequalities, due to low response and attendance of groups already at increased risk (for example, those from deprived areas). To prevent this, primary care practitioners have been encouraged to monitor uptake and where it is low and risk/need is considered potentially high they are exhorted to use other approaches to improve uptake. The Department of Health (DH 2013) has found that the NHS Health Check implementation and uptake are patchy and follow-up management needs to improve. Despite several local observational studies, an overall/national evaluation of its effectiveness and impact has not been done.

Opportunistic risk assessment for primary prevention of CVD we define here as CVD risk assessment occurring sporadically in a primary setting, including primary care, pharmacy chains, supermarket chains, food companies, occupational health departments or small businesses. These activities do not involve systematic planning or invitation systems and are not part of any organised CVD prevention programme. The range of such activities varies from no CVD risk assessment at all (no risk factors are measured/no total risk is scored in healthy individuals), through random (opportunistic) risk assessment in people attending primary care for another reason, to incentivised case-finding, for example through the Quality and Outcomes Framework for UK general practitioners (GPs) (NICE 2016). Every routine physical examination provides an opportunity to obtain information about health behaviours related to CVD risk, such as smoking, eating habits, physical activity and others (Every contact counts 2012). Opportunistic screening can be facilitated by computer prompts on records of eligible patients who may attend the surgery for another complaint. Such initiatives, although not organised, can allow for follow-up to ensure feedback is given to patients and an appropriate disease management plan is offered (UKNSC 2008).

\section{How the intervention might work}

CVD risk assessment strategies have attracted considerable interest both in the clinical and public health communities and the focus on primary prevention has become stronger in recent years.

According to the NHS Health Checks Programme (DH 2008a), a standard assessment, based on simple questions and measurements to identify the risk of CHD, stroke, diabetes and kidney disease, would be effective. After assessing the levels of the main risk factors and the total CVD risk, a follow-up is organised with an individually-tailored assessment, setting out the person's level of vascular risk and what steps they could take to reduce it. For those at low risk, this might be no more than general advice on how to stay healthy. Others at moderate risk may be recommended a weight management programme, stop-smoking service, or a brief intervention to increase levels of physical activity. Those at the highest risk might also require medication or an intensive lifestyle management programme. A few may need further assessment that would require referral to a hospital consultant. People who already have a vascular disease, which has remained undiagnosed, particularly diabetes and chronic kidney disease, may be detected. In such cases, they may benefit from an immediate start on a treatment or a disease-management programme to manage their condition and prevent adverse complications. Modelling work around the Health Checks approach has predicted that it would deliver significant benefits for the UK population, preventing at least 9500 heart attacks and strokes a year (2000 of which would be fatal); preventing at least 4000 people a year from developing diabetes; and detecting diabetes or kidney disease at least a year earlier for 25,000 people. It has predicted high levels of both clinical and cost effectiveness against a range of assumptions when this approach is applied to all those aged 40 to 74 years (DH 2008b).

Recent research, published since the introduction of the NHS Health Checks, suggests that targeting high-risk individuals (high-risk-based systematic risk assessment) rather than mass population screening (population-based systematic risk assessment) is a preferred route (Chamnan 2010; Lawson 2010). Lawson identified that 16 people were needed to be screened, following the population approach, to identify one individual at high risk of CVD, costing GBP 370 per high-risk person. The alternative, e.g. targeted screening of deprived communities, estimates that only six people would need to be assessed for the identification of one high-risk individual, reducing the costs to GBP 141 per positive identification. Jackson 2008 identifies that a screening programme targeted at individuals with likely or known CVD risk factors would be preferable from a costeffectiveness point of view. Previous research (Wood 1994) suggests that when a population screening programme is undertaken, there 
is a persistent level of non-attendance and that whilst the cardiac risk score for non-attenders is similar to those who attended, nonattenders have significantly more risk behaviours such as smoking. Population-based (universal) risk assessment every five years was found to be cost-effective when compared with no screening; however, a cost analysis was not conducted on whether universal risk assessment would remain cost-effective when compared to targeted high-risk screening.

On the other hand, following international and national recommendations, opportunistic CVD risk assessment has become a routine practice in many developed countries. Many primary care practices already run preventive risk assessment programmes, particularly in relation to $\mathrm{CHD}$, as well as looking at overall vascular risk. Most industrialised countries already detect a drop in CVD morbidity and mortality even without population-wide screening programmes. Before the introduction of the NHS Health Checks Programme in the UK, the National Service Framework (DH 2000) had already contributed to a significant improvement, i.e. a $40 \%$ reduction in cardiovascular deaths in people under 75 since 1996 (UKNSC 2008). The effectiveness and cost effectiveness of the systematic risk assessment approach has not been compared to the opportunistic risk assessment approach to prevent CVD in healthy individuals.

\section{Why it is important to do this review}

There is not yet a systematic review comparing the effectiveness of systematic with opportunistic risk assessment for primary prevention of CVD. A recent Cochrane review (Krogsbøll 2012) has looked at the impact of general health checks (as compared to cardiovascular) and has concluded that they are unlikely to be beneficial and that they do not reduce morbidity or mortality, neither overall nor for cardiovascular or cancer causes. This has put into question the evidence base for rolling out general and/or cardiovascular population-wide screening-like programmes. There is currently not enough evidence showing clear clinical or economic benefits of systematic screening-like programmes over the widelypractised opportunistic risk assessment of cardiovascular disease in primary care. A comprehensive systematic review is therefore needed which examines the most up-to-date research to find out whether systematic programmes are more effective in preventing particularly CVD mortality and morbidity in healthy populations than opportunistic risk assessment.

\section{OB JECTIVES}

The primary objective of this review is to assess the effectiveness, costs and adverse effects of systematic risk assessment compared to opportunistic risk assessment for the primary prevention of CVD.

\section{METHODS}

\section{Criteria for considering studies for this review}

\section{Types of studies}

Randomised controlled trials (RCTs).

\section{Types of participants}

Healthy adults (aged 18 years or over) from the general population, including those at moderate to high risk of CVD. The review focuses on the primary prevention of CVD, so we have included RCTs covering participants without known CVD (i.e. without myocardial infarction (MI), stroke, revascularisation procedure (coronary artery bypass grafting (CABG) or percutaneous transluminal coronary angioplasty (PTCA)), angina or angiographically-defined coronary heart disease (CHD)).

We were interested only in primary prevention of CVD, i.e. the effects of CVD risk assessment on healthy individuals or those at increased risk of CVD, because if an individual is already diagnosed with CHD, they are already considered at high risk and cared for by the healthcare system (e.g. put on medication, given active lifestyle change advice, etc.). Previous research has shown that there are a considerable number of individuals who are at high risk of, or already have, CVD who are not recognised/diagnosed; hence, the introduction of screening programmes in the UK such as the Health Checks (DH 2008a).

\section{Types of interventions}

Intervention: systematic risk assessment for primary prevention of CVD, defined as a screening-like programme, involving a predetermined selection process of people, who are systematically invited to attend a CVD health check in a primary care or similar setting, assessing at least two of the following risk factors:

1. Blood pressure (systolic and/or diastolic) or lipid profile (total cholesterol, LDL, LDL/HDL); and

2. Any other modifiable risk factor (smoking, weight, diet, exercise, alcohol, stress).

Control: opportunistic risk assessment for primary prevention of CVD, defined as a range of activities, occurring sporadically in any primary setting, from no risk assessment at all to incentivised case finding.

\section{Types of outcome measures}

\section{Primary outcomes}

1. All-cause mortality

2. Cardiovascular mortality

3. Non-fatal cardiovascular endpoints, including CHD, MI, CABG, PTCA, stroke, transitory ischaemic attack (TIA) and peripheral artery disease

\section{Secondary outcomes}

1. CVD major risk factors: lipid levels, blood pressure, type 2 diabetes

2. Intermediate (programme) outcomes (if reported): case-finding rates (number of high-risk individuals identified by the health check); attendance rates (number of individuals who came for examination); acceptability and participants' satisfaction; and follow-up rates (number of cases who were followed with some intervention in primary and secondary care)

3. Adverse effects

4. Costs

\section{Search methods for identification of studies}

\section{Electronic searches}

We identified trials through systematic searches of the following bibliographic databases between 4 December 2014 and 30 January 2015: 
- The Cochrane Central Register of Controlled Trials (CENTRAL) (Issue 1 of 12, 2015 on the Cochrane Library)

- The Database of Abstracts of Reviews of Effects (DARE) (Issue 4 of 4, 2014 on the Cochrane Library)

- The NHS Economic Evaluation Database (NEED) (Issue 4 of 4 , 2014 on the Cochrane Library)

- The Health Technology Assessment (HTA) Database (Issue 4 of 4, 2014 on the Cochrane Library)

- Ovid MEDLINE (1946 to January Week 4 2015)

- Ovid EMBASE and EMBASE Classic (1947 to 2015 January 15)

- Web of Science Core Collection (Thomson Reuters) ( 1970 to 3 December 2014)

We adapted the preliminary search strategy for MEDLINE (Ovid) for use in the other databases (Appendix 1). We applied the Cochrane sensitivity-maximising RCT filter (Lefebvre 2011) to MEDLINE (Ovid) and adaptations of it to the other databases, except CENTRAL.

We also conducted a search of ClinicalTrials.gov (www.ClinicalTrials.gov) and the World Health Organization International Clinical Trials Registry Platform Search Portal (apps.who.int/trialsearch/).

We searched all databases from their inception to the present, and we imposed no restriction on language of publication.

\section{Searching other resources}

We checked reference lists of all primary studies and review articles for additional references. We also, where necessary, contacted authors for additional information.

\section{Data collection and analysis}

\section{Selection of studies}

Two review authors (from MD, CD, JM, MS, NW, SS) screened the title and abstract of each paper from the searches and retrieved potentially relevant references. We then obtained the full text of potentially relevant studies and two review authors (from MD, CD, MS, SS) independently selected studies to be included in the review by using predetermined inclusion criteria. In all cases we resolved any disagreements about study inclusion by consensus or by consulting a third review author (KR/AC).

\section{Data extraction and management}

One review author (SS) extracted data using a pro forma which was checked by another (JC) and entered into the Characteristics of included studies table. We contacted primary investigators to provide additional relevant information if necessary. We extracted details of the study design, participant characteristics, study setting, interventions and outcome data, including details of outcome assessment, adverse effects and methodological quality (randomisation, blinding and attrition) from each included study. We resolved disagreements about extracted data by consensus or with a third review author (KR).

One review author (JC) transferred data into the Review Manager 5 (RevMan 2014) file. We double-checked that data were entered correctly by comparing the data presented in the systematic review with the study reports.

\section{Assessment of risk of bias in included studies}

We assessed risk of bias by examining the random sequence generation and allocation concealment, description of dropouts and withdrawals (including analysis by intention-to-treat), blinding (participants, personnel and outcome assessment) and selective outcome reporting (Higgins 2011) in each trial. Two review authors (from SS, JC, KR) assessed the risk of bias of included studies.

\section{Measures of treatment effect}

We processed data according to the Cochrane Handbook for Systematic Reviews of Interventions (Higgins 2011). We expressed dichotomous outcomes as risk ratios (RRs), with 95\% confidence intervals (Cls) calculated for each study. We compared net changes for continuous outcomes (i.e. intervention group minus control group differences) with a mean difference (MD) or standardised mean difference (SMD), with $95 \% \mathrm{Cls}$ calculated for each study. We intended to examine change from baseline data for continuous outcomes, but most studies did not report baseline values for the control group, so that we could not calculate mean changes. We pooled endpoint values in meta-analyses where appropriate.

One of the included studies (BFHS 1994) reported men and women overall and separately, and we have preserved this in our metaanalyses (BFHS Men and BFHS Women).

\section{Unit of analysis issues}

For cluster-RCTs we followed the guidance as reported in the Cochrane Handbook (Higgins 2011). Where data were appropriately analysed to take account of the effects of clustering in the original studies, we used these. Where this was not reported we used the approximate analyses of cluster-RCTs to determine the effective sample sizes as outlined in Chaper 16.3.4 (Higgins 2011). For one study (OXCHECK 1995) we were unable to do this, as the number of clusters was not reported.

\section{Dealing with missing data}

Where standard deviations were not reported in a publication, we calculated them from standard errors, confidence intervals or $t$ values. If this was not possible, we imputed standard deviations from another study. We selected the study with the highest standard deviation for an outcome, as this down-weights a study and yields a wider confidence interval (Higgins 2011).

\section{Assessment of heterogeneity}

We conducted tests of heterogeneity for each outcome, using the $\mathrm{Chi}^{2}$ test of heterogeneity and the $\mathrm{I}^{2}$ statistic. Where there was no heterogeneity we performed a fixed-effect meta-analysis. We looked for possible explanations if we detected moderate to substantial heterogeneity (for example, participants and interventions).

Thresholds for the interpretation of $\mathrm{I}^{2}$ can be misleading, since the importance of inconsistency depends on several factors. Approximate guidelines to interpretation from the Cochrane Handbook are as follows:

- $0 \%$ to $40 \%$ : might not be important;

- $30 \%$ to $60 \%$ : may represent moderate heterogeneity*;

- $50 \%$ to $90 \%$ : may represent substantial heterogeneity*;

- $75 \%$ to $100 \%$ : considerable heterogeneity*. 
${ }^{\star}$ The importance of the observed value of $\mathrm{I}^{2}$ depends on (i) magnitude and direction of effects, and (ii) strength of evidence for heterogeneity (e.g. $\mathrm{P}$ value from the $\mathrm{Chi}^{2}$ test, or a confidence interval for $\mathrm{I}^{2}$ ).

If we could not explain the heterogeneity, we considered the following options: provide a narrative overview and not aggregate the studies at all, or use a random-effects model with appropriately cautious interpretation.

\section{Subgroup analysis and investigation of heterogeneity}

We had intended to stratify by the types of risk assessment approaches, if we found sufficient studies. The subgroups were as follows:

1. Systematic risk assessment stratified into: population/universal/ mass risk assessment (targeting the whole population in a certain age group) and high-risk risk assessment (targeting specific population groups, perceived to be at increased risk).

2. Opportunistic risk assessment stratified into: no/minimal risk assessment, sporadic/opportunistic risk assessment and incentivised case finding.

We also planned to examine the effects of the intervention design (setting, personnel involved, invitation and follow-up system).

There are currently insufficient numbers of trials included in the review to conduct these analyses.

\section{Sensitivity analysis}

We had planned to carry out sensitivity analyses excluding studies with a high risk of bias, and to undertake assessment of funnel plots and tests of asymmetry (Egger 1997) to assess possible publication bias, if there were enough studies (at least 10 per outcome) included in the review. There are currently insufficient numbers of trials included in the review to conduct these analyses.

\section{Summary of Findings}

We created a Summary of findings for the main comparison using the following outcomes:

1. Total mortality

2. Total strokes (fatal and non-fatal)

3. Total CHD (fatal and non-fatal)

4. Total cholesterol (mean at endpoint)

5. Systolic blood pressure (mean at endpoint)

6. Diastolic blood pressure (mean at endpoint)

We used the five GRADE considerations (study limitations, consistency of effect, imprecision, indirectness and publication bias) to assess the quality of a body of evidence as it relates to the studies which contribute data to the meta-analyses for the prespecified outcomes. We used the methods and recommendations described in Section 8.5 and Chapter 12 of the Cochrane Handbook for Systematic Reviews of Interventions (Higgins 2011), using GRADEpro software. We justified all decisions to down- or upgrade the quality of studies using footnotes, and made comments to aid the reader's understanding of the review where necessary.

\section{RES U LTS}

\section{Description of studies}

\section{Results of the search}

The searches generated 14,331 hits after duplicates were removed. In addition, we identified five records through other sources. Screening of titles and abstracts identified 307 papers to go forward for formal inclusion and exclusion. Nine randomised controlled trials (22 papers) fulfilled the inclusion criteria and are included in the review. For a detailed description of the included studies see Characteristics of included studies. We also identified five ongoing studies and report them in Characteristics of ongoing studies. We present the flow of studies through the review in Figure 1. 
Figure 1. Study flow diagram.

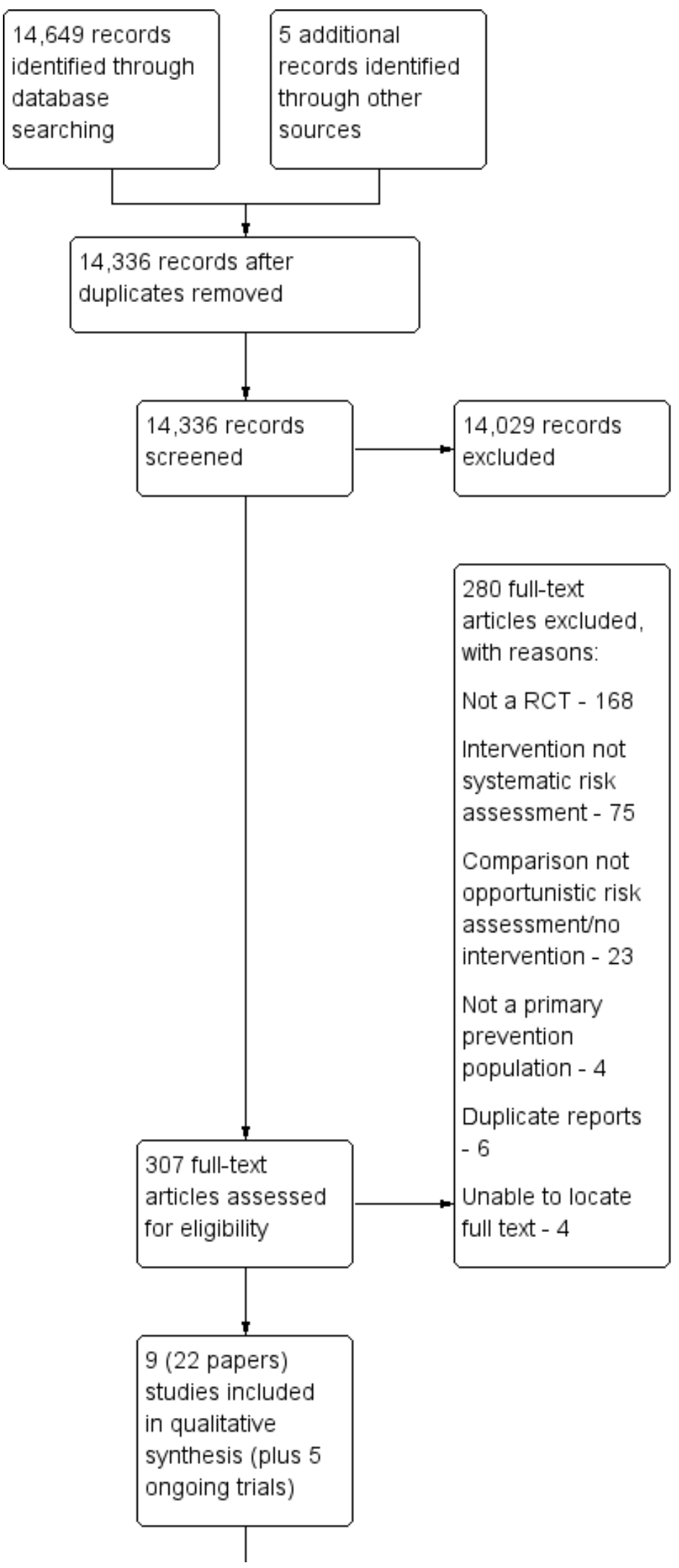


Figure 1. (Continued)

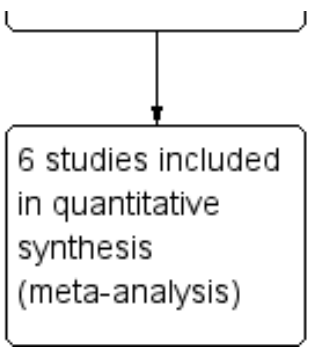

\section{Included studies}

Detailed study characteristics are shown in Characteristics of included studies.

\section{Study design}

We include nine randomised trials; five randomised individuals (EHPP 2002; FIT Heart 2008; Inter99 2014; Murray 1986; Wilhelmsen 1986) and four randomised clusters (BFHS 1994; CHAPS 2011; OXCHECK 1995; WHO 1986). In BFHS 1994, each pair of practices from 13 towns was randomised to intervention or control (termed 'external control' by the study). Families in the intervention practices were further randomised to intervention or 'internal control'. OXCHECK 1995 randomised by household, but the numbers of households or individuals in each household were not reported. WHO 1986 arranged factories in matched pairs (matching variables not reported), and the factories within each pair were randomised to intervention or control. The unit of analysis in BFHS 1994; OXCHECK 1995 and WHO 1986 was the individual rather than the cluster. CHAPS 2011 randomised 39 communities.

Two studies (BFHS 1994; OXCHECK 1995) were conducted in the UK; two were conducted in Denmark (EHPP 2002; Inter99 2014), two were conducted in USA (FIT Heart 2008; Murray 1986), and one study was conducted in each of Canada (CHAPS 2011), and Sweden (Wilhelmsen 1986). WHO 1986 had centres in the UK, Belgium, Italy, Poland and Spain, although the centres in Spain were excluded from the final analysis (before the results were known).

The setting for the intervention was primary care in three studies (BFHS 1994; EHPP 2002; OXCHECK 1995), community pharmacy in one study (CHAPS 2011), the workplace (factories) in one study (WHO 1986), a 'Heart Health Centre' in one study (Murray 1986), a 'screening centre' in one study (Wilhelmsen 1986) and a research centre in one study (Inter99 2014). The setting of the intervention was not clear in one study, but participants were family members of cardiac patients admitted to a secondary centre with acute atherosclerotic cardiovascular disease (FIT Heart 2008).

The year of publication of the main results of the included studies ranged from 1986 to 2014. Recruitment of participants or initial health screening began in 1970 (Wilhelmsen 1986), 1971 (WHO 1986), 1982 (Murray 1986), 1988 (OXCHECK 1995), 1991 (EHPP 2002), 1998 (Inter99 2014), 2005 FIT Heart 2008, and 2006 CHAPS 2011. Study dates were not reported by BFHS 1994. Length of follow-up was one year in four studies (BFHS 1994; CHAPS 2011; FIT Heart 2008; Murray 1986), three years in one study (OXCHECK 1995), five years in one study (EHPP 2002), six years in one study (WHO 1986) and 10 years in two studies (Inter99 2014; Wilhelmsen 1986).

\section{Overview of study populations}

Sample sizes varied. Of the studies randomising individuals, FIT Heart 2008 included 501 participants (intervention $n=250$, control $\mathrm{n}=251$ ), Murray 1986 included 906 participants (intervention $\mathrm{n}=$ 428, control $=478$ ), EHPP 2002 included 1507 participants (health screen $n=502$, health screen + discussion $n=504$, control $n=$ 501) and Inter99 2014 included 59,616 participants (intervention $n=11,629$, control $n=47,987$ ). Wilhelmsen 1986 included 30,022 participants (intervention $n=10,004$, control $1 \mathrm{n}=10,011$, control $2 \mathrm{n}=10,007$ ), but follow-up at four years was only conducted in a random sample (11\%) of the control group, and follow-up at 10 years was only conducted in a random sample (20\%) of both the intervention and control groups. Of the cluster-randomised trials, WHO 1986 randomised 80 factories (excluding the Spanish centres) with 60,881 individuals (intervention $\mathrm{n}=30,489$, control $\mathrm{n}=30,392)$. BFHS 1994 randomised 14,086 households, of which 8605 households responded (intervention: 2373 households (3850 individuals), internal control: 2342 households, external control: 3890 households, number of individuals in the control groups at baseline not clear). OXCHECK 1995 randomised 11,090 participants to four groups, two of which were reported in their publication (total 5999, intervention $n=2776$, control $n=2783$ ). CHAPS 2011 did not report the number of individuals, but randomised 39 communities (intervention 20 clusters, control 19 clusters), each with a population of 10,000 to 60,000 .

In eight of the nine included studies, participants were recruited from the general population (BFHS 1994; CHAPS 2011; EHPP 2002; Inter99 2014; Murray 1986; OXCHECK 1995; WHO 1986; Wilhelmsen 1986), although the age of the target population differed. Murray 1986 included people aged 25 to 74 years, with one person selected at random from each randomised household. EHPP 2002 included people aged 30 to 49 years registered with a local GP. Inter99 2014 included people aged 30 to 60 years identified from the civil registration system. OXCHECK 1995 included people aged 35 to 64 years on the GP register. BFHS 1994 included men aged 40 to 59 years on the registers of included GP practices, and their partners (irrespective of age). CHAPS 2011 included people aged over 65 years recruited from the community via a personalised invitation letter from their physician or other lead organisation or via adverts in the media. Two studies included men only, aged between 40 and 59 years in WHO 1986 who worked in factories in Europe, and between 47 and 55 years on the population register in Wilhelmsen 1986.

One study recruited family members (aged 20 to 79 years, only one family member per index case) of cardiac patients admitted to a secondary centre with acute atherosclerotic cardiovascular disease (FIT Heart 2008); these participants may be at higher risk of cardiovascular disease than the general population. 
As would be expected from the differences in inclusion criteria, where reported the mean age varied between the studies from 30 years (FIT Heart 2008) to 75 years (CHAPS 2011). Among the seven studies including both men and women, the proportion of men ranged from 34\% (FIT Heart 2008) to 63\% (BFHS 1994).

\section{Description of interventions}

\section{Interventions}

The intervention in BFHS 1994 comprised a health check carried out at the practice by a nurse, involving a questionnaire on demographics, past medical history, family history and smoking, height, weight (BMI), waist/hip ratio, BP, total blood glucose and cholesterol measurement (for a random $75 \%$ in five practices), and a coronary risk score (Dundee) was calculated. Participants were told which decile of risk for coronary heart disease they were in relative to other men or women of the same age. Their risk was recorded in a booklet with personally-negotiated lifestyle changes documented. Frequency of follow-up was determined by the coronary risk score and other factors. Adults in the top quintile were offered follow-up every two months, those in the fourth quintile every three months, those in the third quintile every four months, those in the second quintile every six months, and those in the bottom quintile at one year. People with individual high-risk factors were also invited to re-attend every month for up to three months. Patients with glucose concentration of $10 \mathrm{mmol} / \mathrm{l}$ or more, or diastolic blood pressure (DBP) of $115 \mathrm{mmHg}$ or higher on any occasion were referred to a GP, as were those with cholesterol of $6.5 \mathrm{mmol} / \mathrm{l}$ or more, or DBP $100 \mathrm{mmHg}$ or higher sustained for three months.

In CHAPS 2011, weekday sessions (each lasting three hours) on blood pressure and CVD risk-factor assessment and education were held in community bases over a 10-week period. Participants were given their risk profile, specific educational materials and information regarding the availability of local community resources. Any patients identified as being at high risk (according to BP) were assessed by a nurse and referred immediately to a family physician. At the end of the 10 -week programme, results were sent to family physicians (with reports ordering patients by systolic BP) along with their diagnostic/treatment status. These data were resent to the GPs at six months, along with aggregatelevel data showing the performance of their practice compared to others in the locality regarding attaining target systolic BP. The risk factors assessed were BP, smoking, alcohol intake, diet, physical activity, height and weight.

In EHPP 2002 a baseline questionnaire recorded demographics, health, lifestyle and psychosocial status/life events, and Goldberg's 12-item general health questionnaire. There were two intervention groups: 1) health check and written feedback from GP; and 2) health check and written feedback from their GP, plus the opportunity to attend their GP to discuss preventive health. The health checks involved calculation of a cardiovascular risk score based on sex, family history, tobacco, BP, total cholesterol and BMI. Within two weeks of the health check, all participants received personalised written feedback from their GP, including advice relating to lifestyle changes when values indicated that people were at risk, and pamphlets on leading a healthy lifestyle from the Danish Heart Foundation. If signs of disease or indications for further examination were present, the communication also included suggestions about seeking medical care. Those randomised to the health discussions group also received a 45-minute consultation with their own GP covering a maximum of three health-related lifestyle goals for the following year. These were confirmed in writing. It was also possible to book a 30-minute consultation with the GP, to take place three months later. Annual consultations were offered.

In FIT Heart 2008 participants received baseline assessments of diet, lifestyle, and risk factors including demographics, medical history, family history, drug history, lifestyle habits, systolic blood pressure (SBP), DBP, height weight, waist circumference, BMI, physical activity level, and smoking status (with carbon monoxide monitoring). Fasting blood samples were collected for total cholesterol, HDL-cholesterol, triglyceride, glucose, LDL-cholesterol and $\mathrm{C}$-reactive protein. The intervention was personalised CVD riskfactor screening with immediate feedback by a health educator, behavioural counselling, and lifestyle approaches to risk reduction, including ways to improve total blood cholesterol. Diet counselling focused on foods rather than nutrient intake. Participants were encouraged to do physical activity and stop smoking (with referral to a cessation programme). They had regular contact with their educator (by person/phone) at two weeks, six weeks, three months, six months and nine months. All visits were 30 to 60 minutes long. Risk factor results were given to primary care providers as a written report. In addition, those with abnormal lipids were offered fingerprick lipid testing at three, six, and nine months with immediate feedback.

The intervention group in Inter99 2014 received screening with a comprehensive questionnaire (lifestyle, motivation to change lifestyle, symptoms, medical history, family history, psychosocial factors) and physical measurements (electrocardiograph (ECG), $\mathrm{BP}$, height, weight, waist/hip circumference, spirometry), bloods (total cholesterol, total lipid profile), and an oral-glucose tolerance test. A 10-year risk of IHD was calculated using the PRECARD programme, with "at-risk" people defined as being in the upper fifth quintile of risk, or if smokers, SBP higher than $160 \mathrm{mmHg}$, on anti-hypertension medication, total cholesterol higher than $7.5 \mathrm{mmol} / \mathrm{l}$, having lipid-lowering drugs, BMI above 30, history of type 2 diabetes or IHD, or impaired glucose tolerance/type 2 diabetes on oral glucose tolerance test. Using this, $60 \%$ were classified as being at high risk. Each person was simulated in the computer programme as 60 years old to reach a substantial level of risk. Based on risk, each participant had a lifestyle counselling session (15 to 45 minutes) and received written material (on physical activity, smoking, diet, alcohol as relevant). High-risk participants were offered six counselling sessions over four to six months (e.g. smoking cessation, diet, physical activity). High-risk participants were given a letter for their GP with results from the examinations, and re-invited at one and three years for repeat screening, risk assessment and lifestyle counselling as above. Low-risk participants only received a questionnaire. At five years, all of the intervention group were re-invited for final screening, counselling and a plan for maintenance.

Participants in Murray 1986 were invited to attend the Heart Health Centre, where they were tested for total serum cholesterol, height and weight, blood pressure, expired-air carbon monoxide, and leisure-time physical activity. Results of these tests were returned during the visit and participants received a health education message on videotape, printed materials or both, focusing on behaviour change. This included diet, physical activity, stopping 
smoking or helping smokers to stop, and reading food labels. The participant's risk-factor level was recorded and the message was tailored to the risk-factor value. The average visit lasted 75 minutes.

Participants in OXCHECK 1995 received a health check, involving details of personal and family history of IHD, stroke, hypertension, diabetes mellitus, cancer, smoking and dietary intake; and measurement of height/weight (BMI calculated), blood pressure and serum cholesterol. Nurses were instructed to counsel participants about risk factors, ascertaining their views and negotiating priorities and targets for risk reduction. Follow-up was by mutual agreement between the nurse and participant. Set protocols for repeat measurements were laid down for high blood pressure and hyperlipidaemia. The intervention group were further randomised to receive annual re-examinations or a single return visit at three years.

All men in the intervention factories of WHO 1986 were invited to a cardiovascular examination (blood pressure, plasma/serum cholesterol, smoking, weight, exercise). Those with the highest levels of multifactor risks received more individual advice (including personal consultations with physicians) as follows: cholesterol-lowering dietary advice for all; smoking cessation advice for smokers of five or more cigarettes a day; weight reduction advice for those $15 \%$ or more overweight; daily exercise advice for those classified as 'sedentary'; control of hypertension with drugs for those with a mean SBP of $160 \mathrm{mmHg}$ or more. The authors state that a general campaign of risk-factor modification was supported by posters, brochures, personal letters, progress charts and group discussions, but no further information was provided. A $5 \%$ random sample was re-examined annually.

The intervention in Wilhelmsen 1986 comprised a postal questionnaire (family history of heart disease/stroke, participant's cardiac symptoms, known hypertension, smoking, physical activity, stress), a screening examination at baseline (weight, height, total serum cholesterol, BP, ECG, "some interview responses"), and treatment of the risk factors of elevated cholesterol, elevated BP and smoking where relevant. The blood pressure intervention (for BP of $175 / 115 \mathrm{mmHg}$ or higher) involved referral to a specialist clinic (borderline-high blood pressure (160 to $174 \mathrm{mmHg}$ systolic, 95 to $114 \mathrm{mmHg}$ diastolic) patients had regular blood pressure checks). The cholesterol intervention $(7.8 \mathrm{mmol} /$ I or more) involved diet information from a dietician/physician and booklets. Clofibrate/nicotinic acid was given if cholesterol remained elevated after six months. Men with cholesterol values at screening of 6.8 to $7.7 \mathrm{mmol} / \mathrm{l}$ were invited to group meetings together with their wives, and the same material was used. Those with values below $6.8 \mathrm{mmol} / \mathrm{l}$ received written information but no other action. The smoking intervention for those smoking 15 cigarettes a day or more was an invitation to an anti-smoking clinic and nicotine gum. Other smokers were given written information on smoking cessation. Participants were invited to re-screening at four years, and a subgroup (20\%) received final screening at 10 years.

\section{Controls}

The control groups received no intervention in six studies (BFHS 1994; CHAPS 2011; Inter99 2014; Murray 1986; OXCHECK 1995; WHO 1986). In three of these studies, the control group received their first health check at the time of follow-up of the intervention group (BFHS 1994; Murray 1986; OXCHECK 1995). There are therefore no 'baseline' data for the control groups in these three studies. In WHO $1986,10 \%$ of the control group were invited for initial screening to establish baseline characteristics, but these participants were then excluded from the final analysis.

The control group in EHPP 2002 received the same baseline questionnaire as the intervention group, but received no other intervention. In FIT Heart 2008, participants in the control group received the same baseline assessments of diet, lifestyle and risk factors as the intervention group. The control group then received a one-page handout with advice to avoid tobacco, choose good nutrition and be more active. A letter was sent to their healthcare provider only if they had a critical risk factor level, i.e. BP of 140/90 or higher, LDL-Cof $190 \mathrm{mg} / \mathrm{dL}$ or higher, HDL-C less than $25 \mathrm{mg} / \mathrm{dl}$, triglycerides of $500 \mathrm{mg} / \mathrm{dl}$ or more, total cholesterol higher than 300 $\mathrm{mg} / \mathrm{dl}$. Wilhelmsen 1986 had two control groups: in control group 1 (no intervention), $2 \%$ had a postal questionnaire and screening examination with no follow-up, $11 \%$ had a second screening at four years, and $20 \%$ had the final examination at 10 years; in control group 2 (no intervention) none had the initial screening, second screening or final examination.

\section{Types of outcomes}

Four studies reported all-cause mortality (CHAPS 2011; Inter99 2014; WHO 1986; Wilhelmsen 1986) and three reported cardiovascular mortality (CHAPS 2011; WHO 1986; Wilhelmsen 1986). Non-fatal or combined fatal and non-fatal endpoints (such as coronary heart disease, acute myocardial infarction and stroke) were reported by four studies (BFHS 1994; Inter99 2014; WHO 1986; Wilhelmsen 1986). Six studies reported total cholesterol (BFHS 1994; EHPP 2002; FIT Heart 2008; Murray 1986; OXCHECK 1995; Wilhelmsen 1986), but only one of these reported HDL cholesterol, LDL cholesterol and triglycerides (FIT Heart 2008). Blood pressure was also reported by six studies (BFHS 1994; EHPP 2002; FIT Heart 2008, Murray 1986; OXCHECK 1995; Wilhelmsen 1986). The proportion of people with elevated cholesterol (four studies: BFHS 1994; EHPP 2002; FIT Heart 2008; OXCHECK 1995), elevated systolic blood pressure (one study: EHPP 2002), elevated diastolic blood pressure (three studies: BFHS 1994; EHPP 2002; OXCHECK 1995) and diabetes (one study: BFHS 1994) were also reported. Eight studies provided some information on attendance rates (BFHS 1994; EHPP 2002; FIT Heart 2008; Inter99 2014; Murray 1986; OXCHECK 1995; WHO 1986; Wilhelmsen 1986). Acceptability and participant satisfaction, and the number of cases who were followed with some intervention were not reported by the included studies. Only one study assessed adverse effects (EHPP 2002). Three studies reported costs (BFHS 1994; EHPP 2002; OXCHECK 1995).

\section{Ongoing studies}

We identified five ongoing studies during the searching: two cluster-RCTs (Wan 2009; Marshall 2012) and three randomising individuals (Muntendam 2012; Badenbroek 2014; Ijkema 2014). Two trials had a stepped-wedge design (Badenbroek 2014; Marshall 2012). Participants were recruited from primary care in Australia (Wan 2009), private medical insurance companies in the USA (Muntendam 2012), the Netherlands (Badenbroek 2014; ljkema 2014) and the UK (Marshall 2012). The interventions ranged from risk assessment and a follow-up appointment to discuss results (Wan 2009), risk assessment with or without imaging for atherosclerosis (Muntendam 2012), cardiometabolic risk screening 
followed by a tailored lifestyle intervention (Badenbroek 2014), two different risk assessment modalities (classic risk screening and screening for coronary artery calcium using computed tomography) followed by early treatment (ljkema 2014), and targeted case finding and management (Marshall 2012). Three trials are recorded as complete but results are not yet available (Wan 2009; Muntendam 2012; Marshall 2012); the remaining two trials will be complete in March 2017 (Badenbroek 2014), and 2020 (ljkema 2014).

\section{Excluded studies}

We provide details and reasons for exclusion of studies that most closely did not meet the inclusion criteria in the Characteristics of excluded studies table. Reasons for exclusion for the majority of studies included alternative designs (not RCTs), the intervention not being systematic risk assessment, and no control (see Figure 1).

\section{Risk of bias in included studies}

Details of risk of bias assessment are shown in Characteristics of included studies and are summarised in Figure 2 and Figure 3. Overall, we judged five studies to have a high risk of bias (high risk of bias for one or more domains: BFHS 1994; Inter99 2014; Murray 1986; Wilhelmsen 1986; WHO 1986) and four studies to have an unclear risk of bias (unclear risk of bias for one or more domains: CHAPS 2011; EHPP 2002; FIT Heart 2008; OXCHECK 1995).

Figure 2. Risk of bias summary: review authors' judgements about each risk of bias item for each included study.

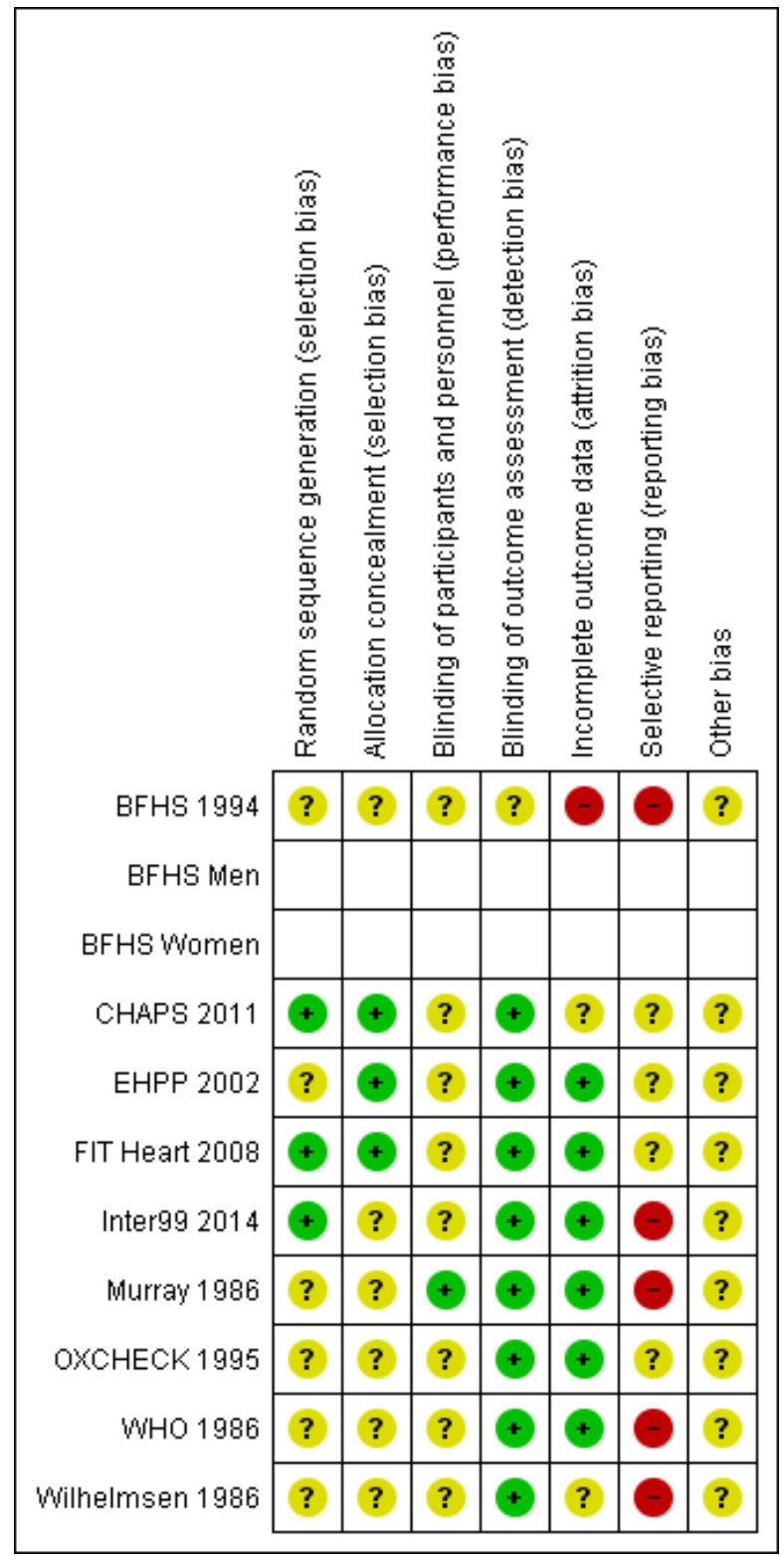


Figure 3. Risk of bias graph: review authors' judgements about each risk of bias item presented as percentages across all included studies.

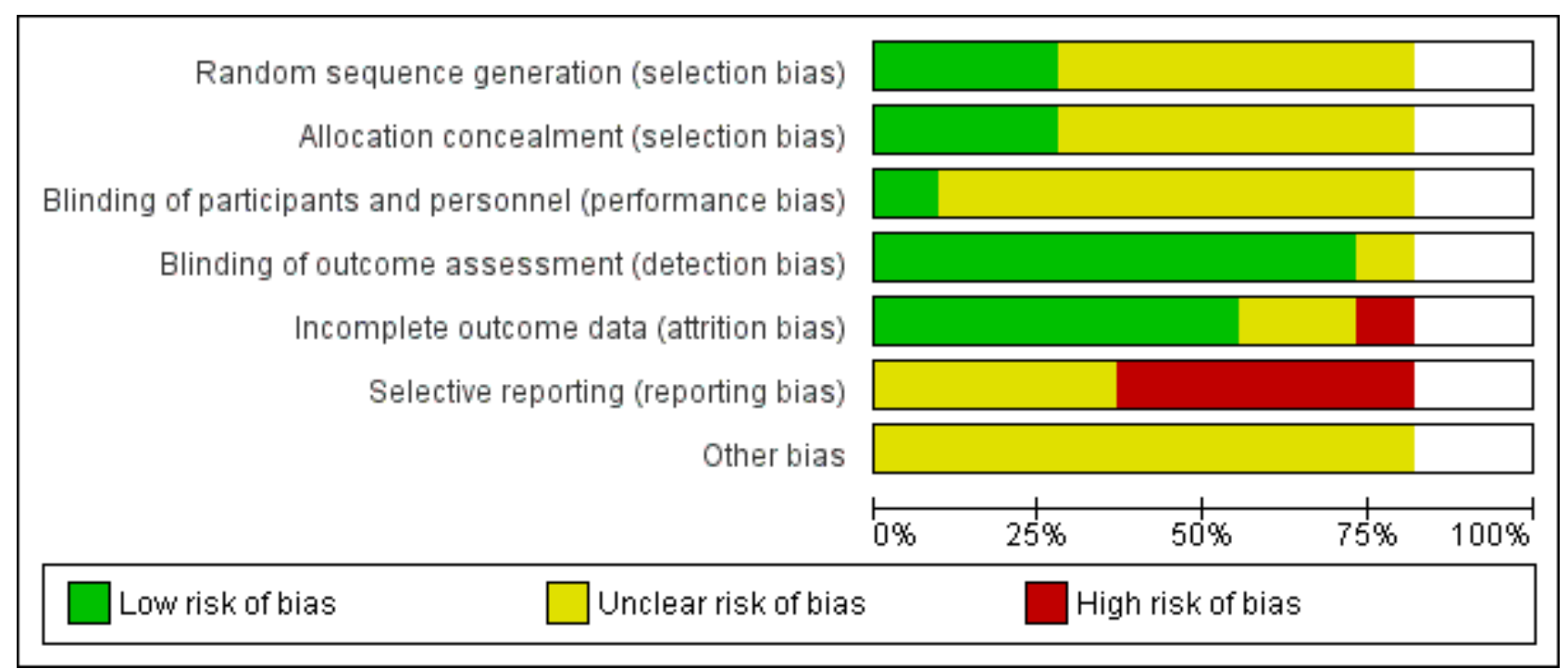

\section{Allocation}

Three out of the nine studies reported an adequate method of sequence generation (CHAPS 2011; FIT Heart 2008; Inter99 2014); two of these also reported adequate allocation concealment (CHAPS 2011; FIT Heart 2008). The method of randomisation was unclear in EHPP 2002, although we judged the study to have adequate allocation concealment. The method of randomisation and allocation concealment was not reported or was unclear in the remaining five studies (BFHS 1994; Murray 1986; OXCHECK 1995; WHO 1986; Wilhelmsen 1986).

\section{Blinding}

Blinding of participants and personnel was not explicitly reported by eight of the nine included studies. As there is the potential for systematic differences between groups in the care that was provided, or in exposure to factors other than the interventions of interest, we rated the studies at uncertain risk of performance bias. Murray 1986 stated that participants were not informed of their treatment condition and staff members at the Heart Health Centre were not informed of the study until its conclusion.

Due to the objective nature of the key outcomes in the included studies, we judged them to be at low risk of detection bias.

\section{Incomplete outcome data}

We judged one study (BFHS 1994) to be at high risk of attrition bias, as the numbers identified and followed up in the control groups were not reported. We rated six studies at low risk of attrition bias (EHPP 2002; FIT Heart 2008; Inter99 2014; Murray 1986; OXCHECK 1995; WHO 1986). The risk of attrition bias was uncertain in two studies: in CHAPS 2011 the numbers of individuals followed and lost to follow-up were not reported, as cluster-level data only were available; and (Wilhelmsen 1986) reported the proportion of participants invited for assessment at four and 20 years, but the number declining the invitation was not clear.

\section{Selective reporting}

We judged five studies to be at high risk of reporting bias. BFHS 1994 and Murray 1986 did not report any measures of variance; limited data were reported by Interg9 2014 and the numbers without IHD and/or stroke at baseline were not reported; and in Wilhelmsen 1986 measures of variance were not reported, baseline data were not separately reported for the intervention group and for control group 1, and the sample sizes were unclear. WHO 1986 reported the primary outcomes of the study, but also measured other relevant outcomes, such as cholesterol levels, that were not reported. The remaining studies appeared to have reported outcomes as intended; however, insufficient information is available to check this, so we have judged them to be at unclear risk of reporting bias.

\section{Other potential sources of bias}

We rated all the included studies at unclear risk of other sources of bias.

\section{Effects of interventions}

See: Summary of findings for the main comparison Systematic screening compared to no/opportunistic screening for the primary prevention of cardiovascular disease

\section{All-cause mortality}

Four studies reported all-cause mortality, three of which could be pooled in a meta-analysis (Analysis 1.1). We found no difference in all-cause mortality between intervention and control (RR 0.98, 95\% $\mathrm{Cl} 0.93$ to 1.03; participants $=103,571$; studies $=3 ;\left.\right|^{2}=0 \%$ ) with lowquality evidence (Summary of findings for the main comparison). No statistical heterogeneity was present.

CHAPS 2011 reported all-cause mortality per 1000 people admitted to hospital (Analysis 1.2), rather than all-cause mortality in individual study participants; this prevented us from including the study data in the meta-analysis presented in Analysis 1.1. There was no difference between intervention and control groups 
(intervention 33.98 versus control 34.55 , RR $0.98,95 \% \mathrm{Cl} 0.92$ to 1.03).

\section{Cardiovascular mortality}

Two studies reported mortality due to coronary heart disease (WHO 1986; Wilhelmsen 1986), and one study reported mortality due to stroke (Wilhelmsen 1986). There was no difference between the intervention and control groups for either outcome (mortality due to coronary heart disease: $\mathrm{RR} 1.0,95 \% \mathrm{Cl} 0.90$ to 1.11 ; participants $=43,955$; studies $=2 ; 1^{2}=0 \%$ (Analysis 1.3 ); mortality due to stroke: RR 0.89, 95\% Cl 0.64 to 1.24; participants $=20,015$ (Analysis 1.4)).

CHAPS 2011 reported in-hospital death from cardiovascular disease per 1000 people admitted to hospital (Analysis 1.2). There was no difference between intervention and control groups (RR $0.86,95 \% \mathrm{Cl} 0.73$ to 1.01$)$.

\section{Non-fatal endpoints}

Two studies reported the total number of participants with stroke (fatal and non-fatal) that could be combined in a meta-analysis (Analysis 1.5). We found no difference between groups, and there was no statistical heterogeneity (RR $0.99,95 \% \mathrm{Cl} 0.90$ to 1.10 ; participants $=79,631 ;$ studies $=2 ; I^{2}=0 \%$ ), and low-quality evidence (Summary of findings for the main comparison). Four studies reported the total number of participants with coronary heart disease (fatal or non-fatal) and could be combined in a metaanalysis (Analysis 1.6). There was no difference between groups, and there was no statistical heterogeneity (RR $1.01,95 \% \mathrm{Cl} 0.95$ to 1.07; participants $=110,168$; studies $=4 ; I^{2}=0 \%$ ), and low-quality evidence (Summary of findings for the main comparison). Two of these studies also reported non-fatal coronary heart disease or non-fatal myocardial infarction (WHO 1986; Wilhelmsen 1986) and one study reported non-fatal stroke (Wilhelmsen 1986). We found no differences between groups for non-fatal coronary heart disease or myocardial infarction (RR 0.98, 95\% $\mathrm{Cl} 0.89$ to 1.09; participants = 43,955 ; studies $=2 ; I^{2}=39 \%$ (Analysis 1.7 ) where there was moderate statistical heterogeneity, or for non-fatal stroke (RR $1.17,95 \% \mathrm{Cl}$ 0.94 to 1.47 ; participants $=20,015$ (Analysis 1.8)) .

CHAPS 2011 reported residents admitted with acute myocardial infarction, congestive heart failure and stroke, per 1000 people admitted to hospital (Analysis 1.2). There was a statistically significant difference favouring the intervention group for acute myocardial infarction (RR $0.89,95 \% \mathrm{Cl} 0.79$ to 0.99 ), but not for congestive heart failure (RR $0.97,95 \% \mathrm{Cl} 0.87$ to 1.08 ), stroke (RR $1.01,95 \% \mathrm{Cl} 0.89$ to 1.15 ), or the composite endpoint of acute myocardial infarction, stroke or congestive heart failure (RR 0.95, $95 \% \mathrm{Cl} 0.89$ to 1.02$)$.

\section{Lipid levels}

\section{Total cholesterol}

Six studies reported total cholesterol levels at follow-up. Pooling these studies in a meta-analysis demonstrated a lower mean total cholesterol level in the intervention group compared with the control group at follow-up (MD $-0.11 \mathrm{mmol} / \mathrm{l}, 95 \% \mathrm{Cl}-0.17$ to -0.04; participants $=12,591$; studies $=6 ; I^{2}=57 \%$; Analysis 1.9 ), with very low-quality evidence (Summary of findings for the main comparison). There was substantial statistical heterogeneity, so we combined the data using a random-effects model. Sensitivity analysis (not shown) demonstrated that no single study had a particular influence on the result.

\section{HDL cholesterol}

Only one study reported HDL cholesterol at follow-up (FIT Heart 2008). We found no difference in HDL cholesterol between intervention and control at one year follow-up (MD $0.03 \mathrm{mmol} / \mathrm{l}$, $95 \% \mathrm{Cl}-0.06$ to 0.12 ; participants $=464$; Analysis 1.10$)$. Participants in this study were family members of cardiac patients and had a mean age of 30 years.

\section{LDL cholesterol}

Only one study reported LDL cholesterol at follow-up (FIT Heart 2008). We found no difference in LDL cholesterol between intervention and control at one-year follow-up (MD $-0.01 \mathrm{mmol} / \mathrm{l}$, $95 \% \mathrm{Cl}-0.18$ to 0.16 ; participants $=464$; Analysis 1.11 ).

\section{Triglycerides}

Only one study reported triglycerides at follow-up (FIT Heart 2008). We found no difference in triglycerides between intervention and control at one-year follow-up (MD $-0.07,95 \% \mathrm{Cl}-0.24$ to 0.10 ; participants $=464$; Analysis 1.12) .

\section{Blood pressure}

\section{Systolic blood pressure}

Six studies reported systolic blood pressure at follow-up and were combined in a meta-analysis. Mean systolic blood pressure was lower in the intervention group compared with the control group (MD $-3.05 \mathrm{mmHg}, 95 \% \mathrm{Cl}-4.84$ to -1.25 ; participants = 12,591 ; studies $=6 ; I^{2}=82 \%$; Analysis 1.13 ), with very low-quality evidence (Summary of findings for the main comparison). There was considerable statistical heterogeneity, so we combined the data with a random-effects model. Sensitivity analysis suggested that BFHS 1994 had a considerable impact on the results. Removing this study from the analysis reduced statistical heterogeneity to $0 \%$ and reduced uncertainty, as demonstrated by a narrower confidence interval. The mean difference, although slightly less, remained statistically significant (MD $-1.91 \mathrm{mmHg}, 95 \% \mathrm{Cl}-2.67$ to -1.16 ; participants $=10,584 ;$ studies $\left.=5 ; I^{2}=0 \%\right)$.

\section{Diastolic blood pressure}

Six studies reported diastolic blood pressure at follow-up and were combined in a meta-analysis. Mean diastolic blood pressure was lower in the intervention group compared with the control group (MD -1.34 $\mathrm{mmHg}, 95 \% \mathrm{Cl}-1.76$ to -0.93 ; participants = 12,591; studies $=6 ; I^{2}=0 \%$; Analysis 1.14 ), with low-quality evidence (Summary of findings for the main comparison).

\section{Case finding rates}

\section{Proportion with elevated cholesterol}

Four studies reported the number of people with elevated cholesterol levels at last follow-up (or data from which this could be calculated). The studies used different thresholds for cholesterol levels (BFHS $1994 \geq 8.0 \mathrm{mmol} / \mathrm{l}$; EHPP $2002 \geq 7.0 \mathrm{mmol} / \mathrm{l}$; FIT Heart $2008 \geq 5.17 \mathrm{mmol} / \mathrm{l}$; OXCHECK $1995>8.0 \mathrm{mmol} /$ ). Combining these studies in a meta-analysis demonstrated a reduction in the proportion of participants with elevated cholesterol levels in the 
intervention group at last follow-up compared with the control group (RR 0.66, $95 \% \mathrm{Cl} 0.48$ to 0.89 ; participants $=7685$; studies $=4 ; I^{2}=80 \%$; Analysis 1.15). There was considerable statistical heterogeneity, so we combined the data with a random-effects model. Sensitivity analysis suggested that FIT Heart 2008 had a considerable impact on the results; this study reported the number of people above a relatively low cholesterol threshold. Removing this study from the analysis reduced statistical heterogeneity to $0 \%$, reduced uncertainty as demonstrated by a narrower confidence interval, and produced a more beneficial risk ratio $(\mathrm{RR} 0.56,95 \% \mathrm{Cl}$ 0.47 to 0.67 ; participants $=14,110$; studies $=3 ; I^{2}=0 \%$ ).

\section{Proportion with elevated systolic blood pressure}

One study reported the number of people with elevated systolic blood pressure at follow-up (EHPP 2002). There was no difference between the intervention and control groups (RR 0.88 , 95\% Cl 0.72 to 1.06; participants $=1093$; studies $=1$; Analysis 1.16).

\section{Proportion with elevated diastolic blood pressure}

Three studies reported the number of people with elevated diastolic blood pressure (thresholds were: BFHS $1994 \geq 100 \mathrm{mmHg}$, EHPP $2002 \geq 90 \mathrm{mmHg}$, OXCHECK $1995>100 \mathrm{mmHg}$ ) at followup and were combined in a meta-analysis. Fewer people in the intervention group had elevated diastolic blood pressure compared with the control group (RR $0.68,95 \% \mathrm{Cl} 0.61$ to 0.76 ; participants $=7221$; studies $=3 ; I^{2}=0 \%$; Analysis 1.17 ). There was no statistical heterogeneity.

\section{Proportion with type 2 diabetes}

One study reported the proportion of people with type 2 diabetes at follow-up (BFHS 1994). This was higher in the intervention group (RR 1.37, 95\% Cl 1.04 to 1.81 ; participants = 2007; studies $=1$; Analysis 1.18).

\section{Proportion with elevated cardiovascular risk score}

One study reported the proportion of people with elevated cardiovascular risk score (BFHS 1994), and found this to be significantly higher in the intervention group (RR $0.54,95 \% \mathrm{Cl} 0.40$ to 0.73 ; participants $=1093$; studies $=1$; Analysis 1.19) .

\section{Attendance}

Attendance rates were inconsistently reported by the studies (Analysis 1.20). In BFHS 1994, 68\%, 73\% and $76 \%$ of households (after adjusting for patients on the practice lists who had died or left the practice) in the intervention, internal control and external control groups respectively responded to the invitation to attend for screening. Of people allocated to the two intervention groups in EHPP 2002, 89.4\% and 90.5\% respectively attended for health screening at baseline. This proportion declined to $75.3 \%$ and $68.7 \%$ respectively attending for screening at five-year follow-up, while $73.3 \%$ of the control group (identified at baseline) attended for their first health screen at this time point. Murray 1986 stated that participation rates at the initial screening were equivalent for the intervention and control groups, averaging $50.6 \%$. The one-year follow-up visit was attended by $88.6 \%$ of the intervention group. The proportion of the intervention group attending for their first health check in OXCHECK 1995 was $79.4 \%$, declining to $59.8 \%$ at the four-year follow-up, with $69.3 \%$ of the control group attending for their first health check at this time. In WHO $1986,87 \%$ of men from the intervention factories had a cardiovascular examination, in Wilhelmsen $198674.9 \%$ of the intervention group attended for the first health check, and in Interg9 $201452.4 \%$ of people randomised to the intervention group attended for screening (the control group were not invited for screening).

Only $18.2 \%$ of eligible people (family members of cardiac patients) agreed to participate in FIT Heart 2008, where people in both the intervention and control groups received a baseline health check and assessment of risk factors.

\section{Acceptability and participants' satisfaction}

Acceptability and participants' satisfaction were not reported by the included studies.

\section{Follow-up rates}

Follow-up rates (number of cases who were followed with some intervention in primary and secondary care) were not explicitly reported by the included studies.

\section{Adverse effects}

Only one study (EHPP 2002) assessed adverse effects of systematic risk assessment. They found no difference in psychological distress as measured by the Goldberg General Health Questionnaire-12 (GHQ): mean change in GHQ scores at five years: intervention ( $\mathrm{n}=$ 745) -0.23 (standard deviation (SD) 7.19) vs control $(n=381)-0.39$ (SD 7.26); $P=0.73$.

\section{Costs}

Three studies reported costs, although differences in the study designs and reporting of results limit comparison. In a UK study published in 1994 (BFHS 1994), the mean overall cost of the intervention per person initially screened was estimated at GBP 51.63 (95\% Cl GBP 12.37 to GBP 90.90). In terms of the direct programme costs for a year, the cost per $1 \%$ reduction in coronary risk was GBP 5.26 per person (GBP 5.08 for men, GBP 5.78 for women), and these values were GBP 4.30 (GBP 5.92 for men, GBP 1.28 for women) taking into account wider health service savings. A second UK study (OXCHECK 1995) estimated the cost per patient attending for screening, with an average amount of follow-up (and excluding trial outcome re-examinations and all research elements), at GBP 29.27. This value assumes that nurses spent 45 minutes on each health check and 20 minutes on followup, although audit found the time varied from 45 to 60 minutes, and 10 to 20 minutes respectively. Changing the assumption to 60 minutes on each health check increased the cost to GBP 30.49 per patient, and changing the assumption to 10 minutes on each follow-up decreased the cost to GBP 27.65 per patient. The cost per $1 \%$ reduction in coronary risk (using Dundee risk score) was GBP 2.25 for all participants (attenders and non-attenders of reexamination), GBP 1.72 for women and GBP 4.18 for men.

The three-arm trial (screening only, screening + discussion, and control) conducted in Denmark (EHPP 2002) calculated life-years gained in 1060 participants. Outcome parameters were life-years gained, and direct and total health costs, discounted by $3 \%$ annually. Expected life-years gained were $0.16,0.24$ and 0.30 in the control, screening-only and screening + discussion groups respectively. The total costs (2004 rates) were EUR 10,667, EUR 9399, and EUR 10,409 per person respectively. Results were 
reported to be insensitive to a range of assumptions regarding costs, effects and discount rates.

\section{DISCUSSION}

\section{Summary of main results}

This systematic review identified nine eligible RCTs, four of which were cluster-RCTs. The studies had a high or uncertain risk of bias. The length of follow-up was just one year in four studies, three years in one study, five or six years in two studies, and 10 years in two studies. Eight studies recruited participants from the general population, although there were differences in the age ranges targeted. One study recruited family members of cardiac patients (high-risk assessment), and the included participants were younger on average than in the other studies. There were also differences between the studies in the interventions received by the intervention and control groups. There was insufficient evidence to stratify by the types of risk assessment approaches.

The limited data available on all-cause mortality and cardiovascular mortality suggest that screening has no statistically significant effect on these outcomes. Data were also limited for combined and non-fatal endpoints; overall, evidence indicates no statistically significant difference in total coronary heart disease (four studies), non-fatal coronary heart disease (two studies) and non-fatal stroke (one study).

Overall, risk assessment screening appears to result in lower total cholesterol levels (MD $-0.11 \mathrm{mmol} / \mathrm{l}, 95 \% \mathrm{Cl}-0.17$ to -0.04 ), lower systolic blood pressure (MD $-3.05 \mathrm{mmHg}, 95 \% \mathrm{Cl}-4.84$ to -1.25 ) and lower diastolic blood pressure (MD $-1.34 \mathrm{mmHg}, 95 \% \mathrm{Cl}-1.76$ to -0.93), as well as reducing the number of people classed as having elevated total cholesterol (RR $0.66,95 \% \mathrm{Cl} 0.48$ to 0.89 ) or elevated diastolic blood pressure ( $\mathrm{R} 0.68,95 \% \mathrm{Cl} 0.61$ to 0.76 ). However, these results should be viewed with caution due to the statistical heterogeneity present in most of the analyses, and the risk of bias of the included studies. The data on HDL cholesterol, LDL cholesterol, triglycerides, and number of people with diabetes are more limited, with only one study reporting these outcomes. Attendance rates were inconsistently reported by the studies, and acceptability and follow-up rates were not reported. One study assessed adverse effects and found no difference in psychological distress. Costs were reported by three studies, although differences in the study designs and reporting of results limit comparison.

\section{Overall completeness and applicability of evidence}

Despite our extensive searching, only nine completed trials met the inclusion criteria for this review. We will incorporate five ongoing trials when the data become available.

Trials were generally large with between one and 10 years followup. Clinical endpoints were reported in longer-term trials; of these, two trials recruited only middle-aged men and recruitment started in the early 1970s (WHO 1986; Wilhelmsen 1986), so the applicability of findings to women and to more recent population groups is unclear. Of note, the Inter99 2014 study, conducted more recently in both men and women, showed larger treatment effects for total mortality than did these earlier studies, although there were also differences between trials in the interventions offered. Four trials recorded total coronary events, with no consistent effects. Few trials reported other clinical endpoints.
Possible (but not exhaustive) explanations for the apparent lack of effect of cardiovascular 'screening' on the primary outcomes (mortality and morbidity) could be: 1) confounding factors and biases which are masking/hiding a real (true) effect; 2) short/ insufficient follow-up for the effect to be seen, especially in the more recent studies (including the ongoing studies which we cannot assess yet); 3) insufficient population 'catchment'/ attendance rate of the screening programmes, limiting its benefit; 4) inadequate follow-up measures and preventive/treatment interventions; and 5) a true lack of effect/population benefit from the cardiovascular screening/check.

It is important to consider what would constitute a meaningful length of follow-up for different outcomes, i.e. for mortality versus reduction in risk factors. One-year mortality is unlikely to be changed by screening. In younger individuals where event rates are low, risk factor control may be more important and could yield considerable downstream benefit. On the other hand, event reduction in older populations is more important, but events after the first year are more likely to yield useful information, i.e. longer follow-up is necessary. Few trials reported other clinical endpoints.

Six of nine trials reported total cholesterol and systolic and diastolic blood pressure (BFHS 1994; EHPP 2002; FIT Heart 2008; OXCHECK 1995; Murray 1986; Wilhelmsen 1986) and showed small but beneficial effects of systematic risk assessment, although there was considerable heterogeneity between trials, indicating that such results should be interpreted cautiously. Only one trial reported other lipid measurements (FIT Heart 2008). Only one trial reported adverse events.

We could not assess costs or cost effectiveness due to the lack of sufficient and comparable data.

There is no evidence on variations in uptake or attendance between, for example, different ethnic groups and age groups, population groups which are important in terms of the health inequality gap.

The heterogeneity between trials in terms of participants recruited, settings and particularly the different interventions offered following risk assessment limit the pooled findings of this review. For example, the studies recruited their participants from different settings: primary care registers (BFHS 1994; EHPP 2002; OXCHECK 1995), population registers (Inter99 2014; Wilhelmsen 1986), the work place (WHO 1986), the community (CHAPS 2011) and from secondary care (FIT Heart 2008). Furthermore, no explicit efforts were made to capture specific populations that might be at high risk of CVD for socioeconomic, educational, or other reasons.

With the inclusion of data from the ongoing trials and future updates of this review, we hope to explore this heterogeneity formally in stratified analyses.

\section{Quality of the evidence}

We formally assessed the overall quality of the review with GRADE, and rated it as low- or very low-quality evidence. We judged the risks of bias of a large proportion of the studies as unclear for many domains, and assessed some studies at high risk of attrition and reporting bias.

From this review it is evident that the quality of the primary research evidence on which the it is based is relatively poor in 
terms of conduct (with selection and attrition bias, lack of adequate follow-up and selective reporting identified) and also in terms of reporting, despite the existence of guidance such as CONSORT 2012 to promote higher standards of reporting.

\section{Potential biases in the review process}

We conducted the review according to the published protocol (Dyakova 2013) and reported any deviations from this under Differences between protocol and review.

We conducted a comprehensive search across major databases for trials of systematic risk assessment for this review. In addition, we screened the reference lists of systematic reviews. Two review authors independently carried out all screening, inclusion and exclusion, and one review author conducted data extraction while a second checked them.

There was significant heterogeneity between the included trials, particularly with regard to the different interventions offered in both the intervention and comparison groups. We had hoped to examine this more closely in stratified analyses, but there are insufficient studies included so far to do this. The heterogeneity limits the findings of this review.

Data from the five ongoing studies remain to be incorporated, and we will include them when the results are made available.

\section{Agreements and disagreements with other studies or reviews}

Our results for clinical endpoints are in agreement with a previous Cochrane review examining general health checks for chronic disease prevention rather than just CVD prevention (Krogsbøll 2012). Indeed, a number of the same trials are in both reviews (BFHS 1994; EHPP 2002; Inter99 2014; OXCHECK 1995; WHO 1986; Wilhelmsen 1986). This review called into question the evidence base for rolling out general and/or cardiovascular population-wide screening-like programmes, as there is as yet insufficient evidence of the benefits of such programmes over the widely-practised opportunistic risk assessment currently conducted in primary care settings.

However, the number of trials contributing to our estimates on total mortality were fewer, at three rather than nine, and so our estimates are less reliable than those for the Krogsbøll 2012 review. The review also found no effects of screening on cardiovascular mortality, which led them to conclude that health checks are unlikely to be beneficial for CVD prevention. Our review has data on CVD mortality from two older trials conducted in men only, and so results for this outcome are also less reliable.

Our review extended the findings of Krogsbøll 2012 by focusing on CVD prevention and by considering a broader range of outcomes. Whilst clinical CVD endpoints are the principal outcomes of interest for CVD prevention, in healthy populations the length of followup required to capture sufficient events is very long. Intermediate outcomes such as CVD risk factors are therefore useful as markers of CVD prevention. Notably, we found very little information on adverse events of screening (such as psychological distress, overdiagnosis) and this is confirmed in the Krogsbøll 2012 review. Similarly there was little information regarding the acceptability of programmes, uptake and adherence to interventions offered following risk assessment.

\section{AUTHORS' CONCLUSIONS}

\section{Implications for practice}

The results of this systematic review do not provide enough evidence to inform changes in clinical practice, national/local policies or the introduction of mass population cardiovascular screening programmes. There is limited evidence for beneficial effects on CVD risk factors, but trials are heterogeneous and at some risk of bias, and results are therefore uncertain. Clinical event data are predominantly limited to selected populations from older trials and it is unclear if these effects are applicable to other more recent populations.The five ongoing trials will add to the evidence base and may reduce some of this uncertainty.

Considering our findings together with results from other systematic reviews and RCTs is very relevant at national and sub-national levels in many countries. Some governments have already introduced population cardiovascular or general health screening programmes; others prefer to target and reach out to vulnerable/disadvantaged populations, thus trying to tackle health inequalities. It is important also to consider marginal costs, which are dependent on the increasing responsibility of nonphysician health and community workers; personal identification initiatives (such as unique health records), and other innovative/ integrated care activities which are introduced in parallel with various cardiovascular programmes and interventions.

\section{Implications for research}

Despite extensive CVD research focus and investment, few trials fulfilled our criteria and could be included in this review. Their heterogeneity precludes certainty about benefits from screeninglike programmes for CVD prevention. There are important gaps in the research, notably the lack of reporting of adverse events and costs/cost effectiveness. It is also crucial to assess unintended consequences such as variations in uptake and attendance which might sustain or eventually increase health inequalities.

However, the nine RCTs included more than 150,000 people and more than 8,000 deaths. This suggests that carrying out similar trials probably would not contribute much more to the existing evidence base. An important issue is balancing large population coverage (sample size) and longer follow-up with the increasing effect of various confounding factors and potential biases (with time and size).

The reporting of results from the five ongoing trials will add to the evidence base. More high-quality and focused research is required to inform changes in routine primary care practice and decisions to roll out universal CVD screening-like programmes. Future study designs should consider more targeted objectives, i.e. total CVD risk reduction, workplace health, identification of high-risk individuals or those with limited access to health care, non-attendance groups, etc. Particular intervention settings, i.e. workplace versus community versus non-medical settings, might provide targeted health data and specific measurable outcomes. There is a particular need for good-quality trials in low- and middleincome countries where political, economic and healthcare factors are different and where the majority of cardiovascular deaths and burden occur. 


\section{A C K N OWLEDGEMENTS}

We are grateful to Nicole Martin for conducting the searches for this review. We also thank Christine Clar for her help with German and Dutch translations. 


\section{R E F E R E N C E S}

\section{References to studies included in this review}

BFHS 1994 \{published data only\}

Family Heart Study Group. British Family Heart Study: its design and method, and prevalence of cardiovascular risk factors. British Journal of General Practice 1994;44(379):62-7.

* Family Heart Study Group. Randomised controlled trial evaluating cardiovascular screening and intervention in general practice: principal results of British Family Heart Study. BMJ 1994;308(6924):313-20.

Marteau TM, Kinmonth AL, Thompson S, Pyke S. The psychological impact of cardiovascular screening and intervention in primary care: a problem of false reassurance? British Family Heart Study Group. The British Journal of General Practice 1996;46(411):577-82.

Wonderling D, McDermott C, Buxton M, Kinmonth AL, Pyke S, Thompson S, et al. Costs and cost effectiveness of cardiovascular screening and intervention: the British Family Heart Study. BMJ 1996;312(7041):1269-73.

\section{BFHS Men \{published data only\}}

Family Heart Study Group. British Family Heart Study: its design and method, and prevalence of cardiovascular risk factors. British Journal of General Practice 1994;44(379):62-7.

* Family Heart Study Group. Randomised controlled trial evaluating cardiovascular screening and intervention in general practice: principal results of British Family Heart Study. BMJ 1994;308(6924):313-20.

Marteau TM, Kinmonth AL, Thompson S, Pyke S. The psychological impact of cardiovascular screening and intervention in primary care: a problem of false reassurance? British Family Heart Study Group. The British Journal of General Practice 1996;46(411):577-82.

Wonderling D, McDermott C, Buxton M, Kinmonth AL, Pyke S, Thompson S, et al. Costs and cost effectiveness of cardiovascular screening and intervention: the British Family Heart Study. BMJ 1996;312(7041):1269-73.

\section{BFHS Women \{published data only\}}

Family Heart Study Group. British Family Heart Study: its design and method, and prevalence of cardiovascular risk factors. British Journal of General Practice 1994;44(379):62-7.

* Family Heart Study Group. Randomised controlled trial evaluating cardiovascular screening and intervention in general practice: principal results of British Family Heart Study. BMJ 1994;308(6924):313-20.

Marteau TM, Kinmonth AL, Thompson S, Pyke S. he psychological impact of cardiovascular screening and intervention in primary care: a problem of false reassurance? British Family Heart Study Group. The British Journal of General Practice 1996;46(411):577-82.

Wonderling D, McDermott C, Buxton M, Kinmonth AL, Pyke S, Thompson S, et al. Costs and cost effectiveness of cardiovascular screening and intervention: the British Family Heart Study. BMJ 1996;312(7041):1269-73.

\section{CHAPS 2011 \{published data only\}}

* Kaczorowski J, Chambers LW, Dolovich L, Paterson JM, Karwalajtys T, Gierman T, et al. Improving cardiovascular health at population level: 39 community cluster randomised trial of Cardiovascular Health Awareness Program (CHAP). BMJ 2011;342:d442.

Kaczorowski J, Chambers LW, Karwalajtys T, Dolovich L, Farrell B, McDonough B, et al. Cardiovascular Health Awareness Program (CHAP): a community cluster-randomised trial among elderly Canadians. Preventive Medicine 2008;46(6):537-44.

\section{EHPP 2002 \{published data only\}}

Christensen B, Engberg M, Lauritzen T. No long-term psychological reaction to information about increased risk of coronary heart disease in general practice. European Journal of Cardiovascular Prevention and Rehabilitation 2004;11(3):239-43.

* Engberg M, Christensen B, Karlsmose B, Lous J, Lauritzen T. General health screenings to improve cardiovascular risk profiles: a randomized controlled trial in general practice with 5year follow-up. Journal of Family Practice 2002;51(6):546-52.

Kanstrup H, Refsgaard J, Engberg M, Lassen JF, Larsen ML, Lauritzen T. Cholesterol reduction following health screening in general practice. Scandinavian Journal of Primary Health Care 2002;20(4):219-23.

Lauritzen T, Jensen MS, Thomsen JL, Christensen B, Engberg M. Health tests and health consultations reduced cardiovascular risk without psychological strain, increased healthcare utilization or increased costs. An overview of the results from a 5-year randomized trial in primary care. The Ebeltoft Health Promotion Project (EHPP). Scandinavian Journal of Public Health 2008;36(6):650-61.

Lauritzen T, Leboeuf-Yde C, Lunde IM, Nielsen KDB. Ebeltoft project: Baseline data from a five-year randomized, controlled, prospective health promotion study in a Danish population. British Journal of General Practice 1995;45(399):542-7.

Rasmussen SR, Thomsen JL, Kilsmark J, Hvenegaard A, Engberg M, Lauritzen T, et al. Preventive health screenings and health consultations in primary care increase life expectancy without increasing costs. Scandinavian Journal of Public Health 2007;35(4):365-72.

\section{FIT Heart 2008 \{published data only\}}

Mosca L, Mochari H, Liao M, Christian AH, Edelman DJ, Aggarwal B, et al. A novel family-based intervention trial to improve heart health: FIT Heart: results of a randomized controlled trial. Circulation. Cardiovascular Quality and Outcomes 2008;1(2):98-106.

\section{Inter99 2014 \{published data only\}}

Jørgensen T, Jacobsen RK, Toft U, Aadahl M, Glümer C, Pisinger $C$. Effect of screening and lifestyle counselling on incidence of ischaemic heart disease in general population: 
Inter99 randomised trial. BMJ 2014;348:g3617. [DOI: 10.1136/ bmj.g3617]

\section{Murray 1986 \{published data only\}}

Murray DM, Luepker RV, Pirie PL, Grimm RH, Bloom E, Davis MA, et al. Systematic risk factor screening and education: a community-wide approach to prevention of coronary heart disease. Preventative Medicine 1986;15(6):661-72.

\section{OXCHECK 1995 \{published data only\}}

Imperial Cancer Research Fund Oxcheck Study Group. Prevalence of risk factors for heart disease in the Oxcheck trial: implications for screening in primary care. $B M J$ 1991;301(6784):1057-60.

* Imperial Cancer Research Fund Oxcheck Study Group. The effectiveness of health checks conducted by nurses in primary care: Final results from the Oxcheck study. BMJ 1995;310(6987):1099-104.

Langham S, Thorogood M, Normand C, Muir J, Jones L, Fowler $\mathrm{G}$. Costs and cost effectiveness of health checks conducted by nurses in primary care: the Oxcheck study. BMJ 1996;312(7041):1265-8.

\section{WHO 1986 \{published data only\}}

* World Health Organization European Collaborative Group. European collaborative trial of multifactorial prevention of coronary heart disease: final report on the 6-year results. Lancet 1986;327(8486):869-72.

World Health Organization European Collaborative Group. Multifactorial trial in the prevention of coronary heart disease: 1. Recruitment and initial findings. European Heart Journal 1980;1(1):73-80.

World Health Organization European Collaborative Group. Multifactorial trial in the prevention of coronary heart disease: 3. Incidence and mortality results. European Heart Journal 1983;4:141-47.

\section{Wilhelmsen 1986 \{published data only\}}

Wilhelmsen L, Berglund G, Elmfeldt D, Tibblin G, Wedel H, Pennert $\mathrm{K}$, et al. The multifactor primary prevention trial in Goteborg, Sweden. European Heart Journal 1986;7(4):279-88.

\section{References to studies excluded from this review}

Boylan 2003 \{published data only\}

Boylan MJ, Renier CM, Knuths JS, Haller IV. Preventing cardiovascular disease in women: an intervention-control randomized study. Minnesota Medicine 2003;86(5):52-6.

\section{Göteborg 1963 \{published data only\}}

Tibblin G, Welin L, Larsson B, Ljungberg IL, Svärdsudd K. The influence of repeated health examinations on mortality in a prospective cohort study, with a comment on the autopsy frequency. The study of men born in 1913. Scandinavian Journal of Social Medicine 1982;10(1):27-32.

\section{Grunfeld 2013 \{published data only\}}

Grunfeld E, Manca D, Moineddin R, Thorpe KE, Hoch JS, Campbell-Scherer D, et al. Improving chronic disease prevention and screening in primary care: results of the BETTER pragmatic cluster randomized controlled trial. BMC Family Practice 2013;14:175.

Holt 2010 \{published data only\}

Holt TA, Thorogood M, Griffiths F, Munday S, Friede T, Stables D. Automated electronic reminders to facilitate primary cardiovascular disease prevention: randomised controlled trial. British Journal of General Practice 2010;60(573):e137-43.

\section{Jacobson 2006 \{published data only\}}

Jacobson TA, Gutkin SW, Harper CR. Effects of a global risk educational tool on primary coronary prevention: the Atherosclerosis Assessment Via Total Risk (AVIATOR) study. Current Medical Research and Opinion 2006;22(6):1065-73.

Kaiser Permanente 1965 \{published data only\}

Friedman GD, Collen MF, Fireman BH. Multiphasic Health Checkup Evaluation: a 16-year follow-up. Journal of Chronic Diseases 1986;39(6):453-63.

\section{Koelewijn-van Loon 2010 \{published data only\}}

Koelewijn-van Loon MS, Van der Weijden T, Ronda G, Van Steenkiste B, Winkens B, Elwyn G, et al. Improving lifestyle and risk perception through patient involvement in nurse-led cardiovascular risk management: a clusterrandomized controlled trial in primary care. Preventive Medicine 2010;50(1-2):35-44.

\section{Malmö 1969 \{published data only\}}

Lannerstad O, Sternby NH, Isacsson SO, Lindgren G, Lindell SE. Effects of a health screening on mortality and causes of death in middle-aged men. A prospective study from 1970 to 1974 of mean in Malmö, born 1914. Scandinavian Journal of Social Medicine 1977;5(3):137-40.

\section{New York 1971 \{published data only\}}

Shapiro S. Evaluation of two contrasting types of screening programs. Preventive Medicine 1973;2(2):266-77.

\section{Northumberland 1969 \{published data only\}}

Bennett AE, Fraser IG. Impact of a screening programme in general practice: a randomized controlled trial. International Journal of Epidemiology 1972;1(1):55-60.

\section{Ogedegbe 2014 \{published data only\}}

Ogedegbe G, Plange-Rhule J, Gyamfi J, Chaplin W, Ntim M, Apusiga $\mathrm{K}$, et al. A cluster-randomized trial of task shifting and blood pressure control in Ghana: study protocol. Implementation Science 2014;9:10.

Salt Lake City 1972 \{published data only\}

Olsen DM, Kane RL, Proctor PH. A controlled trial of multiphasic screening. New England Journal of Medicine 1976;294(17):925-30. 
South-East London 1967 \{published data only\}

The South-East London Study Group. A controlled trial of multiphasic screening in middle-age: results of the South-East London screening study. International Journal of Epidemiology 1977;6(4):357-63.

\section{Stockholm 1969 \{published data only\}}

Theobald H, Bygren LO, Carstensen J, Hauffman M, Engfeldt P. Effects of an assessment of needs for medical and social services on long-term mortality: a randomized controlled study. International Journal of Epidemiology 1998;27(2):194-8.

\section{Titograd 1971 \{published data only\}}

Thorner RM, Djordjevic D, Vuckmanovic C, Pesic B, Culafic B, Mark F. A study to evaluate the effectiveness of multiphasic screening in Yugoslavia. Preventive Medicine 1973;2(2):295-301.

Vagholkar 2014 \{published data only\}

Vagholkar S, Zwar N, Jayasinghe UW, Denney-Wilson E, Patel A, Campbell T, et al. Influence of cardiovascular absolute risk assessment on prescribing of antihypertensive and lipidlowering medications: A cluster randomized controlled trial. American Heart Journal 2014;167(1):28-35.

\section{Voogdt-Pruis 2010 \{published data only\}}

Voogdt-Pruis HR, Beusmans GH, Gorgels AP, Kester AD, Van Ree JW. Effectiveness of nurse-delivered cardiovascular risk management in primary care: a randomised trial. British Journal of General Practice 2010;60(570):40-6.

\section{References to ongoing studies}

Badenbroek 2014 \{published data only\}

Badenbroek IF, Stol DM, Nielen MMJ, Hollander M, Kraaijenhagen RA, De Wit GA, et al. Design of the INTEGRATE study: effectiveness and cost-effectiveness of a cardiometabolic risk assessment and treatment program integrated in primary care. BMC Family Practice 2014;15:90.

ljkema 2014 \{published data only\}

Ijkema R, Van Aerde MA, Van Der Aalst CM, Van Ballegooijen M, Oudkerk M, De Koning HJ. A randomized controlled trial measuring the effectiveness of screening for cardiovascular disease using classic risk assessment and coronary artery calcium: The ROBINSCA study. European Journal of Preventive Cardiology 2014;May:S21.

\section{Marshall 2012 \{published data only\}}

Marshall T, Caley M, Hemming K, Gill P, Gale N, Jolly K. Mixed methods evaluation of targeted case finding for cardiovascular disease prevention using a stepped wedged cluster RCT. BMC Public Health 2012;12:908.

\section{Muntendam 2012 \{published data only\}}

Muntendam P, McCall C, Sanz J, Falk E, Fuster V. The Biolmage Study: Novel approaches to risk assessment in the primary prevention of atherosclerotic cardiovascular disease-study design and objectives. American Heart Journal 2010;160(1):49-57.
Wan 2009 \{published data only\}

Wan Q, Harris MF, Zwar N, Campbell T, Patel A, Vagholkar S, et al. Study protocol for a randomized controlled trial: The feasibility and impact of cardiovascular absolute risk assessment in Australian general practice. American Heart Journal 2009;157(3):436-41.

\section{Additional references}

\section{Bernard 2009}

Bernard SL, Lux L, Lohr KN (RTI International). QQUIPP: Healthcare Delivery Models for Prevention of Cardiovascular Disease (CVD). London: The Health Foundation, 2009.

\section{Beswick 2008}

Beswick AD, Brindle P, Fahey T, Ebrahim S. A Systematic Review of Risk Scoring Methods and Clinical Decision Aids Used in the Primary Prevention of Coronary Heart Disease (Supplement). NICE Clinical Guidelines No. 67S. London: Royal College of General Practitioners, 2008 (available from www.ncbi.nlm.nih.gov/books/NBK55818/).

\section{BHF 2012a}

British Heart Foundation. Cardiovascular disease. www.bhf.org.uk/heart-health/conditions/cardiovasculardisease.aspx (accessed 30 August 2012).

\section{BHF 2012b}

British Heart Foundation. Our heart disease facts. www.bhf.org.uk/media/news-from-the-bhf/bhf-facts.aspx (accessed 29 March 2012).

\section{Chamnan 2010}

Chamnan P, Simmons R, Khaw K, Wareham N, Griffin S. Estimating the population impact of screening strategies for identifying and treating people at high risk of cardiovascular disease: modelling study. BMJ 2010;340:c1693.

\section{CONSORT 2012}

Altman DG, Moher D, Schultz KF. Improving the reporting of randomised trials: The CONSORT statement and beyond. Statistics in Medicine 2012;31(25):2985-97.

\section{Cooney 2009}

Cooney MT, Dudina A, Winchup P, Capewell S, Menotti A, Jousilahti P, et al. SCORE Investigators. Re-evaluating the Rose approach: comparative benefits of the population and highrisk preventive strategies. European Journal of Cardiovascular Prevention and Rehabilitation 2009;16(5):541-9.

\section{DH 2000}

Department of Health. National Service Framework for Coronary Heart Disease. London: Stationery Office, 2000.

\section{DH 2008a}

Department of Health. Putting Prevention First. Vascular Checks: Risk Assessment and Management. Impact Assessment. London: Department of Health, 2008. 


\section{DH 2008b}

Department of Health. Economic Modelling for Vascular Checks. London: Department of Health, 2008.

\section{DH 2013}

Department of Health. Cardiovascular Disease Outcomes Strategy. Improving outcomes for people with or at risk of cardiovascular disease 2013. www.gov.uk/ government/uploads/system/uploads/attachment_data/ file/217118/9387-2900853-CVD-Outcomes_web1.pdf (accessed 22 March 2015).

\section{Egger 1997}

Egger M, Davey Smith G, Schneider M, Minder C. Bias in meta-analysis detected by a simple graphical test. $B M J$ 1997;315(7109):629-34.

\section{Every contact counts 2012}

Every contact counts. Every contact counts. Raising health consciousness using brief interventions. www.everycontactcounts.co.uk/ (accessed 3 August 2012).

\section{GBD 2013}

GBD 2013 Mortality and Causes of Death Collaborators. Global, regional, and national age-sex specific all-cause and causespecific mortality for 240 causes of death, 1990-2013: a systematic analysis for the Global Burden of Disease Study. Lancet 2013;385(9963):117-71.

\section{Higgins 2011}

Higgins JPT, Green S (editors). Cochrane Handbook for Systematic Reviews of Interventions. Version 5.1.0 [updated March 2011]. The Cochrane Collaboration, 2011. Available from www.cochrane-handbook.org.

\section{Jackson 2008}

Jackson R, Wells S, Rodgers A. Will screening individuals at high risk of cardiovascular events deliver large benefits? Yes. BMJ 2008;337:a1371.

\section{Krogsbøll 2012}

Krogsbøll LT, Jørgensen KJ, Grønhøj Larsen C, Gøtzsche PC. General health checks in adults for reducing morbidity and mortality from disease. Cochrane Database of Systematic Reviews 2012, Issue 10. [DOI: 10.1002/14651858.CD009009.pub2]

\section{Lawson 2010}

Lawson K, Fenwick E, Pell ACH, Pell J. Comparison of mass and targeted screening strategies for cardiovascular risk: simulation of the effectiveness, cost-effectiveness and coverage using a cross-sectional survey of 3921 people. Heart 2010;96(3):208-12.

\section{Lefebvre 2011}

Lefebvre C, Manheimer E, Glanville J. Chapter 6: Searching for studies. In: Higgins JPT, Green S (editors). Cochrane Handbook for Systematic Reviews of Interventions. Version 5.1.0 (updated March 2011). The Cochrane Collaboration, 2011. Available from www.cochrane-handbook.org.

\section{NHS 2012}

NHS. Health check. www.nhs.uk/Planners/NHSHealthCheck/ Pages/NHSHealthCheck.aspx (accessed 2 September 2012).

\section{NICE 2016}

National Institute for Health and Care Excellence (NICE). The NICE Indicator Menu for the QOF. https://www.nice.org.uk/ standards-and-indicators/qofindicators (accessed 29th January 2016).

\section{NPSA 2007}

National Patient Safety Agency, NHS. Healthcare Risk Assessment Made Easy. (available from www.nrls.npsa.nhs.uk/ resources/?Entryld45=59825). London: NPSA, 2007.

\section{O'Flaherty 2009}

O'Flaherty M, Bishop J, Redpath A, McLaughlin T, Murphy D, Chalmers J, et al. Coronary heart disease mortality among young adults in Scotland in relation to social inequalities: time trend study. BMJ 2009;339:b2613.

\section{RevMan 2014 [Computer program]}

The Nordic Cochrane Centre, The Cochrane Collaboration. Review Manager (RevMan). Version 5.3. Copenhagen: The Nordic Cochrane Centre, The Cochrane Collaboration, 2014.

\section{Rose 2008}

Commentary by Khaw KT, Marmot M. Rose's Strategy of Preventive Medicine. The Complete Original Text. Oxford: Oxford University Press, 2008.

\section{Short 2009}

Short R. Putting Vascular Disease Management into Practice. Bath: Medical Management Services, 2009.

\section{Tunstall-Pedoe 2003}

Tunstall-Pedoe H (editor). MONICA Monograph and Multimedia Sourcebook. World's Largest Study of Heart Disease, Stroke, Risk Factors and Population Trends 1979-2002. Geneva: WHO, 2003.

\section{UKNSC 2008}

UK National Screening Committee. The Handbook for Vascular Risk Assessment, Risk Reduction and Risk Management. Leicester: University of Leicester, 2008.

\section{WHO 2002}

World Health Organization. Integrated Management of Cardiovascular Risk. Report of a WHO meeting, Geneva, 9-12 July 2002. Geneva: WHO, 2002.

\section{WHO 2007}

World Health Organization. Prevention of Cardiovascular Disease. Guidelines for Assessment and Management of Cardiovascular Risk. Geneva: WHO, 2007.

\section{WHO 2011a}

World Health Organization. Media centre: cardiovascular diseases (CVDs). www.who.int/mediacentre/factsheets/fs317/ en/index.html (accessed 29 March 2012). 


\section{WHO 2011b}

World Health Organization. Noncommunicable diseases and mental health. www.who.int/nmh/countries/en/index.html (accessed 26 June 2012).

\section{WHO 2013}

World Health Organization. The European Health Report 2012: Charting the Way to Well-being. www.euro.who.int/en/ publications/abstracts/european-health-report-2012 (accessed 20 March 2015).

\section{WHO 2014a}

World Health Organization. Global Status Report on Noncommunicable Diseases 2014. www.who.int/nmh/ publications/ncd-status-report-2014/en/ (accessed 6 April 2015).

\section{WHO 2014b}

World Health Organization. World Health Statistics 2014. www.who.int/gho/publications/world_health_statistics/2014/ en/ (accessed 6 April 2015).

\section{Wood 1994}

Wood D, Kinmonth A, Davies G, Yarwood J, Thompson S, Pyke S, et al. Family Heart Study Group. Randomised controlled trial evaluating cardiovascular screening and intervention in general practice: principal results of British family heart study. $B M J$ 1994;308(6924):313-20.

\section{Yusuf 2004}

Yusuf S, Hawken S, Ôunpuu T, Dans T, Avezum A, Lanas F, et al. Effect of potentially modifiable risk factors associated with myocardial infarction in 52 countries (the INTERHEART study): case control study. The Lancet 2004;364(9438):937-52.

\section{References to other published versions of this review \\ Dyakova 2013}

Dyakova M, Drew C, Wright N, Clarke A, Rees K. Systematic versus opportunistic risk assessment for the primary prevention of cardiovascular disease (Protocol). Cochrane Database of Systematic Reviews 2013, Issue 2. [DOI: 10.1002/14651858.CD010411]

* Indicates the major publication for the study

\section{CHARACTERISTICS OF STUDIES}

Characteristics of included studies [ordered by study ID]

\section{BFHS 1994}

Methods

Design: Cluster-RCT (each pair of practices per town randomised to intervention or control. Families in the intervention practices were further randomised to intervention and internal control)

Setting: General practice.

13 towns (10 England, 2 Wales, 1 Scotland) with population 50,000 - 100,000 at 1981 census, separate from major conurbations, no recent large housing development, elderly population no greater than the national average, comparable in employment type, social class distribution and ethnic structure, and with at least 1 district general hospital. From each town, 2 GP practices with 4 - 7 whole-time equivalent GPs were selected.

Dates: Not reported

Follow-up: 1 year

$N$ randomised: 14,086 households (intervention 4158, internal control 3798, external control 6130)

N responded: 8605 households

Intervention $\mathrm{n}=2373$ households (3850 individuals: 2246 men and 1604 women)

Final numbers (at 1 year follow-up):

Intervention: 1767 men, 1217 women, total 2984 (excluding 202 men and 150 women randomised to no measurement of cholesterol)

Internal control: 2174 men, 1402 women (screen at 1 year), total 3576

External control: 3519 men, 2393 women (screen at 1 year), total 5912

Men aged 40 - 59 on the registers of the included GP practices, and their partners (irrespective of their age) 
High risk defined as: $\mathrm{Hx}$ of $\mathrm{CHD}$ (angina, MI, previous coronary bypass graft); current smokers, BMI 25+, DBP 90+, cholesterol 6.5+, random glucose 7.0+ Note different cut-offs are reported in EN22 Table IV

Of $1869^{\star}$ men: 1716 had no disease, 114 had CHD, 280 had high DBP, 150 high cholesterol, 40 diabetes

Of 1379* women: 1321 had no disease, 25 CHD, 211 high DBP, 53 high cholesterol, 12 diabetes

${ }^{\star}$ Denominator data not clear.

\section{Age (mean, SD)}

Men: intervention 51.5 (5.7); internal control 51.6 (5.8); external control 51.5 (5.7)

Women: intervention 49.1 (6.8); internal control 49.0 (6.8); external control 49.0 (7.1)

Intervention group at baseline:

\% CVD: men 114/2246 (5.1\%); women 25/1604 (1.6\%)

\% diabetes: men 40/2246 (1.8\%); women 12/1604 (0.7\%)

\% hypertension medication: men 103/2246 (4.6\%); women 90/1604 (5.6\%)

\% diabetic drugs: men 19/2246 (0.8\%); women 9/1604 (0.6\%)

No.(\%) lost to follow up: men 277 (12.1\%); women 237 (14.6\%)

\section{Intervention:}

- Intervention: health check carried out at the practice by a nurse

- Questionnaire: demographics, past medical history, family history, smoking

- Height, weight (BMI), waist/hip ratio, BP, total blood glucose and cholesterol

- Cholesterol done for a random $75 \%$ in 5 practices

- Coronary risk score (Dundee) calculated

Participants were told which decile of risk for coronary heart disease they were in relative to other men/women of the same age. Risk recorded in booklet with personally negotiated lifestyle changes documented. Frequency of follow-up was determined by the coronary risk score and other factors. Adults in top quintile were offered follow up every two months, those in the fourth quintile every three months, those in the third quintile every four months, those in the second quintile every six months, those in the bottom quintile at one year. People with individual high risk factors also invited to re-attend every month for up to three months. Patients with glucose concentration $\geq 10 \mathrm{mmol} / \mathrm{l}$ or $\mathrm{DBP} \geq$ $115 \mathrm{mmHg}$ on any occasion were referred to GP, as were those with cholesterol $\geq 6.5 \mathrm{mmol} / \mathrm{l}$ or DBP $\geq$ $100 \mathrm{~mm} \mathrm{Hg}$ sustained for three months.

\section{Controls}

2 control groups (no intervention):

1) Families from practices randomised to control (external controls)

2) Families from intervention practices who were further randomised to a control group (internal controls)

Internal and external control groups were identified at the same time as the intervention groups, but were first screened at 1 year (at the same time the intervention group was rescreened) 
BFHS 1994 (Continued)

The proportion of participants who reported having a diagnosis of diabetes, HTN or CHD (angina/MI/ CABG)

Change in Dundee risk score

Attendance rates, case finding rates

Notes

\section{Risk of bias}

\begin{tabular}{|c|c|c|}
\hline Bias & Authors' judgement & Support for judgement \\
\hline $\begin{array}{l}\text { Random sequence genera- } \\
\text { tion (selection bias) }\end{array}$ & Unclear risk & Not reported \\
\hline $\begin{array}{l}\text { Allocation concealment } \\
\text { (selection bias) }\end{array}$ & Unclear risk & Not reported \\
\hline $\begin{array}{l}\text { Blinding of participants } \\
\text { and personnel (perfor- } \\
\text { mance bias) } \\
\text { All outcomes }\end{array}$ & Unclear risk & Not reported \\
\hline $\begin{array}{l}\text { Blinding of outcome as- } \\
\text { sessment (detection bias) } \\
\text { All outcomes }\end{array}$ & Unclear risk & Not reported. \\
\hline $\begin{array}{l}\text { Incomplete outcome data } \\
\text { (attrition bias) } \\
\text { All outcomes }\end{array}$ & High risk & $\begin{array}{l}\text { Not all participants followed, numbers identified and followed up } 1 \text { year later } \\
\text { in control groups not reported }\end{array}$ \\
\hline $\begin{array}{l}\text { Selective reporting (re- } \\
\text { porting bias) }\end{array}$ & High risk & Possible due to chosen presentation of data, no measures of variance reported \\
\hline Other bias & Unclear risk & Not reported \\
\hline
\end{tabular}

BFHS Men

\begin{tabular}{ll}
\hline Methods & See BFHS 1994 \\
\hline Participants & See BFHS 1994 \\
\hline Interventions & See BFHS 1994 \\
\hline Outcomes & See BFHS 1994 \\
\hline Notes & See BFHS 1994 \\
\hline
\end{tabular}

\section{BFHS Women}

\begin{tabular}{ll}
\hline Methods & See BFHS 1994 \\
\hline Participants & See BFHS 1994
\end{tabular}


BFHS Women (Continued)

\begin{tabular}{ll} 
Interventions & See BFHS 1994 \\
\hline Outcomes & See BFHS 1994 \\
\hline Notes & See BFHS 1994 \\
\hline
\end{tabular}

Design: Cluster-RCT
Setting: Ontario, Canada. Cluster eligibility: population of $10,000-60,000,5+$ GPs, $2+$ pharmacies, Reg-
istered Persons Database to Census Population ratio $<10 \%$, no recent geographical amalgamation into
a major centre.
Community recruitment via personalised invitation letter from participating family physicians or other
local lead organisation (e.g. seniors centres, hospitals, community centres) Also advertised CHAP ses-
sions by flyers, posters, paid and unpaid adverts in local media

Dates: Autumn 2006 start

Follow-up: 1 year

Intervention $\mathrm{N}=20$ clusters
Control $\mathrm{N}=19$ clusters
All over-65s included (but anyone could participate)
At baseline, $\%$ diabetic: $22 \%$ control, $21 \%$ intervention
At baseline, $\%$ with history of CCF: 12\% control, 12\% intervention
Age (mean, SD) control: 74.49 (0.43); intervention: 74.82 (0.62)
Men (\%, SD) control: 42.65 (1.19); intervention: 42.92 (2.16)
Diabetes (\%, SD) control: 22.16 (2.34); intervention: 21.20 (2.79)
Hx of CHF (\%, SD) control: 12.19 (1.19); intervention: 12.45 (2.34)
Setting: Community pharmacy
Intervention: Standardised 10-week programme. 3-hour weekday BP and CVS risk factor assessment
and education sessions held in community bases. Participants were given their risk profile, specific ed-
ucational materials and info regarding availability of local community resources. Any participants iden-
tified as high risk (according to BP) were assessed by a nurse and referred immediately to family physi-
cian. At the end of the 10-week programme, results sent to family physicians (with reports ordering par-
ticipants by SBP) along with their diagnostic/treatment status. These data was resent to the GPs at 6
months, along with aggregate-level data showing the performance of their practice compared to oth-
ers in the locality regarding attaining target SBP.

Risk factors assessed: BP, smoking, alcohol intake, diet, physical activity, height, weight

Control: No intervention

Outcomes

Total mortality, stroke, MI, in-hospital death from CVD, CHF, composite (hospital admissions for MI, stroke or CCF)

\section{Notes}


CHAPS 2011 (Continued)

Risk of bias

\begin{tabular}{|c|c|c|}
\hline Bias & Authors' judgement & Support for judgement \\
\hline $\begin{array}{l}\text { Random sequence genera- } \\
\text { tion (selection bias) }\end{array}$ & Low risk & Random number generator \\
\hline $\begin{array}{l}\text { Allocation concealment } \\
\text { (selection bias) }\end{array}$ & Low risk & States undertaken by an independent expert \\
\hline $\begin{array}{l}\text { Blinding of participants } \\
\text { and personnel (perfor- } \\
\text { mance bias) } \\
\text { All outcomes }\end{array}$ & Unclear risk & $\begin{array}{l}\text { Names of control communities were not publicised and the control communi- } \\
\text { ty members were not notified that the study was taking place }\end{array}$ \\
\hline $\begin{array}{l}\text { Blinding of outcome as- } \\
\text { sessment (detection bias) } \\
\text { All outcomes }\end{array}$ & Low risk & $\begin{array}{l}\text { Data outcomes taken from routinely-collected population-based administra- } \\
\text { tive health data, and data analysts were blinded to group allocation }\end{array}$ \\
\hline $\begin{array}{l}\text { Incomplete outcome data } \\
\text { (attrition bias) } \\
\text { All outcomes }\end{array}$ & Unclear risk & $\begin{array}{l}\text { Numbers of individuals followed/lost to follow-up not reported. Cluster-level } \\
\text { data reported only }\end{array}$ \\
\hline $\begin{array}{l}\text { Selective reporting (re- } \\
\text { porting bias) }\end{array}$ & Unclear risk & Unclear \\
\hline Other bias & Unclear risk & Unclear \\
\hline
\end{tabular}

\section{EHPP 2002}

Methods

Design: Individual RCT

Setting: Aarhus County, Denmark (rural area), primary care. 9 GPs from the 4 practices in 1 town (covering $87 \%$ of the study population) agreed to participate. A random sample of 2000 (57.7\%) people were invited to participated. Participants were selected by date of birth, so that an equal number of people were presented from each practitioner and age group.

Dates: Recruitment start 1st January 1991, baseline screening December 1991 - June 1992

Follow-up: 5 years

N: 1507
Pealticipants screen $n=502$
Control $n=501$
Screen + discussion $n=504$
All adults age 30 - 49 registered with a local GP were eligible
Known IHD $4 / 449(0.9 \%)$ health check group; $8 / 456$ health check + discussion group.
Age (mean, SD, range): 40.4 (5.8) control, 40.4 (5.6) screen, 40.6 (5.7) screen + discussion
\% men: $48.3 \%$ control, $48.6 \%$ screen, $49.0 \%$ screen + discussion
Cardiovascular risk score $\geq \mathbf{1 0}$, high risk: screen: $52 / 449$ (11.6\%); screen + disc: $51 / 456(11.2 \%)$


EHPP 2002 (Continued)

Cardiovascular risk score, mean (SD): Screen $(n=449) 5.69(3.11)$; Screen + discussion $(n=456) 5.95$ (3.07)

BMI, mean (SD): Screen $(n=449) 24.8(3.8)$; Screen + discussion $(n=456) 25.3(4.7)$

SBP, mmHg, mean (SD): Screen $(n=449) 122.2(14.5)$; Screen + discussion $(n=456) 123.0(16.0)$

DBP, mmHg, mean (SD): Screen ( $\mathrm{n}=449) 77.7(9.5)$; Screen + discussion $(n=456) 77.2(10.0)$

Serum cholesterol mmol/l, mean (SD): Screen $(n=449) 5.60(1.05)$; Screen + discussion $(n=456) 5.68$ (1.06)

Interventions Setting: Primary care.

All participants had baseline questionnaire (demographics, health, lifestyle, psychosocial status/life events, Goldberg's 12-item general health questionnaire)

Randomised to 3 groups.

1) Health check and written feedback from GP

2) Health check and written feedback from their GP, and the opportunity to attend their GP to discuss preventive health

3) Control - no intervention after baseline questionnaire (health screening and a health discussion at the end of the study period)

Health screenings: calculation of cardiovascular risk score (based on sex, family Hx, tobacco, BP, cholesterol (total) and BMI). Within 2 weeks of health check, all got personalised written feedback from their GP, including advice relating to lifestyle changes when values indicated that people were at risk, and pamphlets on leading a healthy lifestyle from the Danish Heart Foundation. If signs of disease or indications for further examination were present, the communication also included suggestions about seeking medical care.

Health discussions: 45-minute consultation with their own GP, covering a maximum of 3 health-related lifestyle goals for the following year. These were confirmed in writing. It was also possible to book a $30-$ minute consultation with the GP to take place 3 months later. Annual consultations were offered.

\begin{tabular}{ll}
\hline Outcomes & BP, total cholesterol, costs, attendance rates, case-finding rates \\
\hline Notes & $\begin{array}{l}\text { Number (\%) lost to follow-up (at } 5 \text { years); Screen: } 124 \text { (24.7\%); Screen + discussion } 158(31.3 \%) ; \text { control } \\
132(26.3 \%)\end{array}$ \\
\hline
\end{tabular}

\section{Risk of bias}

Bias Authors' judgement Support for judgement

Random sequence genera- Unclear risk Not reported. proportional stratified randomisation by GP, sex, age, cohabitation (selection bias) tion status and BMI. Couples living together were allocated to the same group to avoid bias between groups.

\begin{tabular}{ll}
\hline $\begin{array}{l}\text { Allocation concealment } \\
\text { (selection bias) }\end{array}$ & Low risk Undertaken by an independent person \\
\hline
\end{tabular}

Blinding of participants Unclear risk Not reported
and personnel (performance bias)

All outcomes

$\begin{array}{ll}\text { Blinding of outcome as- } & \text { Low risk }\end{array}$ Not reported but outcomes objective so low risk of bias


EHPP 2002 (Continued)

All outcomes

Incomplete outcome data Low risk
(attrition bias)

All outcomes

\begin{tabular}{lll}
\hline $\begin{array}{l}\text { Selective reporting (re- } \\
\text { porting bias) }\end{array}$ & Unclear risk & Possibly due to presentation of results, e.g. combining of intervention groups \\
\hline Other bias & Unclear risk & Unclear \\
\hline
\end{tabular}

\section{FIT Heart 2008}

\begin{tabular}{ll}
\hline Methods & Design: RCT \\
Setting: secondary care, New York, USA \\
Dates: recruitment January 2005 - June 2007
\end{tabular}

Follow-up: 1 year

$\begin{array}{ll}\text { Participants } & 3649 \text { screened } \\ & \text { N randomised: } 501 \\ & \text { Intervention } \mathrm{n}=250 \\ & \text { Control } \mathrm{n}=251\end{array}$

Healthy. Family members of cardiac patients admitted to a secondary care centre with acute atherosclerotic CVD (including catheter procedures and CABG)

English/Spanish speaking adults aged 20 - 79 who lived within 3 hours of medical centre.

Had to be family member (= blood relative, spouse or other cohabitant for $\geq 1$ year in last 5 years, or for 10 years in the past) - only 1 family member per index case was randomised into study.

Exclusions: current/planned pregnancy, known CVD/ diabetes, active liver disease, chronic kidney disease, life expectancy $<5$ years, on specialised diet not compatible with the programme intervention, or part of a drug trial in last 3 months.

Framingham absolute risk $\geq 10 \%$ - 21/250 (8.5\%) intervention, $23 / 251$ (9.2\%) control

Mean age: intervention 30, control 30

$\%$ men: intervention 34 , control 33

Ethnicity: intervention $64 \%$ white, control $64 \%$ white.

Total cholesterol, mmol/l, mean (SD): intervention 5.24 (0.95), control 5.32 (1.0)

HDL cholesterol, mmol/l, mean (SD): intervention 1.51 (0.45), control 1.55 (0.48)

LDL cholesterol, mmol/l, mean (SD): intervention 3.32 (0.88), control 3.38 (0.95)

Triglycerides, mmol/l, mean (SD): intervention 1.30 (0.72), control 1.33 (0.95)

SBP, $\mathbf{m m}$ Hg, mean (SD): intervention 126.7 (14.69), control 126.4 (15.46)

DBP, $\mathbf{m m ~ H g , ~ m e a n ~ ( S D ) : ~ i n t e r v e n t i o n ~} 77.9$ (10.82), control 77.0 (11.98)

Statin therapy: $31 / 250(13 \%)$ intervention, 40 (16\%) control 
FIT Heart 2008 (Continued)

Antihypertensive therapy: $52 / 250(21 \%)$ intervention, $53 / 251(21 \%)$ control

Interventions

Setting: not clear

All participants received baseline and 1-year assessments of diet, lifestyle, and risk factors: demographics, medical $\mathrm{Hx}$, family $\mathrm{Hx}$, drug $\mathrm{Hx}$, lifestyle habits, SBP, DBP, height, weight, waist circumference, BMI, physical activity level, smoking status (with carbon monoxide monitoring). Fasting blood samples collected for total cholesterol, HDL-C, triglyceride, glucose, LDL-C, CRP.

\section{Intervention:}

Personalised CVD risk factor screening with immediate feedback by health educator, behavioural counselling, taught lifestyle approaches to risk reduction including way to improve total blood cholesterol. Diet counselling focused on foods rather than nutrient intake. Encouraged to do physical activity, stop smoking (and referred to cessation programme). Had regular contact with educator (by person/phone) at 2 weeks, 6 weeks, 3 months, 6 months and 9 months. All visits 30 - 60 minutes long. Risk factor results given to primary care providers as written report.

In addition, those with abnormal lipids were offered fingerprick lipid testing and 3-, 6-, 9-month testing with immediate feedback.

Control: Received a 1-page handout to 1) avoid tobacco, 2) choose good nutrition, 3) be more active.

Brief prevention message and a letter sent to their healthcare provider only if they had a critical risk factor level. i.e. $B P \geq 140 / 90$, LDL-C $\geq 190 \mathrm{mg} / \mathrm{dL}$, HDL-C $<25 \mathrm{mg} / \mathrm{dl}$, triglycerides $\geq 500 \mathrm{mg} / \mathrm{dl}$, total cholesterol $>300 \mathrm{mg} / \mathrm{dl}$

Outcomes SBP, DBP, lipid levels, attendance rates, case-finding rates

Notes Number (\%) lost to follow-up: intervention: 18 (7.2\%); control $19(7.6 \%)$

\section{Risk of bias}

\begin{tabular}{|c|c|c|}
\hline Bias & Authors' judgement & Support for judgement \\
\hline $\begin{array}{l}\text { Random sequence genera- } \\
\text { tion (selection bias) }\end{array}$ & Low risk & Web-based programme, blocks based on sex and race \\
\hline $\begin{array}{l}\text { Allocation concealment } \\
\text { (selection bias) }\end{array}$ & Low risk & Web-based programme \\
\hline $\begin{array}{l}\text { Blinding of participants } \\
\text { and personnel (perfor- } \\
\text { mance bias) } \\
\text { All outcomes }\end{array}$ & Unclear risk & Not reported \\
\hline $\begin{array}{l}\text { Blinding of outcome as- } \\
\text { sessment (detection bias) } \\
\text { All outcomes }\end{array}$ & Low risk & $\begin{array}{l}\text { States research assistants blind to group assignments collected the 1-year out- } \\
\text { come data }\end{array}$ \\
\hline $\begin{array}{l}\text { Incomplete outcome data } \\
\text { (attrition bias) } \\
\text { All outcomes }\end{array}$ & Low risk & Reported and similar between groups \\
\hline $\begin{array}{l}\text { Selective reporting (re- } \\
\text { porting bias) }\end{array}$ & Unclear risk & Unclear \\
\hline Other bias & Unclear risk & Unclear \\
\hline
\end{tabular}


Inter99 2014

\begin{tabular}{ll}
\hline Methods & Design: RCT \\
& Setting: Suburbs of Copenhagen, Denmark. People identified in the civil registration system, selecting
\end{tabular}
all people born in 1939 - 40, 1944 - 45, 1949 - 50, 1954 - 55, 1959 - 60, 1964 - 65, 1969 - 70

Dates: Participants identified December 1998; Baseline examination March 1999 to Jan 2001; Final follow-up: January 2011

Follow-up: 10 years

\begin{tabular}{|c|c|}
\hline \multirow[t]{10}{*}{ Participants } & N randomised: 59,993 \\
\hline & 337 excluded post-randomisation (reasons given) \\
\hline & Study population: 59,616 \\
\hline & Intervention $\mathrm{n}=11,629$ \\
\hline & Control $n=47,987$ \\
\hline & Mainly healthy. 1308 in total had IHD before study start (excluded from IHD/combined outcome) \\
\hline & 676 had stroke before study start (excluded from stroke/combined outcome). \\
\hline & Age $30-60$ years included \\
\hline & $\%$ men: $49.9 \%$ intervention, $49.1 \%$ control \\
\hline & High 10-year risk of IHD: $60 \%$ \\
\hline \multirow[t]{5}{*}{ Interventions } & $\begin{array}{l}\text { Setting: The Research Centre for Prevention and Health (an independent research institute in Den- } \\
\text { mark) }\end{array}$ \\
\hline & Intervention: \\
\hline & $\begin{array}{l}\text { Intervention: Screened with a comprehensive questionnaire (lifestyle, motivation to change lifestyle, } \\
\text { symptoms, medical } \mathrm{Hx} \text {, family } \mathrm{Hx} \text {, psychosocial factors), physical measurements (ECG, BP, height, } \\
\text { weight, waist/hip circumference, spirometry), bloods (total cholesterol, total lipid profile), oral glucose } \\
\text { tolerance test. }\end{array}$ \\
\hline & $\begin{array}{l}\text { A 10-year risk of IHD calculated using the PRECARD programme (now registered as HeartScore), with } \\
\text { "at-risk" people defined as being in the upper 5th quintile of risk; or if smokers, SBP }>160 \mathrm{mmHg} \text {, on } \\
\text { anti-hypertensive treatment, total cholesterol }>7.5 \mathrm{mmol} / \mathrm{l} \text {, having lipid-lowering drugs, BMI }>30, \mathrm{Hx} \\
\text { DM or IHD, or impaired glucose intolerance/DM on oral glucose tolerance test. Each person was simu- } \\
\text { lated in the computer programme as } 60 \text { years old to reach a substantial level of risk. }\end{array}$ \\
\hline & $\begin{array}{l}\text { Based on risk, each intervention pt had lifestyle counselling session ( } 15 \text { - } 45 \text { minutes), written materi- } \\
\text { al (on physical activity, smoking, diet, alcohol as relevant). High-risk participants offered } 6 \text { counselling } \\
\text { sessions over } 4 \text { - } 6 \text { months (e.g. smoking cessation, diet, physical activity). High-risk participants were } \\
\text { given a letter for their GP with results from the examinations, and re-invited at } 1 \text { and } 3 \text { years for repeat } \\
\text { screening, risk assessment ad lifestyle counselling as above. Low-risk participants only got a question- } \\
\text { naire. At } 5 \text { years, all intervention group were re-invited for final screening, counselling and plan for } \\
\text { maintenance. }\end{array}$ \\
\hline
\end{tabular}

Control group: Not invited for screening

\begin{tabular}{ll}
\hline Outcomes & IHD, stroke, mortality (combined event (IHD, stroke or both), attendance rates, case-finding rates \\
\hline Notes & Intervention: \\
& 6091 of intervention group examined at baseline (617 did not attend screening, $47.6 \%$ loss) \\
\end{tabular}


Inter99 2014 (Continued)

4028 participated at 5-year screening (of 6091 who did baseline screening) $=2063(34 \%)$ loss for this intervention

\section{Risk of bias}

\begin{tabular}{lll}
\hline Bias & Authors' judgement & Support for judgement \\
\hline $\begin{array}{l}\text { Random sequence genera- } \\
\text { tion (selection bias) }\end{array}$ & Low risk & $\begin{array}{l}\text { Computer-generated, different randomisation ratios in different age/sex } \\
\text { groups }\end{array}$ \\
\hline $\begin{array}{l}\text { Allocation concealment } \\
\text { (selection bias) }\end{array}$ & Unclear risk & Not reported \\
\hline $\begin{array}{l}\text { Blinding of participants } \\
\text { and personnel (perfor- } \\
\text { mance bias) }\end{array}$ & Unclear risk & Not reported \\
$\begin{array}{l}\text { All outcomes } \\
\text { Blinding of outcome as- } \\
\text { sessment (detection bias) }\end{array}$ & Low risk & \\
All outcomes & Used unique identifiers to extract data \\
\hline $\begin{array}{l}\text { Incomplete outcome data } \\
\text { (attrition bias) }\end{array}$ & Low risk & Numbers lost to follow-up low \\
$\begin{array}{l}\text { All outcomes } \\
\begin{array}{l}\text { Selective reporting (re- } \\
\text { porting bias) }\end{array}\end{array}$ & High risk & $\begin{array}{l}\text { The numbers without IHD and/or stroke at baseline not reported. Limited data } \\
\text { reported }\end{array}$ \\
\hline \begin{tabular}{l} 
Other bias \\
\hline
\end{tabular} & Unclear risk & \begin{tabular}{l} 
Unclear \\
\hline
\end{tabular}
\end{tabular}

Murray 1986

Methods

Design: RCT

Setting: Heart Health Centre in Mankato, Minnesota (a southern Minnesota community of 35,000)

Dates: Intervention group recruited September to December 1982, control group recruited September to December 1983. Intervention group returned for follow-up September to December 1983.

Follow-up: 1 year

\section{Participants}

$N$ randomised: 2323 (Intervention $n=1156$, Control $n=1167$ ) addresses were randomised

Of 2323 addresses, $4.0 \%$ were non-residences and $3.6 \%$ could not be contacted

Of 2146 addresses contacted, $12.6 \%$ had no age-eligible residents

Participation rates at initial screen equivalent for intervention and control groups (50.6\%). No adults agreed to participate in $43.1 \%$ of households and $6.3 \%$ agreed to attend but did not keep appointment

Final numbers included in analyses:

Intervention $\mathrm{n}=428$

Control $n=478$

Overall healthy population. From the addresses randomised, 1 resident was randomly selected from those aged 25 - 74 years. Treatment group participants who moved out of town prior to follow-up were 
excluded from analyses (32, 7\%). 49/428 (11.4\%) of treatment group were lost to follow-up (data from baseline visit were substituted for follow-up data where possible)

Age (assume mean) years: Intervention 43.8 , control 43.9

Men \%: intervention 43.0, control 40.0

Interventions

Setting: Heart Health Centre

Intervention: After giving informed consent, participants were tested for total serum cholesterol, height and weight, blood pressure, expired-air carbon monoxide, and leisure-time physical activity. Results of these tests were returned during the visit. Participants received a health education message on videotape, printed materials or both, focused on changing behaviour, on diet, physical activity, stopping smoking or helping smokers to stop, reading food labels. Color-coded risk factor cards used to record each participant's risk factor level and to provide a message tailored to the risk factor value. Each family spent 20 min with a health educator to review the test results. The average visit lasted $75 \mathrm{~min}$. A second measurement was made if diastolic blood pressure was $90 \mathrm{mmHg}$ or higher or total cholesterol was $300 \mathrm{mg} / \mathrm{dl}$ or greater, if this remained the case a referral was made to a local physician.

Control: received intervention one year later (no baseline assessment of risk factors which might motivate behaviour change).

\begin{tabular}{ll}
\hline Outcomes & BP, total cholesterol, attendance rates \\
\hline Notes
\end{tabular}

\section{Risk of bias}

\begin{tabular}{|c|c|c|}
\hline Bias & Authors' judgement & Support for judgement \\
\hline $\begin{array}{l}\text { Random sequence genera- } \\
\text { tion (selection bias) }\end{array}$ & Unclear risk & Not reported \\
\hline $\begin{array}{l}\text { Allocation concealment } \\
\text { (selection bias) }\end{array}$ & Unclear risk & Not reported \\
\hline $\begin{array}{l}\text { Blinding of participants } \\
\text { and personnel (perfor- } \\
\text { mance bias) } \\
\text { All outcomes }\end{array}$ & Low risk & $\begin{array}{l}\text { Heart Health Centre staff were not informed of the study until its conclusion. } \\
\text { Participants were not informed of their treatment condition and were sched- } \\
\text { uled together during the } 1983 \text { follow-up. }\end{array}$ \\
\hline $\begin{array}{l}\text { Blinding of outcome as- } \\
\text { sessment (detection bias) } \\
\text { All outcomes }\end{array}$ & Low risk & $\begin{array}{l}\text { Cholesterol was analysed at a central laboratory (as well as at the Heart Health } \\
\text { Centre) where staff were blinded to identity and prior Heart Health Centre cho- } \\
\text { lesterol value }\end{array}$ \\
\hline $\begin{array}{l}\text { Incomplete outcome data } \\
\text { (attrition bias) } \\
\text { All outcomes }\end{array}$ & Low risk & $\begin{array}{l}\text { Appears to be similar between groups, in effect the last observation carried } \\
\text { forward was used for losses to follow-up from the intervention group. }\end{array}$ \\
\hline $\begin{array}{l}\text { Selective reporting (re- } \\
\text { porting bias) }\end{array}$ & High risk & Limited data; no measures of variance reported \\
\hline Other bias & Unclear risk & Not reported \\
\hline
\end{tabular}




\section{OXCHECK 1995}

\begin{tabular}{ll}
\hline Methods & Design: RCT by household \\
Setting: 5 primary care practices in Luton and Dunstable, Bedfordshire, England. 3 practices with > \\
10,000 patients in Luton, 2 practices with 7500 patients; 1 in Luton, 1 in Dunstable \\
Dates: Practice registers screened in 1988, participants randomised in 1988, intervention group health \\
check in 1989 - 1990, control group health check $1992-1993$ \\
Follow-up: 3 years (intervention group) \\
N randomised: 11,090 (to 4 groups, only 2 were analysed in publication) \\
Intervention $n=2776$ \\
Control: $n=2783$ \\
Potential participants were all those on the practice register, men or women, aged 35 - 64 on $1 / 1 / 1989$. \\
Some of these (338) were later deemed “not eligible for a health check" but exclusion criteria not stat- \\
ed. \\
For intervention group: mean prevalence of chest pain $10 \%$ in men, $8 \%$ in women (using WHO ques- \\
tionnaire, “indicates angina or infarction") \\
Hypertension, diabetes or IHD mean prevalence $14 \%$ of men, $15 \%$ of women
\end{tabular}

Interventions

Setting: Primary care

Intervention: Health check: details of personal and family history of IHD, stroke, HTN, DM, cancer, smoking, dietary intake; measurement of height/weight (BMI calculated), BP, serum cholesterol.

Nurses were instructed to counsel participants about risk factors, ascertaining their views and negotiating priorities and targets for risk reduction, with follow-up by mutual agreement between nurse and participant. Set protocols for repeat measurement were laid down for high blood pressure and hyperlipidaemia.

The intervention group were further randomised to receive annual re-examinations ( $n=110)$ or a single return visit at 3 years $(n=1105)$.

Control: No intervention during study period (had initial health check at the same time as the 3-year follow-up for intervention group)

\% men: control group 885/1916 (46.2\%); intervention group 987/2205 (44.8\%)

Age: not reported, states groups did not differ significantly in the distribution if age or social class

\begin{tabular}{ll}
\hline Outcomes & BP, lipid levels (total cholesterol), costs, attendance rates, case-finding rates \\
\hline Notes & $\begin{array}{l}\text { Intervention: } 1660 / 2776 \text { attended follow-up (raw } 40.2 \% \text { loss), stated } 18.3 \% \text { loss when removing those } \\
\text { who left the practice area }\end{array}$ \\
& $\begin{array}{l}\text { Control: } 1916 / 2783 \text { attended follow-up (raw } 31.2 \% \text { loss), stated } 18.7 \% \text { loss when removing those who } \\
\text { left the practice area }\end{array}$
\end{tabular}

\section{Risk of bias}

Bias Authors' judgement Support for judgement

$\begin{array}{lll}\text { Random sequence genera- } & \text { Unclear risk } & \text { Not reported } \\ \text { tion (selection bias) }\end{array}$


OXCHECK 1995 (Continued)

\begin{tabular}{lll}
$\begin{array}{l}\text { Allocation concealment } \\
\text { (selection bias) }\end{array}$ & Unclear risk & Not reported \\
\hline $\begin{array}{l}\text { Blinding of participants } \\
\text { and personnel (perfor- }\end{array}$ & Unclear risk & Not reported \\
mance bias) & \\
All outcomes &
\end{tabular}

\begin{tabular}{lll}
\hline $\begin{array}{l}\text { Blinding of outcome as- } \\
\text { sessment (detection bias) } \\
\text { All outcomes }\end{array}$ & Low risk & Not reported, but outcomes objective so low risk of bias \\
\hline $\begin{array}{l}\text { Incomplete outcome data } \\
\begin{array}{l}\text { (attrition bias) } \\
\text { All outcomes }\end{array}\end{array}$ & Low risk & Losses reported and similar between groups \\
\hline $\begin{array}{l}\text { Selective reporting (re- } \\
\text { porting bias) }\end{array}$ & Unclear risk & Unclear \\
\hline Other bias & Unclear risk & Unclear \\
\hline
\end{tabular}

WHO 1986

$\begin{array}{ll}\text { Methods } & \text { Design: Cluster-RCT } \\ \text { Setting: Factories/industrial centres in UK, Belgium, Italy, Poland (and Spain for baseline but not fol- } \\ \text { low-up) } \\ \text { Dates: Recruitment } 1971 \text { - } 1977 \\ \text { Follow-up: } 6 \text { years }\end{array}$

Participants

N eligible: 88 factories (intervention 44, control 44); 60,881 individuals (intervention 30,489, control 30,392).

8 factories in Spain were recruited but excluded from the subsequent incidence estimates due to small participant numbers and the time delay in recruitment.

N analysed: 80 factories (intervention 40, control 40); 57,460 individuals (intervention 30,489, control 26,971)

Men age 40 - 59 years at initial recruitment working in factories in Europe were eligible

Baseline data include the 8 factories from Spain that are excluded from the final analysis, and are for $10 \%$ of the control group (those screened, $n=2974)$. Those screened in the control group $(n=2974)$ were excluded from the final analysis.

Age, mean: intervention 48.5 , control 48.5

$\%$ men: $100 \%$

Angina: intervention $4.3 \%$, control $4.2 \%$

Ischaemic ECG changes: intervention $6.6 \%$, control 5.8\%

Mean plasma cholesterol, mmol/l: intervention 5.58, control 5.61

Mean BMI: intervention 25.5, control 25.4 
WHO 1986 (Continued)

Intervention group only: ECG changes relating to cardiac disease (major Q/QS changes) $1.09 \%$ (SEM \pm 0.06 , age-adjusted prevalence rates); Age-adjusted prevalence: possible infarction (8.9\%), intermittent claudication (1.4\%)

Between 13\% - 23\% (average 17\%) of men in the different intervention centres were classified as having high risk levels and received the more individual advice.

Setting: Intervention provided by the research teams in the workplace

Intervention: All men in the intervention factories invited to a cardiovascular examination (BP, plas$\mathrm{ma}$ /serum cholesterol, smoking, weight, exercise). Those with the highest levels of multifactor risks received more individual advice (including personal consultations with physicians) as follows:

- Cholesterol-lowering dietary advice for all

- Smoking cessation advice for smokers of $5+$ cigarettes a day

- Weight reduction advice for those $15 \%+$ overweight

- Daily exercise advice for those classified as "sedentary"

- Control of hypertension with drugs for those with a mean SBP $160 \mathrm{mmHg}+$

$5 \%$ random sample re-examined annually

A general campaign of risk factor modification was supported by posters, brochures, personal letters, progress charts and group discussions

Control: No intervention. A random $10 \%$ were invited for initial screening, and the same men asked to return for screening at 2 and 4 years, and again at the end of the trial (between 5 and 6 years); these men were excluded from incidence and mortality estimates. The $90 \%$ who were not examined formed the at-risk population for incidence measurements.

At the end of follow-up, all in both the intervention and control groups were invited for examination.

Outcomes

Total mortality, fatal coronary heart disease, non-fatal MI, cardiovascular morbidity (fatal CHD + nonfatal MI)

\section{Notes}

All participants were included in analysis for mortality, but not for morbidity (men who left employment were excluded)

\section{Risk of bias}

\begin{tabular}{|c|c|c|}
\hline Bias & Authors' judgement & Support for judgement \\
\hline $\begin{array}{l}\text { Random sequence genera- } \\
\text { tion (selection bias) }\end{array}$ & Unclear risk & $\begin{array}{l}\text { Factories were arranged in matched pairs (matching variables not mentioned), } \\
\text { and the factories within each pair were randomised to intervention or control } \\
\text { (method of randomisation not stated) }\end{array}$ \\
\hline $\begin{array}{l}\text { Allocation concealment } \\
\text { (selection bias) }\end{array}$ & Unclear risk & Not reported \\
\hline $\begin{array}{l}\text { Blinding of participants } \\
\text { and personnel (perfor- } \\
\text { mance bias) } \\
\text { All outcomes }\end{array}$ & Unclear risk & $\begin{array}{l}\text { Control group not informed about trial, } 10 \% \text { in control factories were } \\
\text { screened, so potential for awareness in control group. Not reported for per- } \\
\text { sonnel or intervention group }\end{array}$ \\
\hline $\begin{array}{l}\text { Blinding of outcome as- } \\
\text { sessment (detection bias) } \\
\text { All outcomes }\end{array}$ & Low risk & $\begin{array}{l}\text { Outcomes were reviewed by investigators and classified according to WHO } \\
\text { Registry criteria. But lack of blinding unlikely to have biased the objective out- } \\
\text { comes }\end{array}$ \\
\hline
\end{tabular}


WHO 1986 (Continued)

Incomplete outcome data Low risk Survival status at end of trial established in $99.8 \%$

(attrition bias)

All outcomes

\begin{tabular}{|c|c|c|}
\hline $\begin{array}{l}\text { Selective reporting (re- } \\
\text { porting bias) }\end{array}$ & High risk & $\begin{array}{l}\text { Primary outcomes of trial reported, but other outcomes such as cholesterol } \\
\text { and BMI were measured but not reported }\end{array}$ \\
\hline
\end{tabular}

Other bias Unclear risk Unclear

Wilhelmsen 1986

Design: RCT
Setting: Participants selected from all men living in Gothenburg, Sweden, and born either between
$1915-1922$ or $1924-1925$, age $47-55$ years at start of study
Dates: Initial screening done 1970 - 1973; 2nd screening (At 4 years) done 1974 - 1977; final examination
(10 year) done 1980 - 1983

Follow-up: 2nd examination after 4 years for all of intervention group $(n=7517)$ and $11 \%$ random sample of control group $1(n=826)$

Final assessment at 10 years, new $20 \%$ random samples of intervention were invited. Of these, 1473 in intervention group and 1404 in control group 1 participated.

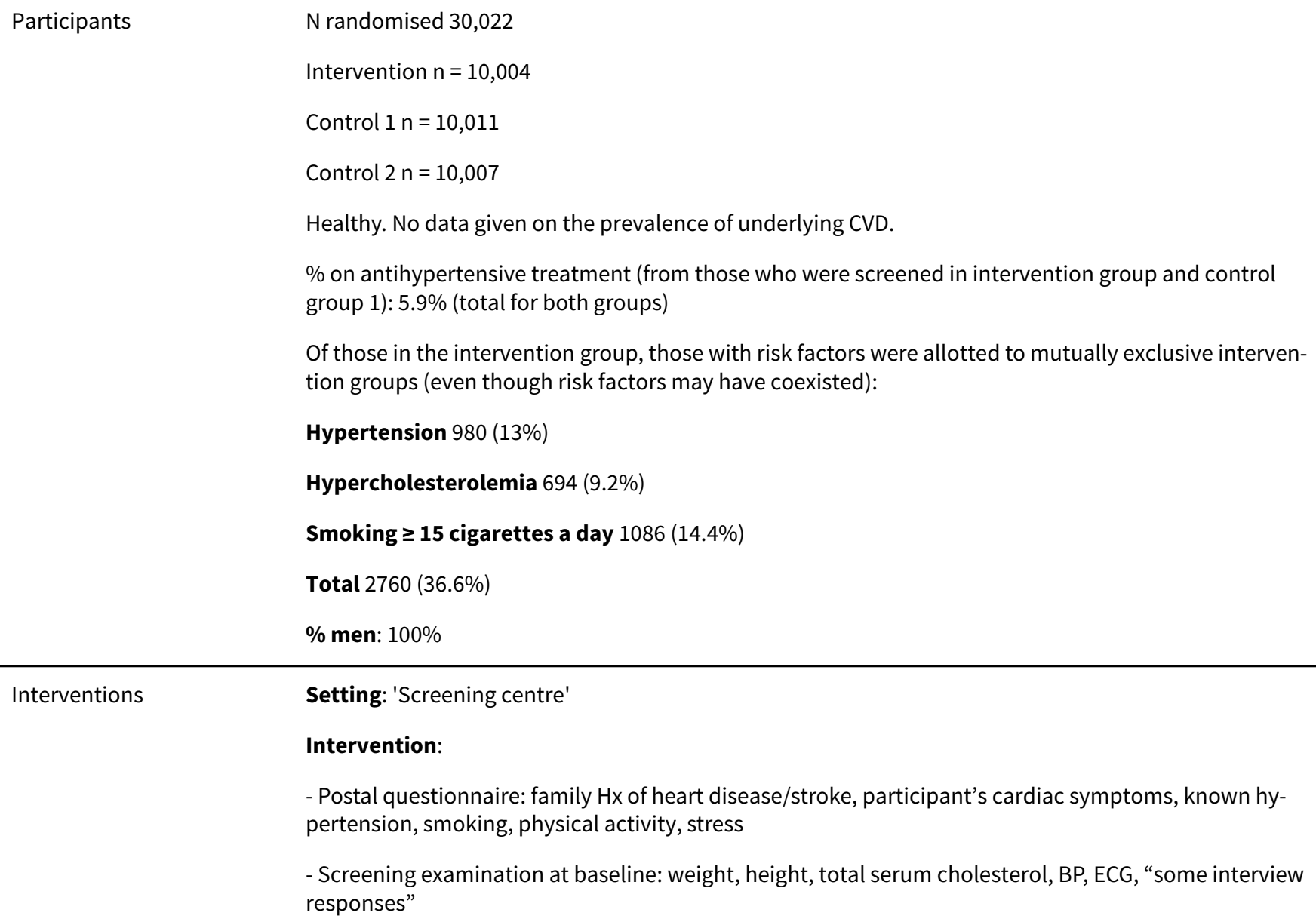

Of those in the intervention group, those with risk factors were allotted to mutually exclusive intervention groups (even though risk factors may have coexisted):

Hypertension 980 (13\%)

Hypercholesterolemia $694(9.2 \%)$

Smoking $\geq 15$ cigarettes a day $1086(14.4 \%)$

Total $2760(36.6 \%)$

\% men: $100 \%$

\section{Intervention:}

- Postal questionnaire: family Hx of heart disease/stroke, participant's cardiac symptoms, known hypertension, smoking, physical activity, stress

- Screening examination at baseline: weight, height, total serum cholesterol, BP, ECG, "some interview responses" 
- BP intervention (for BP $\geq 175 / 115 \mathrm{mmHg}$ ): referred to specialist clinic (for borderline high BP (160 - 174 SBP, 95 - 114 DBP), participants had regular BP checks)

- Cholesterol intervention (>7.8 mmol/l): diet information from dietician/physician, booklets. Clofibrate/nicotinic acid given if cholesterol remained elevated after 6 months. Men with cholesterol values at screening $6.8-7.7 \mathrm{mmol} / \mathrm{l}$ invited to group meetings together with wives, same material used. Those with values $<6.8 \mathrm{mmol} / \mathrm{l}$ received written information but no other action

- Smoking interventions: for $\geq 15 /$ day smokers, invited to anti-smoking clinic and nicotine gum. Other smokers given written information on smoking cessation

- Rescreening at 4 years

- Final screening in subgroup (20\%) at 10 years

Control group 1: No intervention. $2 \%$ of control group 1 had postal questionnaire and screening examination with no follow-up, $11 \%$ had 2 nd screening at 4 years, and $20 \%$ had the final exam at 10 years

Control group 2: none of the 2nd control group had the initial screening/2nd screening/final exam

\begin{tabular}{ll}
\hline Outcomes & Total mortality, stroke, MI, BP, attendance rates, case-finding rates \\
\hline Notes & "F/U complete for all subjects included" for the endpoints of the study (Fatal and non-fatal CHD and \\
stroke, cancer deaths, other deaths, and total mortality), but not all those who were invited for screen- \\
ing attended.
\end{tabular}

\section{Risk of bias}

\begin{tabular}{lll}
\hline Bias & Authors' judgement & Support for judgement \\
\hline $\begin{array}{l}\text { Random sequence genera- } \\
\text { tion (selection bias) }\end{array}$ & Unclear risk & Not reported \\
\hline $\begin{array}{l}\text { Allocation concealment } \\
\text { (selection bias) }\end{array}$ & Unclear risk & Not reported \\
\hline $\begin{array}{l}\text { Blinding of participants } \\
\text { and personnel (perfor- } \\
\text { mance bias) } \\
\text { All outcomes }\end{array}$ & Unclear risk & Not reported \\
\hline
\end{tabular}

\begin{tabular}{lll}
\hline $\begin{array}{l}\text { Blinding of outcome as- } \\
\text { sessment (detection bias) } \\
\text { All outcomes }\end{array}$ & Low risk & Not reported, but outcomes objective so low risk of bias \\
\hline $\begin{array}{l}\text { Incomplete outcome data } \\
\text { (attrition bias) } \\
\text { All outcomes }\end{array}$ & Unclear risk & $\begin{array}{l}\text { Reported proportion invited for assessment at 4 and 20 years, but numbers de- } \\
\text { clining invitation not clear }\end{array}$ \\
\hline $\begin{array}{l}\text { Selective reporting (re- } \\
\text { porting bias) }\end{array}$ & High risk & $\begin{array}{l}\text { No measures of variance reported, baselines not reported for intervention } \\
\text { group and control group 1 separately, Numbers unclear }\end{array}$ \\
\hline Other bias & Unclear risk & Unclear \\
\hline
\end{tabular}

BMI: body mass index

CABG: coronary artery bypass graft

CCF: congestive cardiac failure

CHD: congenital heart disease 
CHF: congestive heart failure DBP: diastolic blood pressure

DM: diabetes mellitus

ECG: electrocardiograph

HTN: hypertension

$\mathrm{Hx}$ : history

IHD: ischaemic heart disease

MI: myocardial infarction

SBP: systolic blood pressure

SEM: standardised error of the mean

Characteristics of excluded studies [ordered by study ID]

\begin{tabular}{|c|c|}
\hline Study & Reason for exclusion \\
\hline Boylan 2003 & No control \\
\hline Grunfeld 2013 & Intervention not systematic risk assessment \\
\hline Göteborg 1963 & $\begin{array}{l}\text { In Cochrane review of general health checks (Krogsbøll 2012), but excluded here as it does not fo- } \\
\text { cus on systematic risk assessment for the primary prevention of CVD }\end{array}$ \\
\hline Holt 2010 & Intervention not systematic risk assessment \\
\hline Jacobson 2006 & No control \\
\hline Kaiser Permanente 1965 & $\begin{array}{l}\text { In Cochrane review of general health checks (Krogsbøll 2012), but excluded here as it does not fo- } \\
\text { cus on systematic risk assessment for the primary prevention of CVD }\end{array}$ \\
\hline Koelewijn-van Loon 2010 & No control \\
\hline Malmö 1969 & $\begin{array}{l}\text { In Cochrane review of general health checks (Krogsbøll 2012), but excluded here as it does not fo- } \\
\text { cus on systematic risk assessment for the primary prevention of CVD }\end{array}$ \\
\hline New York 1971 & $\begin{array}{l}\text { In Cochrane review of general health checks (Krogsbøll 2012), but excluded here as it does not fo- } \\
\text { cus on systematic risk assessment for the primary prevention of CVD }\end{array}$ \\
\hline Northumberland 1969 & $\begin{array}{l}\text { In Cochrane review of general health checks (Krogsbøll 2012), but excluded here as it does not fo- } \\
\text { cus on systematic risk assessment for the primary prevention of CVD }\end{array}$ \\
\hline Ogedegbe 2014 & Intervention not systematic risk assessment \\
\hline Salt Lake City 1972 & $\begin{array}{l}\text { In Cochrane review of general health checks (Krogsbøll 2012), but excluded here as it does not fo- } \\
\text { cus on systematic risk assessment for the primary prevention of CVD }\end{array}$ \\
\hline South-East London 1967 & $\begin{array}{l}\text { In Cochrane review of general health checks (Krogsbøll 2012), but excluded here as it does not fo- } \\
\text { cus on systematic risk assessment for the primary prevention of CVD }\end{array}$ \\
\hline Stockholm 1969 & $\begin{array}{l}\text { In Cochrane review of general health checks (Krogsbøll 2012), but excluded here as it does not fo- } \\
\text { cus on systematic risk assessment for the primary prevention of CVD }\end{array}$ \\
\hline Titograd 1971 & $\begin{array}{l}\text { In Cochrane review of general health checks (Krogsbøll 2012), but excluded here as it does not fo- } \\
\text { cus on systematic risk assessment for the primary prevention of CVD }\end{array}$ \\
\hline Vagholkar 2014 & No control \\
\hline Voogdt-Pruis 2010 & No control \\
\hline
\end{tabular}


Characteristics of ongoing studies [ordered by study ID]

Badenbroek 2014

\begin{tabular}{|c|c|}
\hline Trial name or title & INTEGRATE Study \\
\hline Methods & Stepped-wedge randomised control trial \\
\hline \multirow[t]{5}{*}{ Participants } & Inclusion Criteria \\
\hline & - Men and women aged 45 to 70 years \\
\hline & Exclusion Criteria \\
\hline & - Previous diagnosis of cardiometabolic disease \\
\hline & - Receiving antihypertensive or lipid-lowering treatment \\
\hline Interventions & $\begin{array}{l}\text { The intervention programme "Personalised Prevention Approach for Cardiometabolic Risk" com- } \\
\text { bines screening for cardiometabolic risk with a tailored lifestyle intervention programme. The con- } \\
\text { trol group will receive the intervention at the end of the study period of } 12 \text { months. }\end{array}$ \\
\hline \multirow[t]{10}{*}{ Outcomes } & Primary outcomes: \\
\hline & - Number of newly-detected cases of cardiometabolic disease \\
\hline & $\begin{array}{l}\text { - Change in individual risk factors (e.g. smoking, physical inactivity, blood pressure, cholesterol lev- } \\
\text { els) }\end{array}$ \\
\hline & $\begin{array}{l}\text { - The expected number of newly-detected participants with CMD and mortality after 5, } 10 \text { and } 20 \\
\text { years }\end{array}$ \\
\hline & - Cost effectiveness of the programme \\
\hline & - Non-participation and compliance with the programme \\
\hline & Secondary outcomes: \\
\hline & - Measuring the effect of implementing different response-enhancing strategies \\
\hline & - Change in willingness to change lifestyle \\
\hline & - Change in health status \\
\hline
\end{tabular}

\begin{tabular}{ll}
\hline Starting date & 1st April 2014 \\
\hline Contact information & Professor N. J. de Wit \\
& Julius Health Centre \\
& UMC Utrecht \\
& Huispost Str. 6.131 \\
& PO Box 85500 \\
& 3508 GA Utrecht \\
& Netherlands \\
& N.J.deWit@umcutrecht.nl \\
\hline
\end{tabular}


Ijkema 2014

\begin{tabular}{|c|c|}
\hline Trial name or title & ROBINSCA (Risk Or Benefit IN Screening for CArdiovascular disease) \\
\hline Methods & A large-scale, population-based randomised, controlled trial \\
\hline Participants & $\begin{array}{l}\text { Approximately } 330,800 \text { men ( } 45-74 \text { years) and women ( } 55 \text { - } 74 \text { years) will be drawn from the gener- } \\
\text { al population living in the regions of Apeldoorn, Den Haag and Groningen (Netherlands) and invit- } \\
\text { ed to take part in the trial. An information package, informed consent form, risk questionnaire and } \\
\text { waist circumference tape are sent by post. The authors expect } 25 \% \text { ( } N=82,700 \text { ) to respond to the } \\
\text { questionnaire. Inclusion criteria for the study are persons without diagnosed CVD, but with a possi- } \\
\text { ble increased risk of CVD. The authors intend to randomise } 39,000 \text { people at increased risk for CVD } \\
\text { to } 1 \text { of } 3 \text { groups. }\end{array}$ \\
\hline
\end{tabular}

1. Intervention A - classic risk screening based on the Systematic COronary Risk Evaluation (SCORE) model

(lipids and blood pressure)

2. Intervention B - screening for coronary artery calcium using computed tomography (CT)

3. Control group - usual care (no screening)

Participants of all 3 groups will receive written general lifestyle advice. Participants in intervention group $A$ with an intermediate or high risk of CVD are referred to their general practitioner (GP) for lifestyle advice and if necessary, medication, following the Dutch College of GPs' standard 'Cardiovascular Risk Management'. Participants in intervention group B with a high or very high risk of CVD based on their coronary artery calcification (CAC) score are also referred to their GP and will be treated following the study protocol for the CAC score.

Outcomes All participants will be followed for 5 years. The primary outcome is cumulative 5 -year fatal and non-fatal coronary heart disease

\section{Starting date}

Contact information
Invitations to participate in the study will be sent in the first quarter of 2014. By March 2015 the first 5196 participants were randomised and enrolled in the study.

The principal investigator of the ROBINSCA study is Prof. Dr. H.J. de Koning, Professor of Evaluation of Screening of the Department of Public Health, Erasmus MC, Rotterdam. Contact the research team by e-mail (robinsca@erasmusmc.nl) or telephone (+31-10-7030084).

Notes The aim of this trial is to investigate whether early detection of the risk of cardiovascular diseases (CVD), quantified by either the classical risk score (SCORE) or a coronary artery calcium score (CT scan), will reduce morbidity and mortality from CVD in a high-risk population.

The ROBINSCA study is funded by the European Research Council. Further information, updates and publications will be posted on the study web site: www.robinsca.nl/for-researchers/study-design/ 
Marshall 2012

Trial name or title

The Sandwell Project. Mixed-methods evaluation of targeted case finding for cardiovascular disease prevention using a stepped-wedged cluster-RCT

\begin{tabular}{|c|c|}
\hline Methods & Stepped-wedged cluster-randomised controlled trial \\
\hline \multirow[t]{6}{*}{ Participants } & Inclusion Criteria \\
\hline & $\begin{array}{l}\text { - Men and women aged } 35 \text { to } 74 \text { not currently on cardiovascular or diabetes registers and who are } \\
\text { not currently receiving antihypertensive or statin therapy }\end{array}$ \\
\hline & $\begin{array}{l}\text { - Patients subsequently found to have an estimated } 10 \text {-year cardiovascular disease risk } \geq 20 \% \text { will } \\
\text { be selected }\end{array}$ \\
\hline & Exclusion Criteria \\
\hline & - Patients who had moved practice \\
\hline & - Judged by GP to be unsuitable for CVD prevention \\
\hline Interventions & $\begin{array}{l}\text { The intervention is a risk assessment, followed by targeted pharmacological and lifestyle manage- } \\
\text { ment. All clusters will receive the intervention at some point over an 18-month period, with the pe- } \\
\text { riod before intervention being the control period. }\end{array}$ \\
\hline \multirow[t]{7}{*}{ Outcomes } & Primary outcomes: \\
\hline & $\begin{array}{l}\text { - Number of high-risk participants started on at least one preventative treatment (antihypertensive } \\
\text { or statin) }\end{array}$ \\
\hline & Secondary outcomes: \\
\hline & - Number of participants who have cardiovascular risk factors assessed \\
\hline & $\begin{array}{l}\text { - Number of participants referred to services for lifestyle advice (e.g. smoking cessation, physical } \\
\text { activity) }\end{array}$ \\
\hline & - Changes in cardiovascular risk factors (blood pressure, lipid levels) \\
\hline & - Cardiovascular events \\
\hline Starting date & 1st May 2009 \\
\hline \multirow[t]{8}{*}{ Contact information } & T.P. Marshall \\
\hline & School of Health and Population Sciences \\
\hline & University of Birmingham \\
\hline & Edgbaston, \\
\hline & Birmingham, \\
\hline & UK \\
\hline & B15 2TT \\
\hline & T.P.Marshall@bham.ac.uk \\
\hline \multirow[t]{2}{*}{ Notes } & Registered clinical trial no.: ISRCTN32114200 \\
\hline & Listed as "completed" on 17th July 2013 \\
\hline
\end{tabular}


Muntendam 2012

\begin{tabular}{|c|c|}
\hline Trial name or title & Biolmage Study \\
\hline Methods & Randomised parallel-group controlled trial \\
\hline \multirow[t]{8}{*}{ Participants } & Inclusion Criteria \\
\hline & - Men aged 55 - 80 years, women aged 60 - 80 years \\
\hline & - Resident in Chicago, Illinois; Fort Lauderdale, Florida; and surrounding areas \\
\hline & - Registered with Humana, a private medical insurance company \\
\hline & Exclusion Criteria \\
\hline & - History of cardiovascular disease (cardiovascular risk factors allowed) \\
\hline & - Active treatment of cancer \\
\hline & $\begin{array}{l}\text { - Any serious medical condition precluding long-term participation or inability to complete 3-year } \\
\text { follow-up (e.g. dementia, cognitive impairment, advanced COPD) }\end{array}$ \\
\hline Interventions & $\begin{array}{l}\text { Participants will be randomised into } 1 \text { of } 3 \text { arms: (1) control group (telephone survey); (2) a risk as- } \\
\text { sessment group (who have physical parameters measured, including weight, blood pressure and } \\
\text { ECG); and (3) an imaging group, who have a risk assessment as in arm (2), as well as an imaging as- } \\
\text { sessment for subclinical atherosclerosis }\end{array}$ \\
\hline \multirow[t]{5}{*}{ Outcomes } & Primary outcomes: \\
\hline & - Identify imaging biomarkers that predict near-term (3-year) atherothrombotic events \\
\hline & Secondary outcomes of relevance include: \\
\hline & - Compare event rates in participants in each group \\
\hline & $\begin{array}{l}\text { Development of an economic and health impact model in the primary prevention of cardiovascu- } \\
\text { lar disease }\end{array}$ \\
\hline Starting date & January 2008 \\
\hline \multirow[t]{6}{*}{ Contact information } & Valentin Fuster \\
\hline & Mount Sinai School of Medicine \\
\hline & Floor 1 \\
\hline & 1190 Fifth Avenue \\
\hline & New York \\
\hline & valentin.fuster@mssm.edu \\
\hline \multirow[t]{3}{*}{ Notes } & Registered clinical trial no.: NCT00738725 \\
\hline & Study marked as "completed" on 26th January 2015 \\
\hline & Completion date: December 2014 \\
\hline
\end{tabular}


Wan 2009

\begin{tabular}{|c|c|}
\hline Trial name or title & ART (Absolute Risk Trial) \\
\hline Methods & Cluster-randomised controlled trial of 32 primary care practices \\
\hline \multirow[t]{2}{*}{ Participants } & Men and women aged 45 - 69 inclusive without existing CVD \\
\hline & Attended the practice in the previous 12 months \\
\hline Interventions & $\begin{array}{l}\text { Those patients in the intervention practices will complete a self-assessment form and have a 15- } \\
\text { minute GP appointment to perform a cardiovascular risk assessment and discuss the results. The } \\
\text { results will be used to guide further management of risk factors. The control practice patients will } \\
\text { receive usual general practice care of their risk factors. }\end{array}$ \\
\hline \multirow[t]{9}{*}{ Outcomes } & Primary outcomes: \\
\hline & - Prescribing of medications \\
\hline & - Physiological risk (e.g. blood pressure, blood lipids) \\
\hline & - Lifestyle risk factors (e.g. smoking status and diet) \\
\hline & Secondary outcomes: \\
\hline & - Cardiovascular absolute risk \\
\hline & - Referrals to dietician, exercise programme, smoking cessation programme \\
\hline & - Patient response and activation \\
\hline & Follow-up : 12 months \\
\hline Starting date & 1st July 2008 \\
\hline \multirow[t]{7}{*}{ Contact information } & Mark F. Harris \\
\hline & Centre for Primary Health Care and Equity, \\
\hline & School of Public Health and Community Medicine, \\
\hline & University of New South Wales, \\
\hline & Australia \\
\hline & +61293852511 \\
\hline & m.f.harris@unsw.edu.au \\
\hline \multirow[t]{2}{*}{ Notes } & Registered clinical trial no.: ACTRN12608000387325 \\
\hline & Final results expected late 2010 \\
\hline
\end{tabular}

\section{DATA AND ANALYSES}


Comparison 1. Systematic screening vs no/opportunistic screening

\begin{tabular}{|c|c|c|c|c|}
\hline Outcome or subgroup title & $\begin{array}{l}\text { No. of } \\
\text { studies }\end{array}$ & $\begin{array}{l}\text { No. of } \\
\text { partici- } \\
\text { pants }\end{array}$ & Statistical method & Effect size \\
\hline 1 All-cause mortality & 3 & 103571 & Risk Ratio (M-H, Fixed, 95\% Cl) & $0.98[0.93,1.03]$ \\
\hline $\begin{array}{l}2 \text { Outcomes in residents admitted to } \\
\text { hospital per } 1000 \text { (post-intervention } \\
\text { rate) }\end{array}$ & & & Other data & No numeric data \\
\hline 3 Cardiovascular mortality & 2 & 43955 & Risk Ratio (M-H, Fixed, 95\% Cl) & $1.00[0.90,1.11]$ \\
\hline 4 Mortality due to stroke & 1 & & Risk Ratio (M-H, Fixed, 95\% Cl) & Totals not selected \\
\hline 5 Stroke (total) & 2 & 79631 & Risk Ratio (M-H, Fixed, 95\% Cl) & $0.99[0.90,1.10]$ \\
\hline 6 Coronary heart disease (total) & 5 & 110168 & Risk Ratio (M-H, Fixed, 95\% Cl) & $1.01[0.95,1.07]$ \\
\hline 7 Non-fatal coronary heart disease & 2 & 43955 & Risk Ratio (M-H, Fixed, 95\% Cl) & $0.98[0.89,1.09]$ \\
\hline 8 Non-fatal stroke & 1 & & Risk Ratio (M-H, Fixed, 95\% Cl) & Totals not selected \\
\hline 9 Total cholesterol, mmol/l & 7 & 12591 & $\begin{array}{l}\text { Mean Difference (IV, Random, 95\% } \\
\text { Cl) }\end{array}$ & $-0.11[-0.17,-0.04]$ \\
\hline $10 \mathrm{HDL}$ cholesterol, mmol/l & 1 & & Mean Difference (IV, Fixed, 95\% CI) & Totals not selected \\
\hline 11 LDL cholesterol, mmol/l & 1 & & Mean Difference (IV, Fixed, 95\% CI) & Totals not selected \\
\hline 12 Triglycerides, $\mathrm{mmol} / \mathrm{l}$ & 1 & & Mean Difference (IV, Fixed, 95\% CI) & Totals not selected \\
\hline 13 Systolic blood pressure, $\mathrm{mmHg}$ & 7 & 12591 & $\begin{array}{l}\text { Mean Difference (IV, Random, 95\% } \\
\mathrm{CI} \text { ) }\end{array}$ & $-3.05[-4.84,-1.25]$ \\
\hline 14 Diastolic blood pressure, $\mathrm{mmHg}$ & 7 & 12591 & Mean Difference (IV, Fixed, 95\% Cl) & $-1.34[-1.76,-0.93]$ \\
\hline $\begin{array}{l}15 \text { Number with elevated choles- } \\
\text { terol }\end{array}$ & 5 & 7685 & Risk Ratio (M-H, Random, 95\% Cl) & $0.66[0.48,0.89]$ \\
\hline 16 Number with elevated SBP & 1 & & Risk Ratio (M-H, Fixed, 95\% Cl) & Totals not selected \\
\hline 17 Number with elevated DBP & 4 & 7221 & Risk Ratio (M-H, Fixed, 95\% Cl) & $0.68[0.61,0.76]$ \\
\hline 18 Number with diabetes & 2 & 2007 & Risk Ratio (M-H, Fixed, 95\% Cl) & $1.37[1.04,1.81]$ \\
\hline $\begin{array}{l}19 \text { Number with elevated cardiovas- } \\
\text { cular risk score }\end{array}$ & 1 & & Risk Ratio (M-H, Fixed, 95\% Cl) & Totals not selected \\
\hline 20 Attendance rates & & & Other data & No numeric data \\
\hline
\end{tabular}


Analysis 1.1. Comparison 1 Systematic screening vs no/opportunistic screening, Outcome 1 All-cause mortality.

\begin{tabular}{|c|c|c|c|c|c|}
\hline Study or subgroup & $\begin{array}{c}\text { Screening } \\
n / N\end{array}$ & $\begin{array}{c}\text { Control } \\
n / N\end{array}$ & $\begin{array}{c}\text { Risk Ratio } \\
\text { M-H, Fixed, } 95 \% \mathrm{CI}\end{array}$ & Weight & $\begin{array}{c}\text { Risk Ratio } \\
\text { M-H, Fixed, 95\% Cl }\end{array}$ \\
\hline Inter99 2014 & $595 / 11629$ & $2568 / 47987$ & \begin{tabular}{l|l}
+1 \\
\end{tabular} & $35.41 \%$ & $0.96[0.88,1.04]$ \\
\hline WHO 1986 & $552 / 12703$ & $494 / 11237$ & * & $18.53 \%$ & $0.99[0.88,1.11]$ \\
\hline Wilhelmsen 1986 & $1293 / 10004$ & $1304 / 10011$ & & $46.07 \%$ & $0.99[0.92,1.07]$ \\
\hline Total $(95 \% \mathrm{Cl})$ & 34336 & 69235 & & $100 \%$ & $0.98[0.93,1.03]$ \\
\hline \multicolumn{6}{|c|}{ Heterogeneity: $\mathrm{Tau}^{2}=0 ; \mathrm{Chi}^{2}=0.45, \mathrm{df}=2(\mathrm{P}=0.8) ; \mathrm{I}^{2}=0 \%$} \\
\hline Test for overall effec & & & & & \\
\hline
\end{tabular}

Analysis 1.2. Comparison 1 Systematic screening vs no/opportunistic screening, Outcome 2 Outcomes in residents admitted to hospital per 1000 (post-intervention rate).

\begin{tabular}{|c|c|c|c|c|}
\hline \multicolumn{5}{|c|}{ Outcomes in residents admitted to hospital per 1000 (post-intervention rate) } \\
\hline Study & Admission & Intervention & Control & Rate ratio $(95 \% \mathrm{Cl}), \mathrm{P}$ value \\
\hline CHAPS 2011 & Residents admitted & 69,942 & 75,499 & $\mathrm{n} / \mathrm{a}$ \\
\hline CHAPS 2011 & $\begin{array}{l}\text { Composite (acute MI, stroke, } \\
\text { CHF) }\end{array}$ & 23.43 & 24.22 & 0.95 (0.89 to 1.02$), 0.13$ \\
\hline CHAPS 2011 & Acute MI & 8.17 & 9.34 & 0.89 (0.79 to 0.99$), 0.03$ \\
\hline CHAPS 2011 & Congestive heart failure & 8.85 & 9.31 & 0.97 (0.87 to 1.08$), 0.59$ \\
\hline CHAPS 2011 & Stroke & 7.23 & 6.56 & 1.01 (0.89 to 1.15$), 0.87$ \\
\hline CHAPS 2011 & In-hospital death from CVD & 3.88 & 4.66 & 0.86 (0.73 to 1.01$), 0.06$ \\
\hline CHAPS 2011 & All-cause mortality & 33.98 & 34.55 & 0.98 (0.92 to 1.03 ), 0.38 \\
\hline CHAPS 2011 & $\begin{array}{l}\text { Anti-hypertensive treatment } \\
\text { started }\end{array}$ & 16.35 & 15.31 & 1.10 (1.02 to 1.20$), 0.02$ \\
\hline
\end{tabular}

Analysis 1.3. Comparison 1 Systematic screening vs no/ opportunistic screening, Outcome 3 Cardiovascular mortality.

\begin{tabular}{|c|c|c|c|c|c|}
\hline Study or subgroup & $\begin{array}{c}\text { Screening } \\
\mathrm{n} / \mathrm{N}\end{array}$ & $\begin{array}{c}\text { Control } \\
\mathrm{n} / \mathrm{N}\end{array}$ & $\begin{array}{c}\text { Risk Ratio } \\
\text { M-H, Fixed, 95\% Cl }\end{array}$ & Weight & $\begin{array}{c}\text { Risk Ratio } \\
\text { M-H, Fixed, 95\% Cl }\end{array}$ \\
\hline WHO 1986 & $178 / 12703$ & $166 / 11237$ & $\longrightarrow$ & $28.01 \%$ & $0.95[0.77,1.17]$ \\
\hline Wilhelmsen 1986 & $462 / 10004$ & $453 / 10011$ & & $71.99 \%$ & $1.02[0.9,1.16]$ \\
\hline Total $(95 \% \mathrm{CI})$ & 22707 & 21248 & & $100 \%$ & $1[0.9,1.11]$ \\
\hline \multicolumn{6}{|c|}{ Total events: 640 (Screening), 619 (Control) } \\
\hline Test for overall effect & & & & & \\
\hline
\end{tabular}


Analysis 1.4. Comparison 1 Systematic screening vs no/opportunistic screening, Outcome 4 Mortality due to stroke.

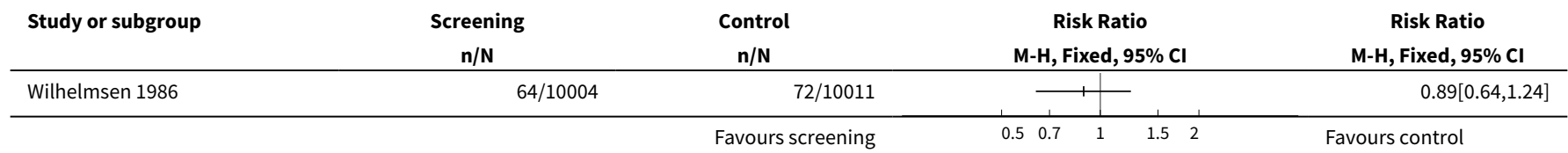

Analysis 1.5. Comparison 1 Systematic screening vs no/opportunistic screening, Outcome 5 Stroke (total).

\begin{tabular}{|c|c|c|c|c|c|}
\hline Study or subgroup & $\begin{array}{c}\text { Screening } \\
n / N\end{array}$ & $\begin{array}{c}\text { Control } \\
n / N\end{array}$ & $\begin{array}{c}\text { Risk Ratio } \\
\text { M-H, Fixed, 95\% Cl }\end{array}$ & Weight & $\begin{array}{c}\text { Risk Ratio } \\
\text { M-H, Fixed, 95\% Cl }\end{array}$ \\
\hline Inter99 2014 & $326 / 11629$ & $1400 / 47987$ & \begin{tabular}{l|l}
+1 & \\
\end{tabular} & $73.6 \%$ & $0.96[0.85,1.08]$ \\
\hline Wilhelmsen 1986 & $211 / 10004$ & $196 / 10011$ & $\longrightarrow$ & $26.4 \%$ & $1.08[0.89,1.31]$ \\
\hline Total $(95 \% \mathrm{Cl})$ & 21633 & 57998 & & $100 \%$ & $0.99[0.9,1.1]$ \\
\hline \multicolumn{6}{|c|}{ Total events: 537 (Screening), 1596 (Control) } \\
\hline \multicolumn{6}{|c|}{ Heterogeneity: $\mathrm{Tau}^{2}=0 ; \mathrm{Chi}^{2}=0.98, \mathrm{df}=1(\mathrm{P}=0.32) ; \mathrm{I}^{2}=0 \%$} \\
\hline \multicolumn{6}{|c|}{ Test for overall effect: $Z=0.16(P=0.87)$} \\
\hline
\end{tabular}

Analysis 1.6. Comparison 1 Systematic screening vs no/ opportunistic screening, Outcome 6 Coronary heart disease (total).

\begin{tabular}{|c|c|c|c|c|c|}
\hline Study or subgroup & $\begin{array}{c}\text { Screening } \\
\mathrm{n} / \mathrm{N}\end{array}$ & $\begin{array}{c}\text { Control } \\
n / N\end{array}$ & $\begin{array}{c}\text { Risk Ratio } \\
\text { M-H, Fixed, 95\% CI }\end{array}$ & Weight & $\begin{array}{c}\text { Risk Ratio } \\
\text { M-H, Fixed, 95\% Cl }\end{array}$ \\
\hline BFHS Men & $75 / 1262$ & $162 / 2514$ & & $4.9 \%$ & $0.92[0.71,1.2]$ \\
\hline BFHS Women & $18 / 951$ & $24 / 1870$ & & $0.73 \%$ & $1.47[0.8,2.7]$ \\
\hline Inter99 2014 & $565 / 11629$ & $2217 / 47987$ & + & $39.13 \%$ & $1.05[0.96,1.15]$ \\
\hline WHO 1986 & $386 / 12703$ & $363 / 11237$ & $\because$ & $17.43 \%$ & $0.94[0.82,1.08]$ \\
\hline Wilhelmsen 1986 & $837 / 10004$ & $836 / 10011$ & & $37.81 \%$ & $1[0.91,1.1]$ \\
\hline Total $(95 \% \mathrm{Cl})$ & 36549 & 73619 & & $100 \%$ & $1.01[0.95,1.07]$ \\
\hline \multicolumn{6}{|c|}{ Total events: 1881 (Screening), 3602 (Control) } \\
\hline \multicolumn{6}{|c|}{ Heterogeneity: $\operatorname{Tau}^{2}=0 ; \mathrm{Chi}^{2}=3.73, \mathrm{df}=4(\mathrm{P}=0.44) ; \mathrm{I}^{2}=0 \%$} \\
\hline Test for overall effect & & & & & \\
\hline
\end{tabular}

Analysis 1.7. Comparison 1 Systematic screening vs no/ opportunistic screening, Outcome 7 Non-fatal coronary heart disease.

\begin{tabular}{|c|c|c|c|c|c|}
\hline Study or subgroup & $\begin{array}{c}\text { Screening } \\
\mathrm{n} / \mathrm{N}\end{array}$ & $\begin{array}{c}\text { Control } \\
n / N\end{array}$ & $\begin{array}{c}\text { Risk Ratio } \\
\text { M-H, Fixed, 95\% Cl }\end{array}$ & Weight & $\begin{array}{c}\text { Risk Ratio } \\
\text { M-H, Fixed, 95\% Cl }\end{array}$ \\
\hline WHO 1986 & $210 / 12703$ & $210 / 11237$ & \begin{tabular}{l|l}
$\mathbf{*}$ & \\
-
\end{tabular} & $31.31 \%$ & $0.88[0.73,1.07]$ \\
\hline Wilhelmsen 1986 & $501 / 10004$ & $489 / 10011$ & -2 & $68.69 \%$ & $1.03[0.91,1.16]$ \\
\hline Total $(95 \% \mathrm{Cl})$ & 22707 & 21248 & & $100 \%$ & $0.98[0.89,1.09]$ \\
\hline \multicolumn{6}{|c|}{ Total events: 711 (Screening), 699 (Control) } \\
\hline
\end{tabular}




\begin{tabular}{|c|c|c|c|c|c|}
\hline Study or subgroup & $\begin{array}{c}\text { Screening } \\
\mathrm{n} / \mathrm{N}\end{array}$ & $\begin{array}{c}\text { Control } \\
\mathrm{n} / \mathrm{N}\end{array}$ & $\begin{array}{c}\text { Risk Ratio } \\
\text { M-H, Fixed, } 95 \% \mathrm{CI}\end{array}$ & Weight & $\begin{array}{c}\text { Risk Ratio } \\
\text { M-H, Fixed, } 95 \% \mathrm{Cl}\end{array}$ \\
\hline $\begin{array}{l}\text { Heterogeneity: } \operatorname{Tau}^{2}=0 ; \mathrm{Chi}^{2}=1.65, \mathrm{df}= \\
\text { Test for overall effect: } \mathrm{Z}=0.36(\mathrm{P}=0.72)\end{array}$ & $P=0.2) ; I^{2}=39$ & & & & \\
\hline
\end{tabular}

Analysis 1.8. Comparison 1 Systematic screening vs no/opportunistic screening, Outcome 8 Non-fatal stroke.

\begin{tabular}{|c|c|c|c|c|c|c|}
\hline Study or subgroup & $\begin{array}{c}\text { Screening } \\
n / N\end{array}$ & $\begin{array}{c}\text { Control } \\
n / N\end{array}$ & \multicolumn{3}{|c|}{$\begin{array}{c}\text { Risk Ratio } \\
\text { M-H, Fixed, 95\% Cl }\end{array}$} & \multirow{2}{*}{$\begin{array}{c}\text { Risk Ratio } \\
\text { M-H, Fixed, 95\% Cl } \\
1.17[0.94,1.47]\end{array}$} \\
\hline Wilhelmsen 1986 & $164 / 10004$ & $140 / 10011$ & & & 1 & \\
\hline
\end{tabular}

Analysis 1.9. Comparison 1 Systematic screening vs no/ opportunistic screening, Outcome 9 Total cholesterol, mmol/l.

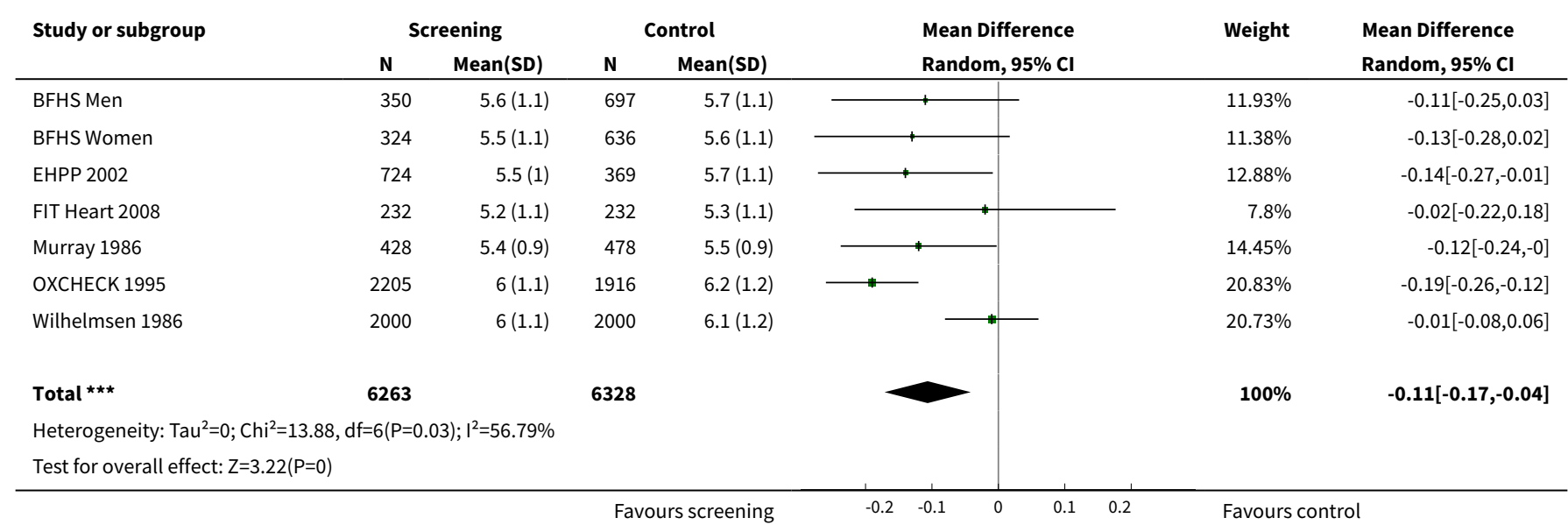

Analysis 1.10. Comparison 1 Systematic screening vs no/ opportunistic screening, Outcome $10 \mathrm{HDL}$ cholesterol, mmol/l.

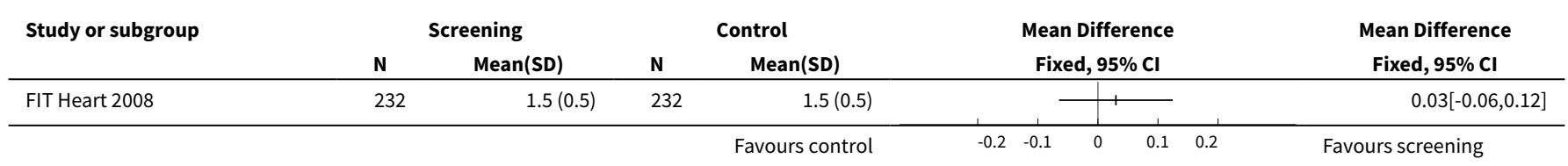


Analysis 1.11. Comparison 1 Systematic screening vs no/ opportunistic screening, Outcome 11 LDL cholesterol, mmol/l.

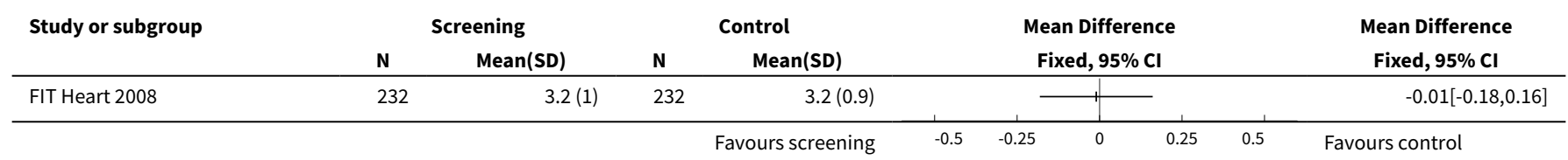

Analysis 1.12. Comparison 1 Systematic screening vs no/ opportunistic screening, Outcome 12 Triglycerides, mmol/l.

\begin{tabular}{|c|c|c|c|c|c|c|c|}
\hline \multirow{3}{*}{$\begin{array}{l}\text { Study or subgroup } \\
\text { FIT Heart } 2008\end{array}$} & \multicolumn{2}{|c|}{ Screening } & \multicolumn{2}{|c|}{ Control } & \multirow{2}{*}{\multicolumn{2}{|c|}{$\begin{array}{c}\text { Mean Difference } \\
\text { Fixed, } 95 \% \mathrm{Cl}\end{array}$}} & \multirow{3}{*}{$\begin{array}{c}\text { Mean Difference } \\
\text { Fixed, } 95 \% \mathbf{~ C l} \\
-0.07[-0.24,0.1]\end{array}$} \\
\hline & $\mathbf{N}$ & Mean(SD) & $\mathbf{N}$ & Mean(SD) & & & \\
\hline & 232 & $1.3(1)$ & 232 & $1.4(0.9)$ & 1 & \begin{tabular}{l|l} 
\\
\end{tabular} & \\
\hline
\end{tabular}

Analysis 1.13. Comparison 1 Systematic screening vs no/ opportunistic screening, Outcome 13 Systolic blood pressure, mmHg.

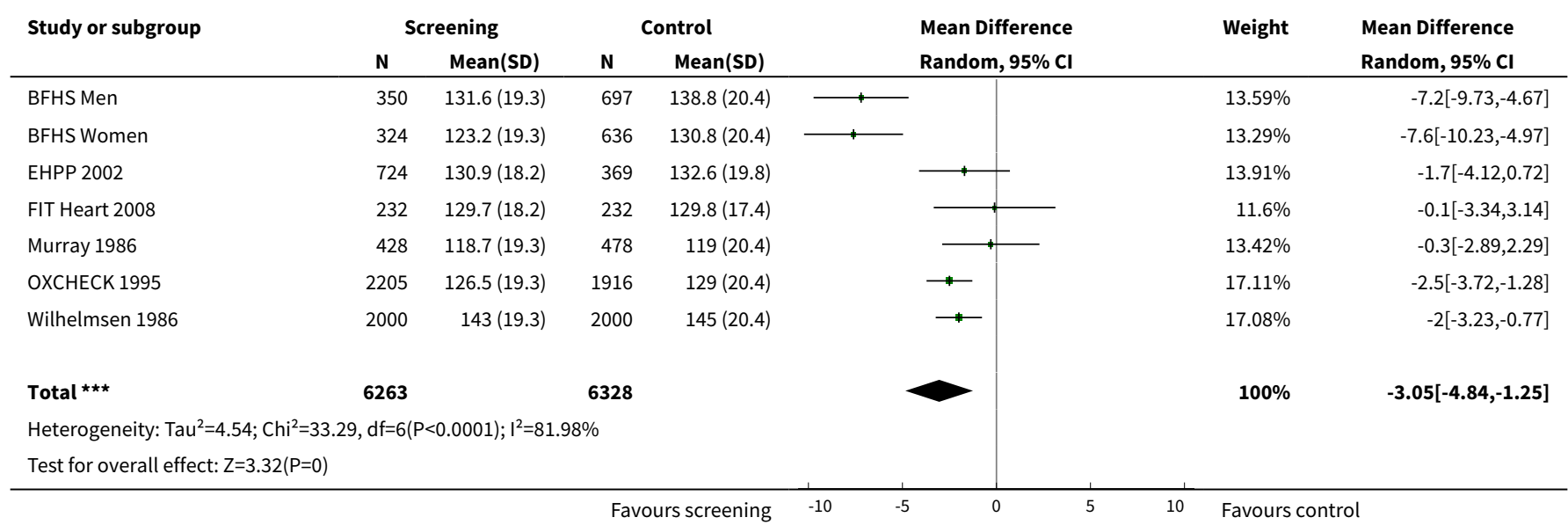

Analysis 1.14. Comparison 1 Systematic screening vs no/ opportunistic screening, Outcome 14 Diastolic blood pressure, $\mathrm{mmHg}$.

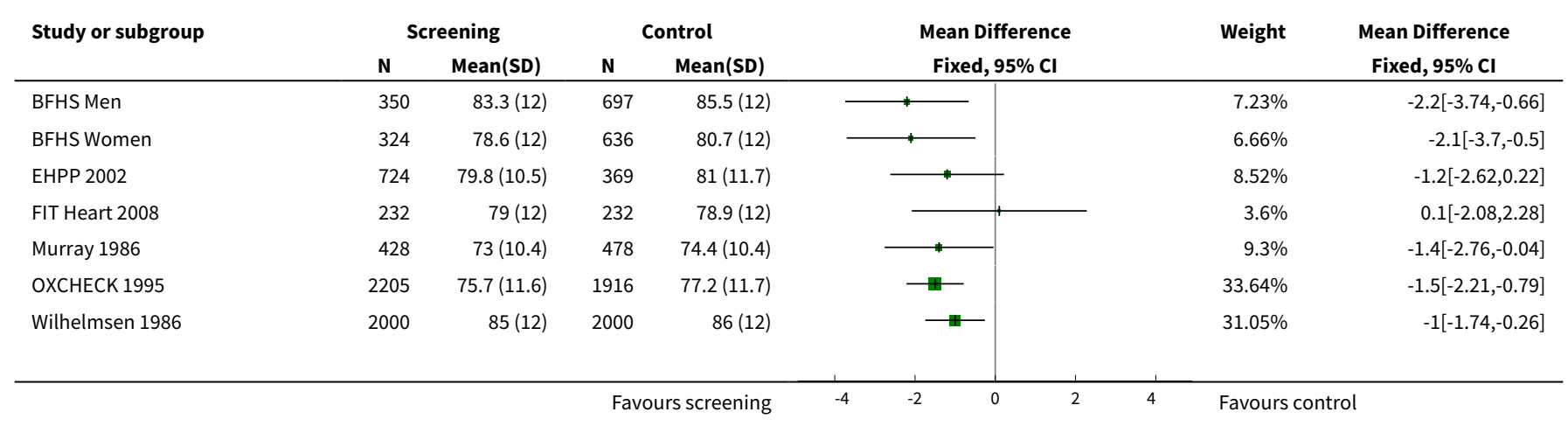




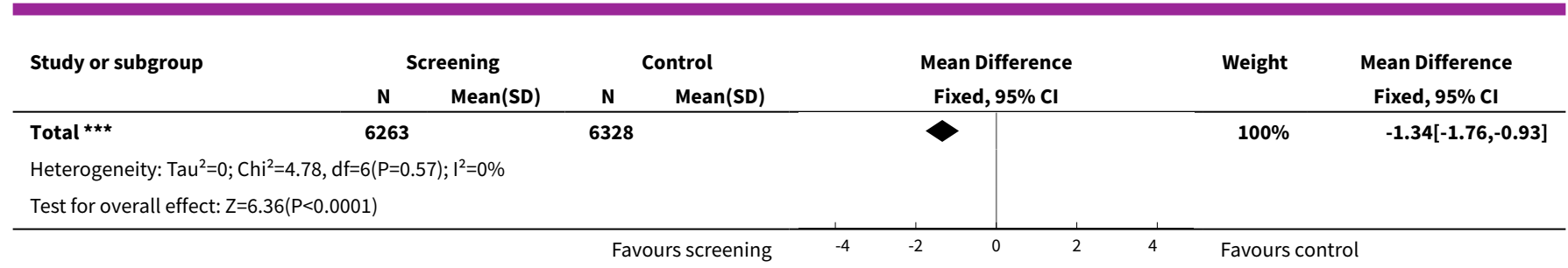

Analysis 1.15. Comparison 1 Systematic screening vs no/ opportunistic screening, Outcome 15 Number with elevated cholesterol.

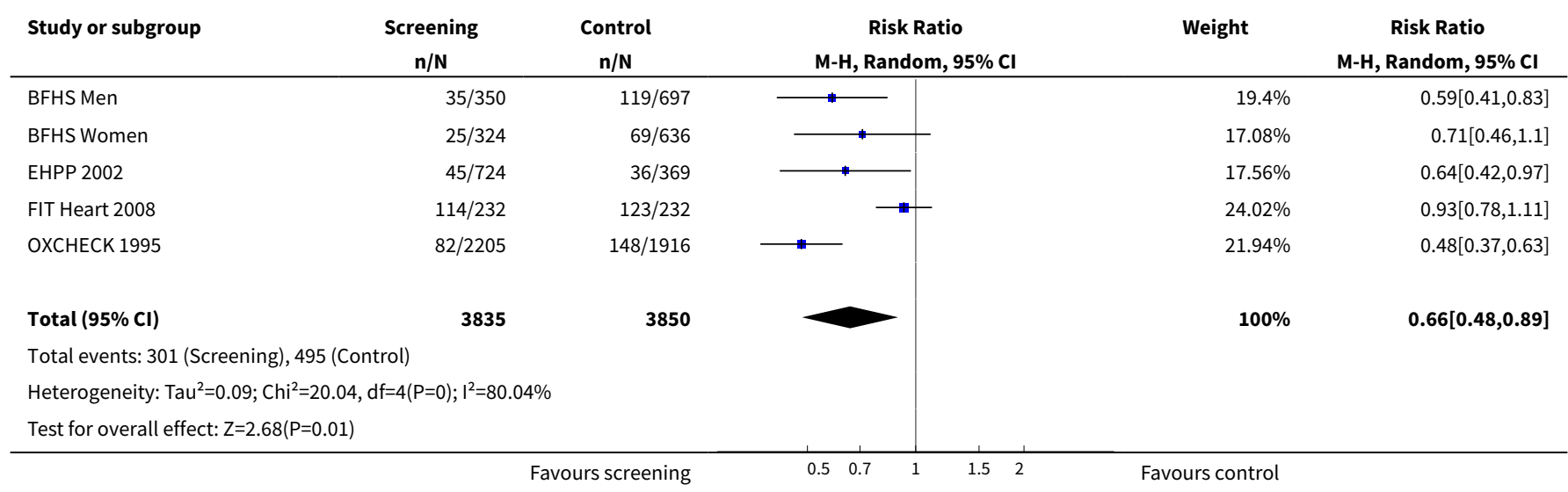

Analysis 1.16. Comparison 1 Systematic screening vs no/ opportunistic screening, Outcome 16 Number with elevated SBP.

\begin{tabular}{|c|c|c|c|c|}
\hline Study or subgroup & $\begin{array}{c}\text { Screening } \\
\mathrm{n} / \mathrm{N}\end{array}$ & $\begin{array}{c}\text { Control } \\
n / N\end{array}$ & $\begin{array}{c}\text { Risk Ratio } \\
\text { M-H, Fixed, } 95 \% \mathrm{Cl}\end{array}$ & $\begin{array}{c}\text { Risk Ratio } \\
\text { M-H, Fixed, 95\% Cl }\end{array}$ \\
\hline EHPP 2002 & $196 / 724$ & $114 / 369$ & \begin{tabular}{l|l}
+ & \\
\end{tabular} & $0.88[0.72,1.06]$ \\
\hline
\end{tabular}

Analysis 1.17. Comparison 1 Systematic screening vs no/ opportunistic screening, Outcome 17 Number with elevated DBP.

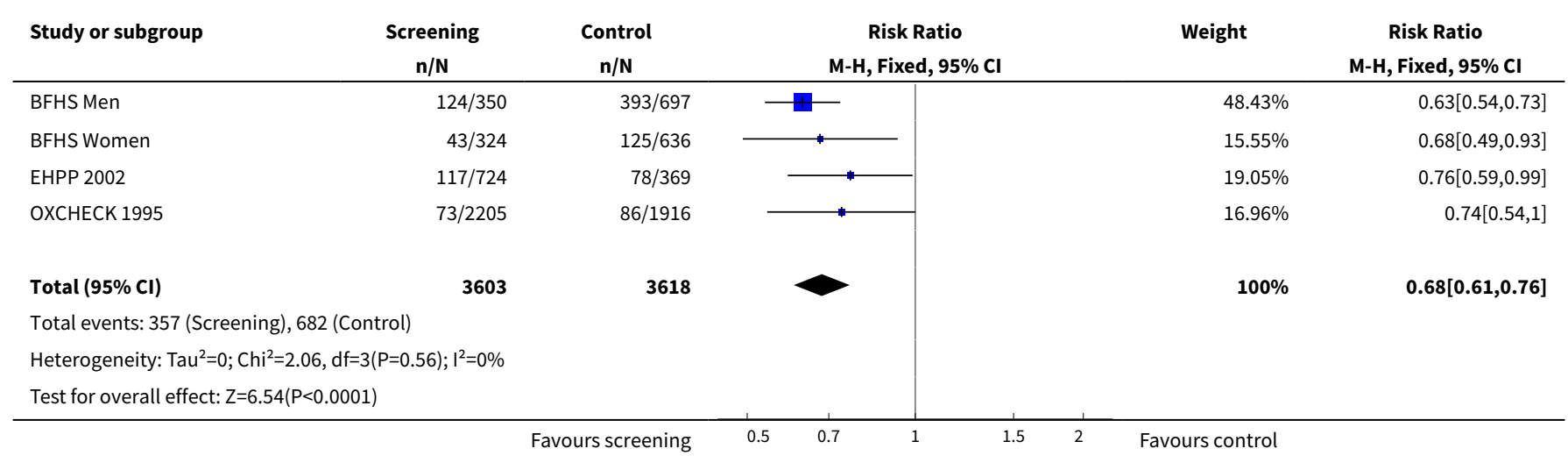


Analysis 1.18. Comparison 1 Systematic screening vs no/ opportunistic screening, Outcome 18 Number with diabetes.

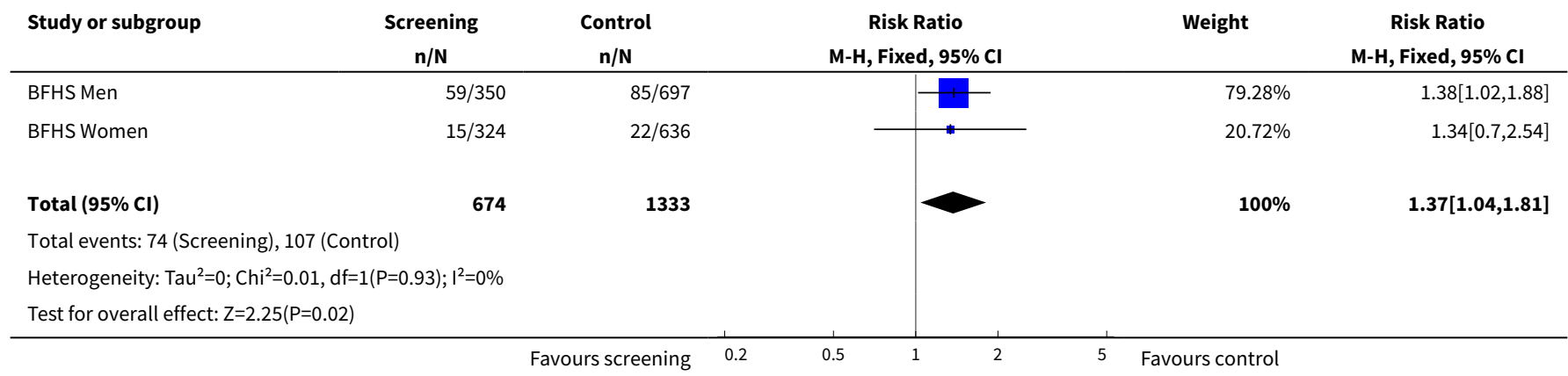

Analysis 1.19. Comparison 1 Systematic screening vs no/opportunistic screening, Outcome 19 Number with elevated cardiovascular risk score.

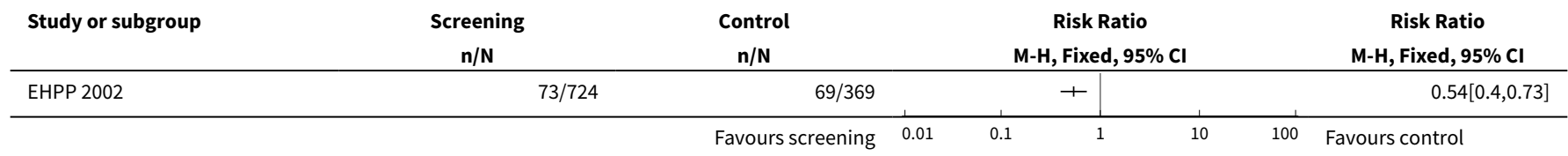

Analysis 1.20. Comparison 1 Systematic screening vs no/opportunistic screening, Outcome 20 Attendance rates.

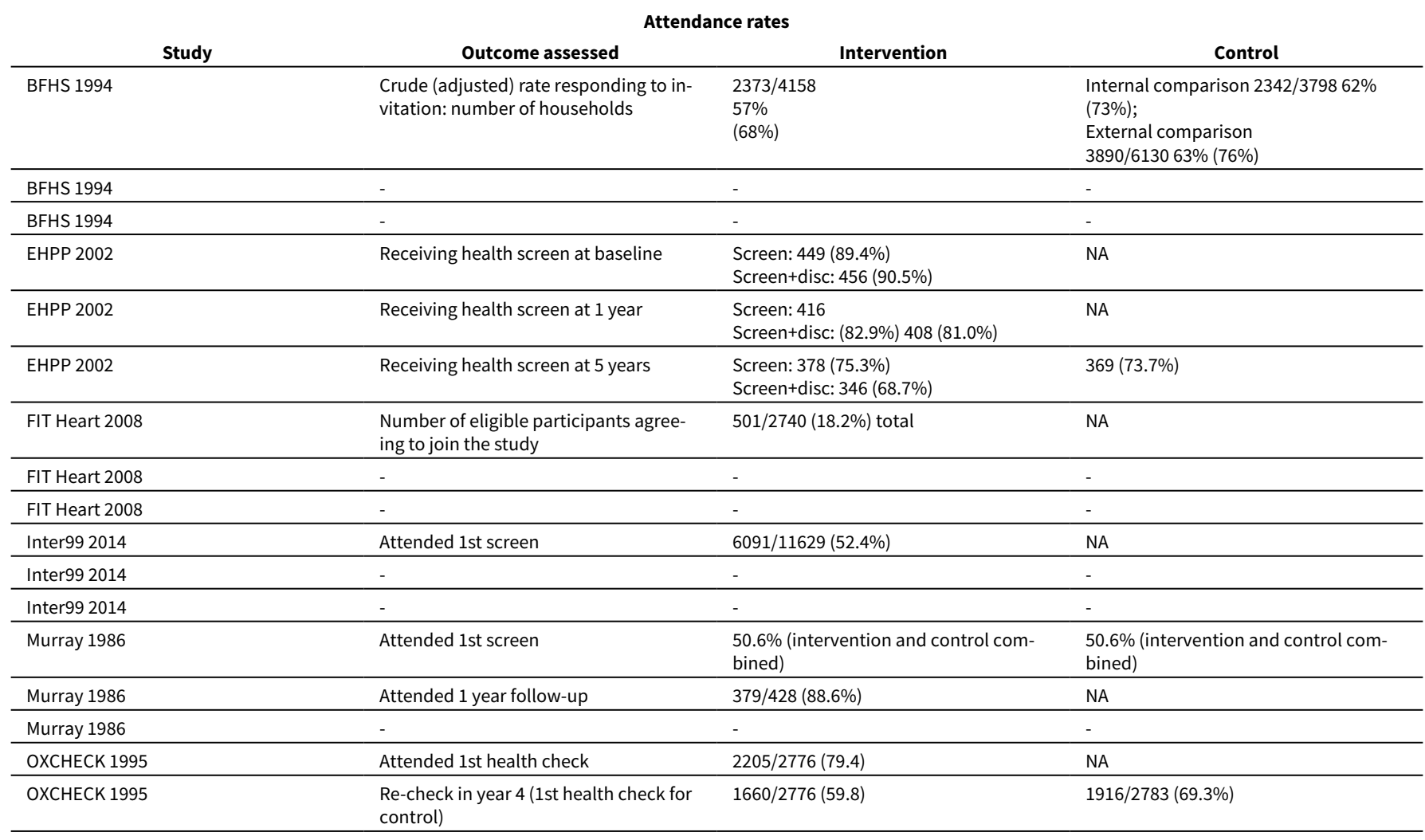




\begin{tabular}{|c|c|c|c|}
\hline \multicolumn{4}{|c|}{ Attendance rates } \\
\hline Study & Outcome assessed & Intervention & Control \\
\hline OXCHECK 1995 & - & - & - \\
\hline WHO 1986 & $\begin{array}{l}\text { Attended initial cardiovascular exami- } \\
\text { nation }\end{array}$ & $87 \%$ & NA \\
\hline WHO 1986 & - & - & - \\
\hline WHO 1986 & - & - & - \\
\hline Wilhelmsen 1986 & - & - & - \\
\hline Wilhelmsen 1986 & - & - & - \\
\hline
\end{tabular}

\section{APPENDICES}

\section{Appendix 1. Search strategies}

\section{CENTRAL}

\#1 MeSH descriptor: [Cardiovascular Diseases] explode all trees

\#2 cardio*

\#3 cardia*

\#4 heart*

\#5 coronary*

$\# 6$ angina*

$\# 7$ ventric $^{*}$

\#8 myocard*

\#9 pericard*

$\# 10$ isch?em*

\#11 emboli*

\#12 arrhythmi*

\#13 thrombo*

\#14 "atrial fibrillat*"

\#15 tachycardi*

$\# 16$ endocardi*

\#17 "sick sinus"

\#18 MeSH descriptor: [Stroke] explode all trees

\#19 (stroke or stokes)

\#20 cerebrovasc*

\#21 "cerebral vascular"

\#22 apoplexy

\#23 (brain near/2 accident ${ }^{\star}$ )

\#24 ((brain* or cerebral or lacunar) near/2 infarct $^{\star}$ )

\#25 MeSH descriptor: [Hypertension] explode all trees

\#26 hypertensi*

\#27 "peripheral arter ${ }^{\star}$ disease ${ }^{\star "}$

\#28 ((high or increased or elevated) near/2 blood pressure)

\#29 MeSH descriptor: [Hyperlipidemias] explode all trees

\#30 hyperlipid*

\#31 hyperlip?emia*

\#32 hypercholesterol ${ }^{*}$

\#33 hypercholester?emia*

\#34 hyperlipoprotein?emia*

\#35 hypertriglycerid?emia*

\#36 MeSH descriptor: [Arteriosclerosis] explode all trees

\#37 MeSH descriptor: [Cholesterol] explode all trees

\#38 cholesterol

\#39 "coronary risk factor $"$

\#40 MeSH descriptor: [Blood Pressure] this term only

\#41 "blood pressure" 
$\# 42 \# 1$ or $\# 2$ or \#3 or \#4 or \#5 or \#6 or \#7 or \#8 or \#9 or \#10 or \#11 or \#12 or \#13 or \#14 or \#15 or \#16 or \#17 or \#18 or \#19 or \#20 or \#21 or \#22 or \#23 or \#24 or \#25 or \#26 or \#27 or \#28 or \#29 or \#30 or \#31 or \#32 or \#33 or \#34 or \#35 or \#36 or \#37 or \#38 or \#39 or \#40 or \#41 \#43 MeSH descriptor: [Mass Screening] explode all trees \#44 "Systematic risk assessment*"

\#45 "Case finding"

\#46 ((screen ${ }^{\star}$ or assess ${ }^{\star}$ or test ${ }^{\star}$ or diagnos ${ }^{\star}$ or surveill* or identifi ${ }^{\star}$ or prevelence or incidence ${ }^{\star}$ ) near/10 (structured or systematic or organised or organized or opportunistic or random))

\#47 MeSH descriptor: [Risk Assessment] this term only

\#48 (risk* near/3 assess ${ }^{\star}$ )

\#49 \#43 or \#44 or \#45 or \#46 or \#47 or \#48

\#50 MeSH descriptor: [Primary Prevention] this term only

\#51 (prophylaxis or prevent ${ }^{\star}$ )

\#52 \#50 or \#51

$\# 53$ \#42 and \#49 and \#52

\section{MEDLINE OVID}

1. exp Cardiovascular Diseases/

2. cardio*.tw.

3. cardia*.tw.

4. heart ${ }^{\star}$. tw

5. coronary ${ }^{\star}$. tw.

6. angina*.tw.

7. ventric ${ }^{\star}$. tw.

8. myocard*.tw.

9. pericard ${ }^{\star} . t w$.

10. isch?em*.tw.

11. emboli*.tw.

12. arrhythmi ${ }^{\star}$. tw.

13. thrombo*.tw.

14. atrial fibrillat ${ }^{\star}$. tw.

15. tachycardi ${ }^{\star}$. tw.

16. endocardi*.tw.

17. (sick adj sinus).tw.

18. exp Stroke/

19. (stroke or stokes).tw.

20. cerebrovasc ${ }^{\star}$. tw.

21. cerebral vascular.tw.

22. apoplexy.tw.

23. (brain adj2 accident $\left.{ }^{\star}\right)$.tw.

24. ((brain* or cerebral or lacunar) adj2 infarct $\left.{ }^{\star}\right)$.tw.

25. exp Hypertension/

26. hypertensi ${ }^{\star}$.tw.

27. peripheral arter ${ }^{\star}$ disease ${ }^{\star}$.tw.

28. ((high or increased or elevated) adj2 blood pressure).tw.

29. exp Hyperlipidemias/

30. hyperlipid*.tw.

31. hyperlip?emia*.tw.

32. hypercholesterol ${ }^{\star}$. tw.

33. hypercholester?emia*.tw.

34. hyperlipoprotein?emia*.tw.

35. hypertriglycerid?emia*.tw.

36. $\exp$ Arteriosclerosis/

37. $\exp$ Cholesterol/

38. cholesterol.tw.

39. "coronary risk factor* ".tw.

40. Blood Pressure/

41. blood pressure.tw.

42. or/1-41

43. Mass Screening/

44. Systematic risk assessment ${ }^{\star}$.tw.

45. Case finding.tw. 
46. ((screen ${ }^{\star}$ or assess ${ }^{\star}$ or test $^{\star}$ or diagnos ${ }^{\star}$ or surveill ${ }^{\star}$ or identifi ${ }^{\star}$ or prevelence or incidence ${ }^{\star}$ ) adj10 (structured or systematic or organised or organized or opportunistic or random)).tw.

47. Risk Assessment/

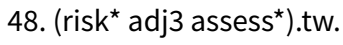

49. or $/ 43-48$

50. Primary Prevention/

51. (prophylaxis or prevent $\left.{ }^{\star}\right)$.tw.

52.50 or 51

53. 42 and 49 and 52

54. randomized controlled trial.pt.

55. controlled clinical trial.pt.

56. randomized.ab.

57. placebo.ab.

58. drug therapy.fs.

59. randomly.ab.

60. trial.ab.

61. groups.ab.

62.54 or 55 or 56 or 57 or 58 or 59 or 60 or 61

63. exp animals/ not humans.sh.

64.62 not 63

65.53 and 64

\section{EMBASE OVID}

1. exp Cardiovascular Diseases/

2. cardio ${ }^{\star}$. tw.

3. cardia*.tw.

4. heart*.tw.

5. coronary ${ }^{\star}$. tw.

6. angina* ${ }^{\star}$.tw.

7. ventric ${ }^{\star}$. tw.

8. myocard ${ }^{*} . \mathrm{tw}$.

9. pericard*.tw.

10. isch?em*.tw.

11. emboli*.tw.

12. arrhythmi*.tw.

13. thrombo*.tw.

14. atrial fibrillat*.tw.

15. tachycardi ${ }^{\star}$. tw.

16. endocardi ${ }^{*}$.tw.

17. (sick adj sinus).tw.

18. exp Stroke/

19. (stroke or stokes).tw.

20. cerebrovasc ${ }^{\star}$.tw.

21. cerebral vascular.tw.

22. apoplexy.tw.

23. (brain adj2 accident $\left.{ }^{\star}\right)$.tw.

24. ((brain* or cerebral or lacunar) adj2 infarct $\left.{ }^{\star}\right)$.tw.

25. exp Hypertension/

26. hypertensi ${ }^{\star} . t w$.

27. peripheral arter ${ }^{\star}$ disease ${ }^{\star}$. tw.

28. ((high or increased or elevated) adj2 blood pressure).tw.

29. exp Hyperlipidemias/

30. hyperlipid ${ }^{*}$.tw.

31. hyperlip?emia*.tw.

32. hypercholesterol ${ }^{\star} . t w$.

33. hypercholester?emia*.tw.

34. hyperlipoprotein?emia*.tw.

35. hypertriglycerid?emia*.tw.

36. exp Arteriosclerosis/

37. exp Cholesterol/

38. cholesterol.tw. 
39. "coronary risk factor* ".tw.

40. Blood Pressure/

41. blood pressure.tw.

42. or/1-41

43. Mass Screening/

44. Systematic risk assessment ${ }^{\star}$.tw.

45. Case finding.tw.

46. ((screen ${ }^{\star}$ or assess ${ }^{\star}$ or test ${ }^{\star}$ or diagnos ${ }^{\star}$ or surveill ${ }^{\star}$ or identifi ${ }^{\star}$ or prevelence or incidence ${ }^{\star}$ ) adj10 (structured or systematic or organised or organized or opportunistic or random)).tw.

47. Risk Assessment/

48. $\left(\right.$ risk $^{\star}$ adj3 assess $\left.{ }^{\star}\right)$.tw.

49. or/43-48

50. Primary Prevention/

51. (prophylaxis or prevent ${ }^{\star}$ ).tw.

52.50 or 51

53. 42 and 49 and 52

54. random\$.tw.

55. factorial\$.tw.

56. crossover\$.tw.

57. cross over\$.tw.

58. cross-over\$.tw.

59. placebo\$.tw.

60. (doubl\$ adj blind\$).tw.

61. (singl\$ adj blind\$).tw.

62. assign\$.tw.

63. allocat\$.tw.

64. volunteer\$.tw.

65. crossover procedure/

66. double blind procedure/

67. randomized controlled trial/

68. single blind procedure/

69.54 or 55 or 56 or 57 or 58 or 59 or 60 or 61 or 62 or 63 or 64 or 65 or 66 or 67 or 68

70. (animal/ or nonhuman/) not human/

71.69 not 70

72. 53 and 71

73. limit 72 to embase

\section{Web of Science}

\#40 \#39 AND \#38

\#39 TS=(((random ${ }^{\star}$ or blind ${ }^{\star}$ or allocat ${ }^{\star}$ or assign* or trial $^{\star}$ or placebo* or crossover $^{\star}$ or cross-over $\left.\left.\left.^{\star}\right)\right)\right)$

\#38 \#37 AND \#36 AND \#31

$\# 37 \mathrm{TS}=\left(\left(\right.\right.$ prophylaxis or prevent $\left.\left.{ }^{\star}\right)\right)$

\#36 \#35 OR \#34 OR \#33 OR \#32

\#35 TS=((risk* near/3 assess $\left.\left.{ }^{\star}\right)\right)$

\#34 TS=(((screen ${ }^{\star}$ or assess ${ }^{\star}$ or test ${ }^{\star}$ or diagnos ${ }^{\star}$ or surveill ${ }^{\star}$ or identifi ${ }^{\star}$ or prevelence or incidence $\left.{ }^{\star}\right)$ near/10 (structured or systematic or organised or organized or opportunistic or random)))

\#33 TS=("Case finding")

\#32 TS=("Systematic risk assessment*")

\#31 \#30 OR \#29 OR \#28 OR \#27 OR \#26 OR \#25 OR \#24 OR \#23 OR \#22 OR \#21 OR \#20 OR \#19 OR \#18 OR \#17 OR \#16 OR \#15 OR\#14 OR \#13

OR \#12 OR \#11 OR \#10 OR \#9 OR \#8 OR \#7 OR \#6 OR \#5 OR \#4 OR \#3 OR \#2 OR \#1

\#30 TS=(arteriosclerosis or "blood pressure")

\#29 TS=(cholesterol or "coronary risk factor ${ }^{* ")}$

\#28 TS=((hypertriglycerid?emia*))

$\# 27$ TS=((hyperlipoprotein?emia*))

\#26 TS=((hypercholester?emia*))

\#25 TS=((hypercholesterol $\left.\left.{ }^{\star}\right)\right)$

\#24 TS=((hyperlip?emia* $))$

\#23 TS=((hyperlipid $\left.\left.{ }^{\star}\right)\right)$

\#22 TS=(((high or increased or elevated) near/2" blood pressure"))

\#21 TS=("peripheral arter ${ }^{\star}$ disease*")

\#20 TS=((hypertensi $\left.\left.{ }^{\star}\right)\right)$ 
\#19 TS=(((brain* or cerebral or lacunar) near/2 infarct $\left.\left.{ }^{\star}\right)\right)$

\#18 TS=((brain near/2 accident $\left.\left.{ }^{\star}\right)\right)$

\#17 TS=((apoplexy))

\#16 TS=("cerebral vascular")

\#15 TS= $=\left(\right.$ cerebrovasc $\left.\left.^{\star}\right)\right)$

\#14 TS=((stroke or stokes))

\#13 TS=("sick sinus")

\#12 TS=((endocardi $\left.\left.{ }^{\star}\right)\right)$

\#11 TS=((tachycardi $\left.\left.{ }^{\star}\right)\right)$

\#10 TS=("atrial fibrillat*")

\#9 TS=((thrombo*))

\#8 TS= $\left(\left(\right.\right.$ arrhythmi $\left.\left.{ }^{\star}\right)\right)$

\#7 TS=((emboli*))

\#6 TS=((isch?em*))

\#5 TS $=\left(\left(\right.\right.$ pericard $\left.\left.^{\star}\right)\right)$

\#4 TS $=\left(\left(\right.\right.$ myocard $\left.\left.^{\star}\right)\right)$

\#3 TS=(ventric $\left.{ }^{\star}\right)$

\#2 TS= $(($ angina* $))$

\#1 TS=(cardio* or cardia* or heart* or coronary $\left.{ }^{\star}\right)$

WHAT'S NEW

\begin{tabular}{lll}
\hline Date & Event & Description \\
\hline 9 March 2018 & Amended & Minor correction of event data for all-cause mortality. \\
\hline
\end{tabular}

\section{H I S T O R Y}

Protocol first published: Issue 2, 2013

Review first published: Issue 1, 2016

\begin{tabular}{lll}
\hline Date & Event & Description \\
\hline 2 February 2016 & Amended & Authors initial added - Christian M Drew \\
\hline
\end{tabular}

\section{CONTRIBUTIONS OF AUTHORS}

MD: screened titles and abstracts, assessed studies for formal inclusion/exclusion, wrote first draft of review

SS: abstracted data and assessed risk of bias, contributed to the review draft

JC: abstracted data, assessed risk of bias, conducted analyses and updated the draft of the review

CD: screened titles and abstracts, assessed studies for formal inclusion/exclusion

MS: screened titles and abstracts, assessed studies for formal inclusion/exclusion

JM: screened titles and abstracts, assessed studies for formal inclusion/exclusion

NW: screened titles and abstracts

AC: acted as a third author for formal inclusion/exclusion, critically read review draft

KR: oversaw the conduct of the review, acted as a third review author for formal inclusion/exclusion and data abstraction, conducted analyses, assessed GRADE and updated the draft of the review

\section{DECLARATIONS OF INTEREST}

None known. 


\section{SOURCES OF SUPPORT}

\section{Internal sources}

- Warwick Medical School, University of Warwick, UK.

\section{External sources}

- NIHR Cochrane Programme Grant, UK.

- Karen Rees and Aileen Clarke are also supported by the National Institute for Health Research (NIHR) Collaboration for Leadership in Applied Health Research and Care West Midlands at University Hospitals Birmingham NHS Foundation Trust, UK, UK.

\section{DIFFERENCES BETWEEN PROTOCOLANDREVIEW}

We had intended to stratify by the types of risk assessment approaches, but found insufficient studies. The subgroups were as follows.

1. Systematic risk assessment stratified into: population/universal/mass risk assessment (targeting the whole population in a certain age group) and high-risk risk assessment (targeting specific population groups, perceived to be at increased risk).

2. Opportunistic risk assessment stratified into: no/minimal risk assessment, sporadic/opportunistic risk assessment and incentivised case finding.

We had also planned to examine the effects of the intervention design (setting, personnel involved, invitation and follow-up system), but there were insufficient numbers of trials included in the review to conduct these analyses.

We had planned to carry out sensitivity analyses excluding studies with a high risk of bias, and to undertake assessment of funnel plots and tests of asymmetry (Egger 1997) to assess possible publication bias, but there were insufficient studies included in the review to conduct these analyses.

For cluster-RCTs we followed the guidance as reported in the Cochrane Handbook. Where data were appropriately analysed to take account of the effects of clustering in the original studies we used these. Where this was not reported we used the approximate analyses of clusterRCTs to determine the effective sample sizes as outlined in Chaper 16.3.4 (Higgins 2011). For one study we were unable to do this as the number of clusters was not reported (OXCHECK 1995).

Where standard deviations were not reported in a publication, we calculated them from standard errors, confidence intervals or $t$ values. If this was not possible, we imputed standard deviations from another study. The study with the highest standard deviation for an outcome was selected as this down-weights a study and yields a wider confidence interval (Higgins 2011).

We had planned to search AMED but there were insufficient time and resources to do this.

We have added more details about the assessment of heterogeneity.

\section{NDEX TERMS}

\section{Medical Subject Headings (MeSH)}

Cardiovascular Diseases [mortality] [ ${ }^{\star}$ prevention \& control]; Cholesterol [blood]; Primary Prevention [*methods]; Randomized Controlled Trials as Topic; Risk Assessment [methods]; Risk Factors; Stroke [mortality]

\section{MeSH check words}

Adult; Aged; Humans; Middle Aged 